\title{
THE METHOD OF INDEPENDENT TIMESTEPS IN THE NUMERICAL SOLUTION OF INITIAL VALUE PROBLEMS
}

Andrew Reabody Porter

(Ph. D. Theals)

July, 1976

Prepared for U.S. Energy Research \& Development

Administration under contract No. W-7405-Eng-48

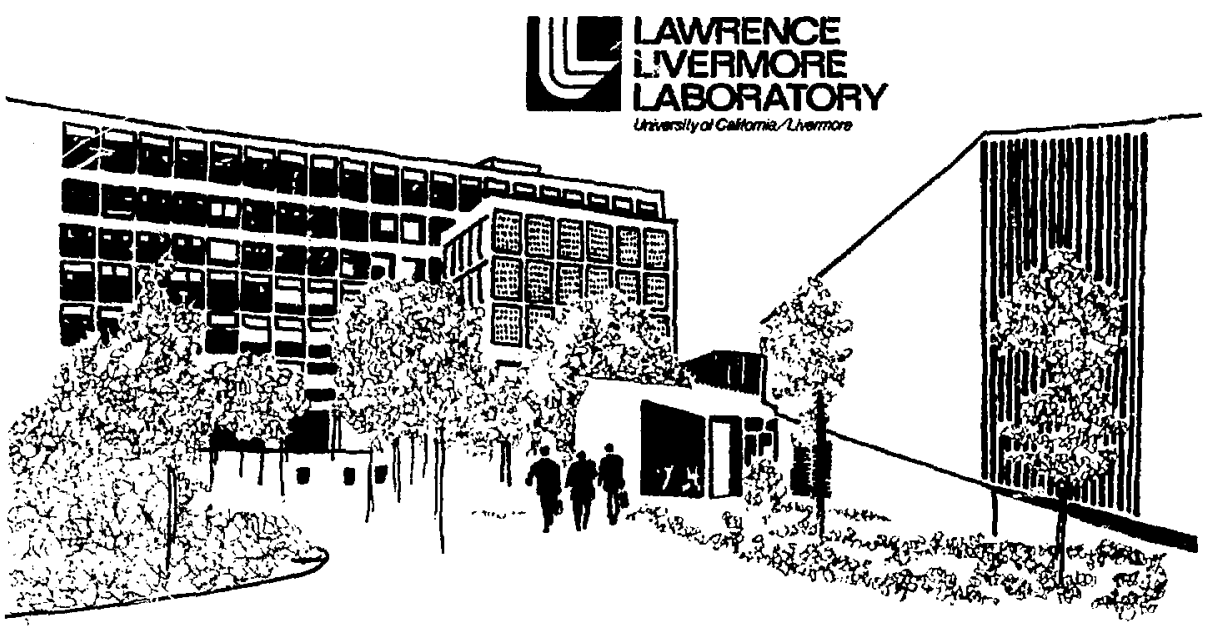

LAWRENCE ITVERMORE IABORATORY
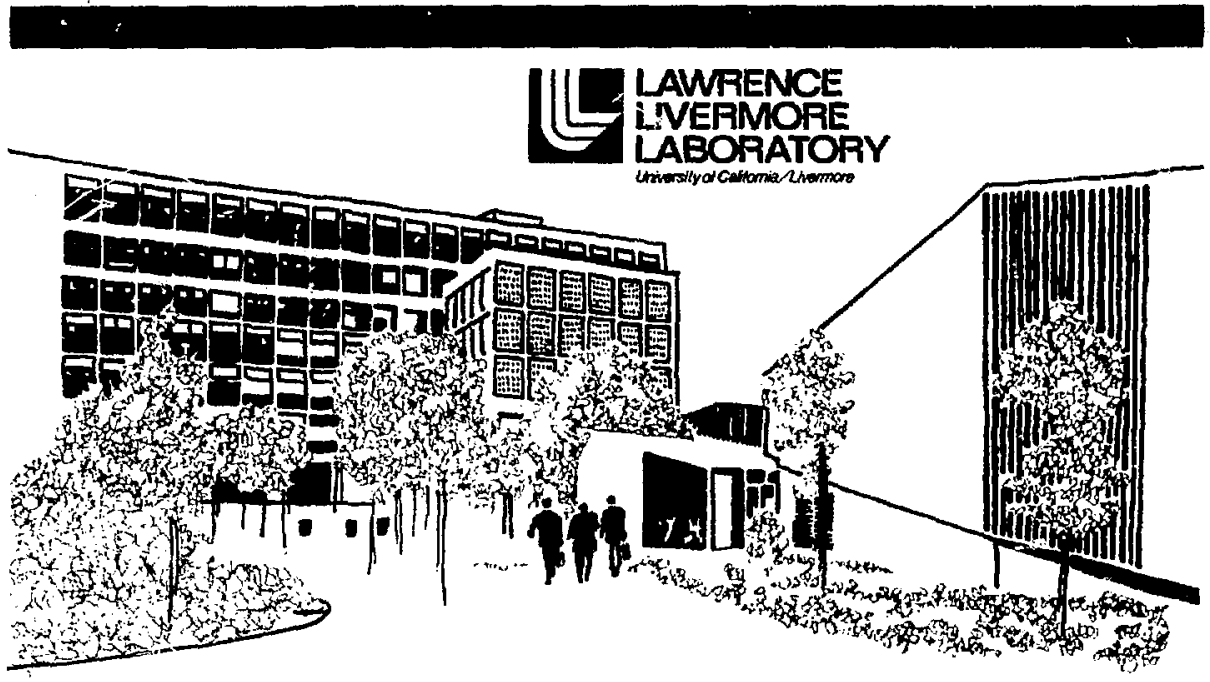


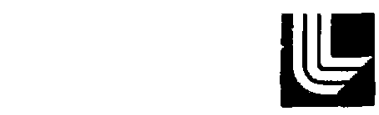

LAWRENCE LIVERMORE LABORATOR"

University ol Cahtornia Livermore,Calisornia 94550

\section{UCRL-52108 \\ THE METHOD OF INDEPENDENT TIMESTEPS IN THE NUMERICAL SOLUTION OF INITIAL VALUE PROBLEMS}

Andrew Peabody Porter

(Ph. D. Thesis)

MS. Date: July 21, 1976

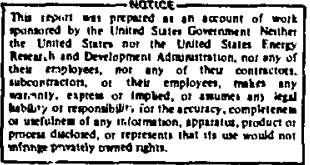

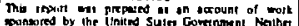

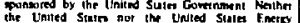

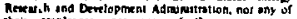

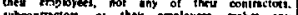

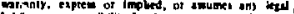

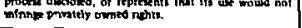




\title{
ABSTRACT
}

THE METHOD OF INDEPENDENT TIMESTEPS

IN THE NUMERICAL NOLUTION OF INITIAI, BULCE PROBLEMS

\author{
Andrew P. Porley
}

In the numerical solution of laltial value problems in vereral independent variables the timestep is controlled. espectally in the presence of shocks. by a small portion of the logiral mesh. whal one may call the crisis zone. One is frustrated by the necessity of doung in the whole mesh frequent calculations required by only a small part of the mesh. It is shown that it is possible 10 choose diflerent limesteps naturel to different parts of the mesh and 10 advance each zone in lime only as often as is approprlate to that zone's own natural limestep. III what may be called the Method of lindependent Timesteps. The prior work is reviewed and for the first lime an investightion of the canditions lor well posedness, consistency and stability in independent timesteps is presented. resulting in a new method. The proctironis and parachronic Cauchy surfaces are identified and the reasons (well posedness) for constraining the Cauchy surfaces to be prochronic. (in distinction from ihe method of Grandey) that is. to lie prior to the lime of the crisis zone. (the zone of least timestep) are indicated. Sitability (in the maximum norm) of parabolic equations and (in the l.2 norm) of hyperbolic equations is reviewed. without restricting the trealment to linear equations or constant coefficients, and stablily of the new method is proven in this tramework. The details of the method of independent timesteps, the rutes for shoosing timesteps and for deciding when to update and when to skip zones, and the method of joining adjacent regions of differing timestep are described. The stability of independent timestep difference schemes is analysed and exhibited. A summary of experience with the method is appended. The economic advantages of the method. which often amount 10 an order of magnilude decrease in running time relative to conventional or implicit difference methods, are noted. 
TABI.E: OF CONTENTS

Arknow Irdurment :

11

List of Pinures

symol Table

4

1.11

Introductioll: Nolivalion and sifraleay

shork Itretrodynamics, the Contexl of Ihe Prexent Work

posilie ine Problem

Alloration of Compulaliounl biffort

The Experielire of (relexilint Hechunirs

The sitrallay of Approarll

An lllustralive biample of tudependest Timestepu

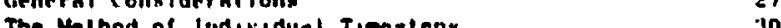

The Diflerence schemes

Test Prohlems 19

IIt The Celieral thithod of Independent Timenleps

On Notalion $\quad 53$

The Helnod is

Fxemplex in One Dimetision GI

Diflisionn i, Tro Dimensions GG

Implitil liquations it

Considerations in Impleamentine ludependent Timexlops bI

IV stabilily ol Pormbolic Piqustions in the Maximim Norm 60

The Clasenral sitability Analysin Ho

The liqualion of Dufort and reanket 90

stability in Generai $\quad 9: 1$

stabilily in Ihr Maximim Norm 0 ?

Implicel billerence tiqual iollx 101

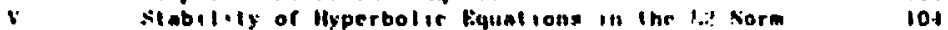

in Bxaspor with Viariable Corlfietents 101

Plane waves 100

The Wave Sorm 109

Cylindrisal Waven

Hydrodynases 115

H Stability and Converamer

Parabolit Bqualionn: siabilily

llydrodunamirx: Stabilily 120

Parabolir kiqualionx: Trumalion Pirrol 126

llydrodynimics: Trun at ion birror

vil Comparalive ficonomicy: Timine Trials

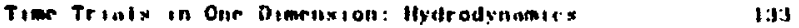

Tine Trials in One Dimension: Diffusion lis

Time Triale in Two Dimerisions

Genernl Collsiderilious in All ninine sperd is

VIII Conclusions

In sumerery

Implirat iolly 
v

Reforences

Index

$$
\begin{aligned}
& 154 \\
& 156
\end{aligned}
$$

$\checkmark$ 


\section{LIST OF FIGIRES}

Fin. (1.1) Initial Condilions 17

Fig. (1.2) Donall of Dependence 18

Fig. (1.3) Palliological Inilial Condilions 20

Fia. (1.4) Cauchy surfaces in the Melliod of Cirandey 22

Fia. (1.5) puochionis :auchy surlaces 24

Fia. (1.6) Timesteps and Prochronic Cauchy surlaces 25

Fig. (2.1) A Problem History 28

Fik. (3.2) Courant and Physical Timexleps 31

Fie. (2.3) Timesleps for Viations Zones 33

Fig. (2.d) Timesieps for Various Zones

FiR. (2.5) Timesleps lor Various Zones

Fig. (2.6) Timesleps for Various Zones 36

Fig. (2.7) The Test Priblem of Figs. (2.2-2.6) th

Fig. (2.8) Siettilig Conqutalion Selltinels 45

Fig. (2.9) Adjarent Zones with Ditferent Timesteps 47

Fie. (2.10) a Mesh with Independent Timesteps 48

Fig. (2.11) a Test Problem 50

Pig. (3.1) Nomenclature of Times and Timesteps 55

Fig. (3.2) Disparale Neighboring Timesteps 60

FiR. (3.3) Indexing Conventions $6 B$

Fie. (3.4) Condurlixily Coefficients 69

PiR. (3.5) Inilial Conditions of a Two Dimensional Problem 75

FiR. (3.6) Temperature Irom an ADI Calculation 76

Fig. (3.7) Temperature from a MITs Calculation 77

Fig. (3.8) Rate of Change of Temperature: ADI 78

Fig. (3.9) Rate of Change of Temperature: MIT: 79

Fig. (3.10) Timesteps in an ADI Calculation BO

Fig. (3.11) Timesleps in a MiTs Calculalion B)

Fig. (J.13) Caurhy Surface in a Mits Calculation B:

Fie. (4.1) Amplifiration Factors 69

Fig. (4.2) A Mesh with Independent Timeslips 92

Fir. (4.3) Solutions of Eqn. (4.10) 9t

Fie. (6.1) An Estimale of a Neighbor ing Temperalure ial

Fir. (6.2) A Mesh with Independeme Timesleps 123

Fie. (7.1) A One Dimensional Heal Diffusion Problem

Fig. (7.2) a Two Dimensional Heal Diffusion irablem 142

FiR. (7.3) A Two Dimensional Heal Diffusion Problem 1.! 


\section{ACKNOWLEDGFMKANT:}

Mally people have been tenerous with their support and ravice in the course of this work. The preparation of the nitnuselipt was made a ereat deal easiev by the assistance of Charlotin Richnond. Betsy Kruger. C. Wetheroll, K. Booth, H. Moll, B. Farsaci, J, Heally, an' H, Hamilton. P. Moulthrop. P. GIIcs, J. Nuckolis, and L. Hood pal inntly sisipported lhe project ax supervisors. C, sherman. N. Sherman. T. Axelrod. l.. Wood, Lairv Howard and John Flelchel colltibuled livaluable advice.

R. A. Grandes getterassly gave his advice and help over the long dosiance te lephone in tiacking dowl his work.

Specinl thanks go 10 ny thesis committec. Iohn De Groot. Alian

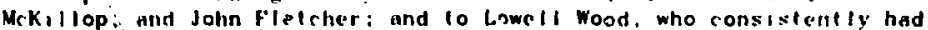
Itill in hilie project. even when l often did not.

This woyk was supporled in part by the falln ie and John Hertz Fundalion. and in part by the l'niversily of California lawrence Livermore labo:atory, livermore. Colifornia.

This manusciopl was prepared using the fac lities of the lill compuling system. in particular. the TRIX report editor RED. and Its post-processor, REDPP.

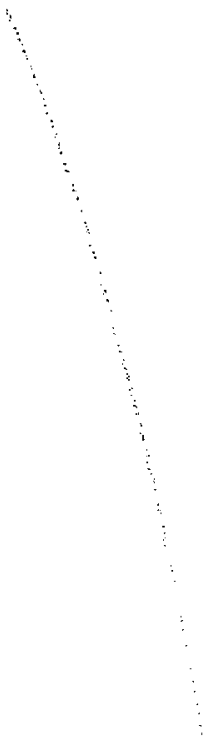


1: 11

SYMbOL. TABLE:

Indices

f As a subscript. the sour index in one dimensional calculations.

f Greatest zone index in one dimensional calculations.

a Zone index is iwo dimensional problems.

n Indexes quantities at lime in.

Operators

s. $s_{0} x_{1}=x_{1+1}-x_{1}$

s. $a_{-} x_{1}=x_{1}-x_{1}-1$

d. $d x^{n}=x^{n+1}-x^{n}$

b. $a_{-} x^{n}=x^{n}-x^{n-1}$

o. $\quad 0, x^{n}=x^{n+x^{n+1}}$

o. $\quad 0_{-} x^{n}=x^{n+x^{n-1}}$ 


$$
\begin{aligned}
& \text { v. } \quad y_{4} x_{1}=x_{1}+x_{1}+1 \\
& \because . \quad z_{1}=x_{1-1}+x_{1}
\end{aligned}
$$

Myscral Qmantimen

$\lambda$

A product of constants. fillte differences, properties of mutler. as is convenunt. ser far example Equs. (3.22.3.23). $(4.10) \cdot(5.13)$

n Coefficient in Ein. (7.1)

a) Coneral averaging function of lemperolwey ndiacent to zone,

H) Auxillary quantily. Fan. (4.29)

b) Collection of montants and coefficients, fiqns, (5.1:3), (4.29)

BT. BTh Houndary terms in Fqn. $(5,11)$

$r$ Auxiliary quanilly in a tri-diagonal matrix inversion rouline.

C A general Inite differrnee operator. Eqn. (4.21)

- Wave propagation speed in hyperbolis equations.

D, Auxiliary quantity in tri-diagonal matrix inversion routine.

E, Inlermal encrey per unil mass in hydrudinamies

E Number of times a code does major output, Eqn. (7.1) 
f. General functiun, sec context.

$f$ cienrial function. ser context.

$c_{\text {j }}$ Divergence of fiux.

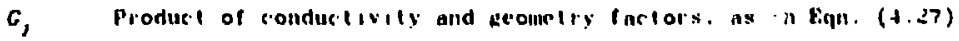

9 Vinlinble parmeler, $0=9 \cdot 1,9$ o lor hackwatd differencink.

g: t lor forward differenci:k: see Eqn. (4.35)

$C_{\text {t., }}$ Product of conductivity and meomelry tactors. as in Equ. (3.25)

Gist? One of a fumily of operalors. rh. "I.

$\kappa$ Constanl. Eqn. $(1.19)$

$H_{4,}$ Product of conductivity and ueometr fartors, as in Eqn. $(3,25)$

$A_{j}$ Product of condetelsvily and geometry factors. as in Equ. (4.27)

n. Zonel mass.

(1) mesh

$N$ Number of cycles a probtem has ruil, as in Ban. (7.1)

- Geonetry sentinel, as in Eqn. (3.8)

JXN Number of zones times number of cycles run.

F, Piessure fron rquation of stale

$p_{j} \quad p_{j}+Q_{j}$ 
$\times 1$

$P$ Time derivenc of $P$

$p^{\circ}$ tixisupolated vilue of $p$.

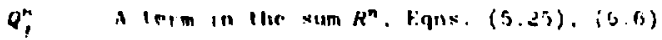

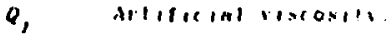

$K^{n} \quad$ square of the wase norm, as in fiqn. (5.18)

$\boldsymbol{R}$ Rutio of surcestor linexteps in one ons.

r. Rindeal cootallater

' Computat ion sert inel

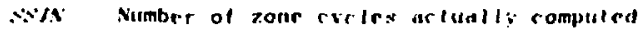

WRAT JAY $\therefore$ TIS

$\therefore$ Gelleral oprealor. liqn. $(4.17)$

- Hound of operaior $\therefore$ as in Hign. ( 1,17$)$

$t^{n}$ Time al cyelr $n$.

to Time at which iultial conditions are spre ified.

i) Proper time of the $f^{\text {in }}$ zone.

$T: x$ Caluchs surlace on which Inilial conditions ale specifid.

T) Temperalure 


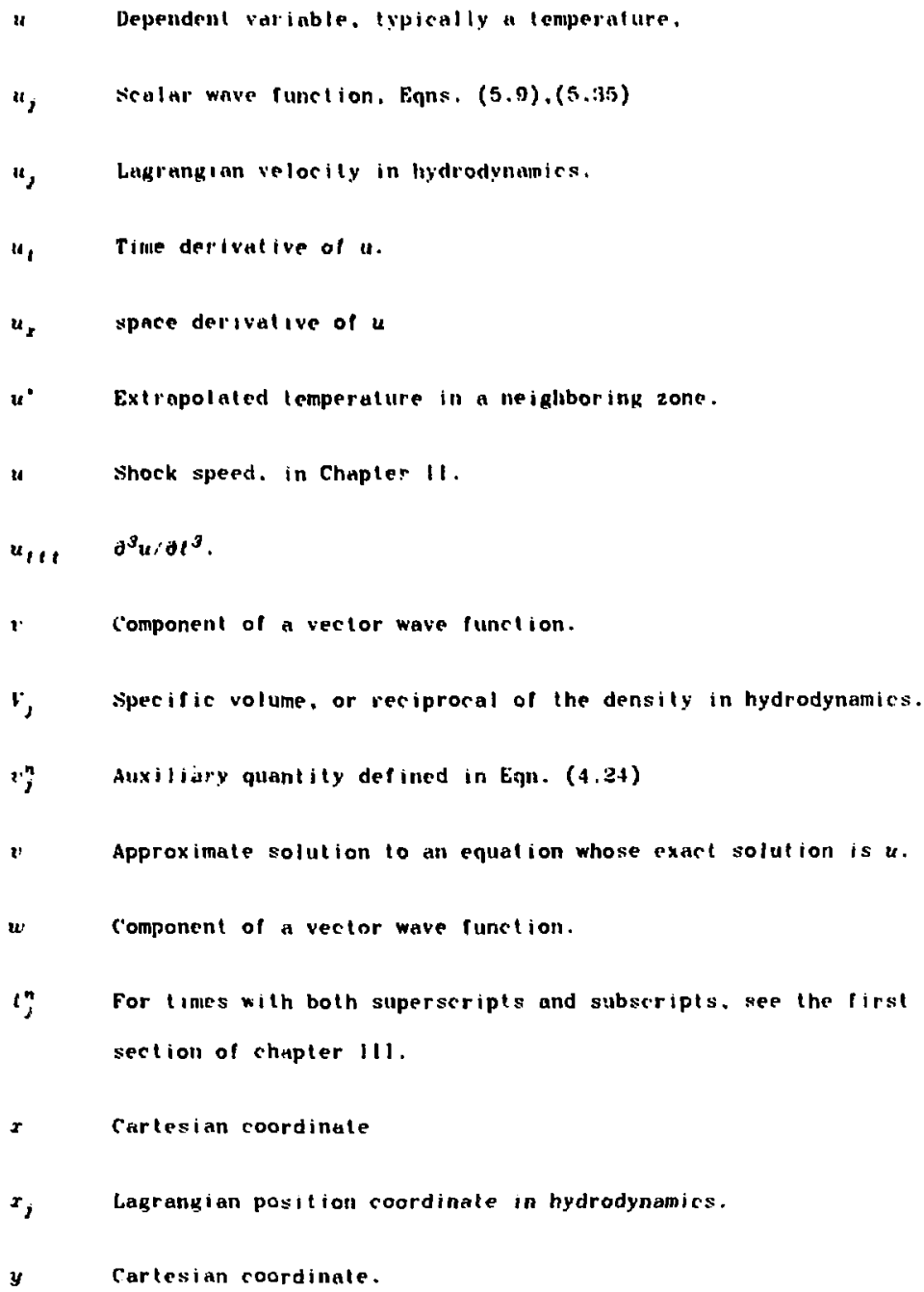




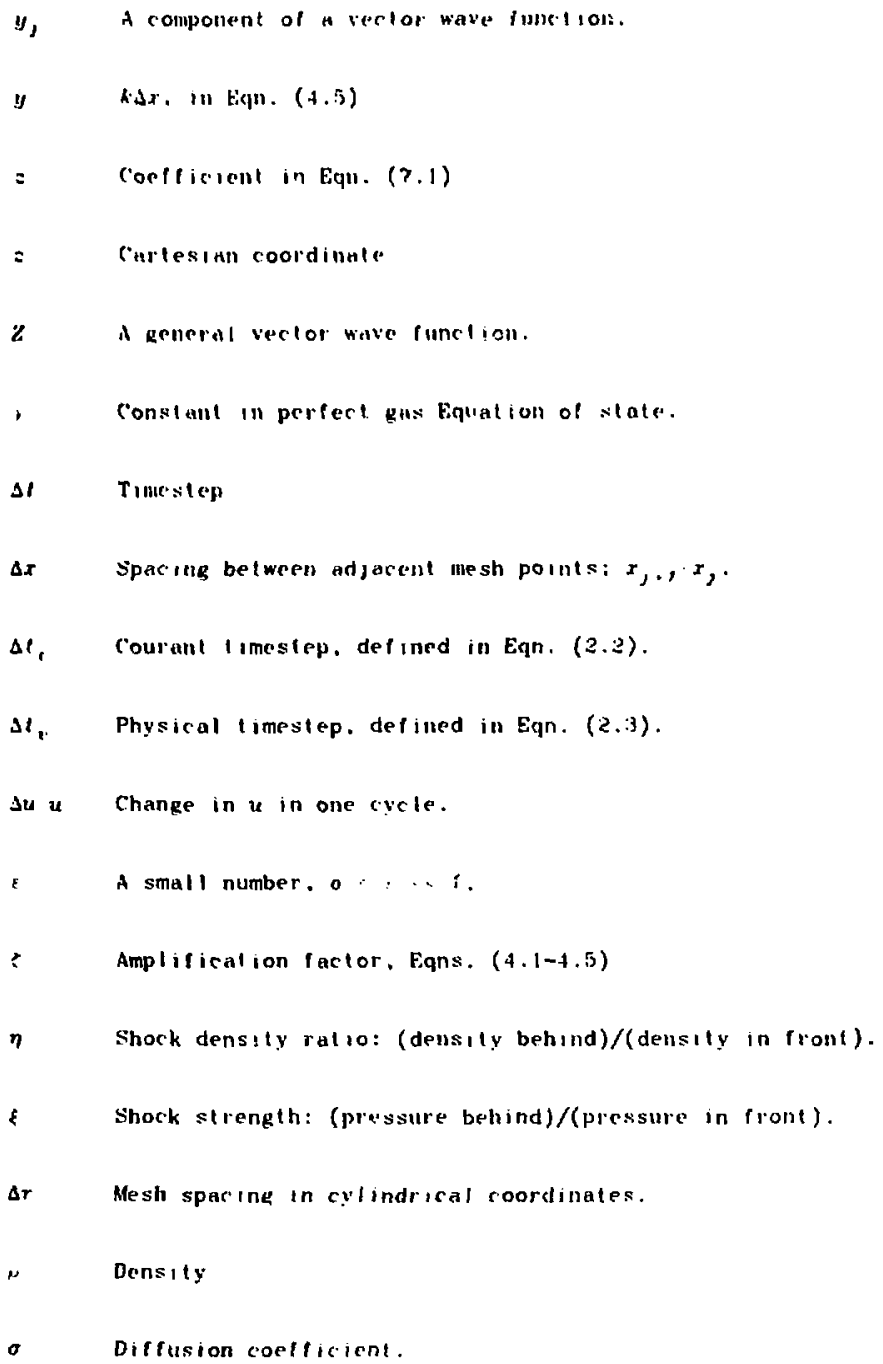


$x$ iv

0

Fius of heat 


\section{CHAPTER 1}

\section{INTRODUCTION: MOTIVATION AND STRATEGY}

\section{Shock Hydrodynamics, the Context of the Present Mork}

This dissertation develops and describes a method of apeeding up shock hydrodynamics and related calculations by on order of magnitude. a gain in effective comput ine power usually usually realited only over several generations of digital computers. The methodology developed treats its calculations with elements of the perspective and discrimination until now seen only in the human approach to such problems. The present work grew out of the Irustrating experience that numerical simulation of shock hydrodynamics problems can be very slaw. even with the fastest modern digital computers. Such a hydrodynamic simulation requires many computalions, with varying degrees of accuracy appropriate to each. The usual pra ise (in finite approximation of partial differential equalions as well as in their analytic treatment) is to provide a single approximation which is uniformly adequate to all parts of the calculation. A human calculator. by contrast. has a sure feeling for where he must be careful and where he can lolerale 
impresision and still obtain stable and acceptably accurate answers in a rensouable amount of time. The same motivation governs the present numerical serategy. Before making concrele its outline and details of its implementation, it is perhaps belter to wait unlil the terms and usage of this tield have been defined in the next sectiun. Is appropriate to foint oul now, however, the place of shock hydrodynamics in the history of numerical analysis, and to indicate that, because of its sophisticalion of physical effects and conceptual simplicity of nimerical techniques, it presents a singularly fortuitous opportumily for computational programe such as the present one.

There are many genera of problens which lend themselves readily to numerical solution, among which one may single out initial value or time evolution problems. problems in time and one or more space varjables. Shock hydrodynamics forms a somewhat more limjted genus of differential equations than this broad class. but it is not too much to claim that it has motivated much of modern numerical analysis. By contrasl. Ihe early numerical work. which paralleled the conceptual development of the differential calculus, was in ordinary differential equations: this work was motivated largely by celestial mechanics. Its strategy was inspired by the Taylor series, and it has sufliced rather well for ordinary diflerential equations. Partial differential equations had to wait tor large digital computers, not available until after 1945. George Boole' in 1872 laid the loundations for a tormal ireatment of finite difference equations. and Courant. Friedrichs, and Lewy in 1928 published the classic work on stability of difference approximations 10 equations in

1 Boole, (1872). 
several Independenl variables. 2 . The name of John von Neumann as most widely associalid wilh the nexl sianificant work, bolh in construction of computers themselves, necessary for ans practical work in partint difference equations, and ill the theoretichl and prouraming techulques of approximation in such equalions. His inlerests were in shock hydrodynamics, teginning with theorelical's applications. Since thell engineering" and astrophysical ${ }^{3}$ concerns have flour ished. These practical motives have provided the imperus for a major theorelical body of arl and scielice in numerical melliodso

Like so much that has qone before it. lhe presell work is siluated II shock hydrodynnmics, and for two reasons. Nhock hydrodynamics. broadly construed. encompasses geteat subtlety and richness of physical effect. and numerically il is essentially simple. Delailed calculations of real rather than idealised physical effects can lead to Irustratingly slow hydrodynamic calculations. One would like lo see the computer struclure ils calculations wilh a litlle more care, as does the human calculater. rather than indiscriminalely recalculating many limes physical quantilies il already had avallabic if ouly il could recognise them. This constilutes a mujor departure from nearly universal philosophy. Ior all previoun piaclise has beel lo find an approximation

2 Courant. Friedrishs, lewy, (1928).

3 von Neumanis Richlmuer. (1050).

- Par a recent example of enelinecring applicalions of shork hydrodynamics. ste the references by Zimanermann, Wood. Nuckol Is. Thies xen.

s For recent anlroplyysicil applicalions. sere Weaver (1976) Wi ixon. I.ePinnt (1970) Yay. Mile (1960) Coteate. While (1906) Cheralier. R. A. (1976)

6 For a habthook of numet tcal nirthods in the solution of lime depandent patial differential equations. see Richtmuer a Mrtion (1967). 
which is adequate (untormly) even in the worst parts of onc"s calculalional problen. regardless of how over-line it may be lil other palls of the problem. The work here described is a mothod of locd!ly sutting the finencss of the approxintion to the conditions at hand, and II wil be lilroduced to tittie more fully ln the next seetion.

Hydrodvinmics is numericulty simple and Iraclable enough so lhal this plokram miny be carriad oul practically, and the physics is sophisticaled ellougl that the Inculties kained arr of greal gignificance. This is all turusual rombijation of circumstances, thet bripf survey of olher kinds of initial yalue problems will indicate how fertile a selling is hydrodunamiss for the numerical propramme lo be out linea shorlly.

It is sufficient simply to catalogue different regimes of physics and 10 note which aspects of each require or lend themselves to special treatment. and it wil be apparent why the present programe is situated in shock hydrodynamics. In the case of weather prediction, one is colfronted with fluid medium which is homogeneous and subsonic. suggest ing Eulerian hydrodynamics. The $t$ ime scales of processes are similar Ihroughoul the spatial extent of the problem, obviating the need for special handling of shocks by means such as artificial viscosity. and render ing a method such as independent imesteps unecessary. There is spatial structure at all scales, from one neter turbulence to kilometer topographic elfects to $100 \mathrm{kilometer} \mathrm{storms} \mathrm{to} \mathrm{global} \mathrm{weather}$ patterns. Weather is intrinsically three-dimensional, implying that (now. In 1976 and for at least a rew more years) computer memory must be husbanded with care. Appropriate numerical strategies have evolved to suil the simulation of the atmosphere?. Turbulent hydrodynamics by

? Leith, C. E. $(1964,1965)$. 
viltue of is very fise spatial structure has difficulties of ts own. laxilu all the cesources of a diallal compuler and 1 is propramer,

The mumerical modellina of plasmas can confront one with equations that defy stable inleuration by ordinary means. The Boltzmann equation II al Its varirtions presells one with physics in as many a six dimensions (three of position and three of velocily). In the velocity dimensions. The interactiony are quite lloll-local. and Ihe implications Ior compulational simulation do not promige an rasy or early solution.

Shock hydrodynamics is in many ways the simplest, and certainly the earliest explored genus of initial value problems. The physics is confined to one scale, always marroscopic: shorks can be treated easily by an arliticial viscosity $y^{8}$ one needs only fairly conventional inite difference inlegrations motivated by the Taylor siories expansion of the physical quantilies at hand. Shock hydrodynamics may seem a I imited area of numerical work. but there is room even here lor a surprising richness of method and experience, as the written and oral tradilion amply show". In practical shock hydrodynamics problems'o one is usually obliged to treal also physics of one or more diffusion processes, such as neutron tlow, heat conduction, conduction of heat by free electrons and even by positrons't. Such an efforl con quickly come to resemble a symphony more than a sondta. and as the computation progresses, many physical and computational effects will contribule to the time evolution B con Neumann \&ichlmyer (1950).

9 See for rxample the I iteratura rited in Richtmyer \& Morton (1967)

10 See the refcrences by Zimmermasun. Nuckolls, Wood, and Thiessen.

i) Weaver (111 press) 
of the problem. but despite atl the physical complirntions. the numerical work renains essentially sumple.

\section{Posing the Probleng}

Initial vahue problems of shork hydrodynamics may be described by coupled partial differential equalions in the physical quantitips of inleresl. There are al least two bibspendent variables. One or mare having the character of cartestan coordinates in space, and one and only one independent variable having the character of $t$ inte; denoled by $t$. rarely by $T$. The equations are of such a nature that if the state of the physical system is specified at some time $t=t_{0}$. A solution of those equations exists for times $t \geq t_{0}$. The physical extent of the problem is defined by some region $R$ with boundary $+R$, and it is usually necessary not only to specily some condilions throughout $R$ in time $t_{0}$ but also on $I R$ al all limes $t \geq t_{0}$. These are the matial conditions and the boundary condifions.

By way of a specific example. the heat conduction equation may be considered:

$$
\begin{aligned}
& \text { du d du } \\
& \cdot=-0 . \\
& \text { if to } 1 x
\end{aligned}
$$

Its domain $R$ may be taken as $x=[0, x]$, and $i l s$ initial and houndary candilions specified by functions $f, x), g(t)$, and hil: 


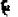

$$
\begin{array}{ll}
u(x .0)=f(x) & \text { for } 0 \leq x) \\
u(0 . t)=g(t) & \text { for } t t_{j} \\
u(x . t)=h(t) & \text { for } t \geq t_{0}
\end{array}
$$

It may be proven that a solution 1 it $x, t$ of Eqns. $(1,1-1,2)$ exists and is III) 1 que 12 .

The system Equs, $(1.1-1.2)$ may be approximated, not at all points $(x, 1)$ in $R$. but on a finite grid or mrsh of points $x$, at times $t^{n}$. The subscripls (ustally, and $k$ ) will index the space coordinates of all quantilies defined on this mesh, and superseripls (usually $n$. occasionally $m$ or some other letter) will index the tume. Thus $u^{n}$ is the temperature $u$ at point $x_{j}$ and $t$ ime $t^{n}$. The mesh may be defined by the sequence of points $x_{,}$, for $1 \leq y \leq J$, with $r_{1}=0$ and $x_{j}=x$ : and by the sequence of $t$ imes $t^{n}$. With $t^{0}=f_{0}$ and $t=T$. the "slop time" ror the problem. The portion of the problem delineated by points $r$ and $r$, , may be called a zonc, zonf $J$. The symbol $u^{n}$ with no subscript may denote the whole array $\left(u_{1}, u_{2} \ldots \ldots u_{j}, \ldots u_{j}\right)$ and $\left.u_{j}, f^{m}\right)$ may denote $u$ at $x_{j}$ and some for the moment variable time $t^{\text {m }}$. One $f$ inite epproximation lo Eqns. $(1,1-1.2)$ may be exhibited:

$$
\frac{u_{j}^{n+t}-u_{j}^{n}}{\Delta t}=\frac{\sigma}{\Delta x^{2}}\left(u_{j+1}^{n}-2 u_{j}^{n}+u_{j-1}^{n} \cdot\right.
$$

together with its initial and boundary conditit.ns:

12 Garabediun (1966). 


$$
\begin{array}{ll}
\left.u_{j}^{0}=f(x)\right) & \text { tor } i: j=j \\
u_{j}^{n}=g\left(t^{\prime}\right) & \text { for } n=1.2 . \\
u_{j}^{n}=n\left(t^{n}\right) & \text { for } n=1.2 .
\end{array}
$$

The equalion (1.3) may be used to advance the array $u^{n}$ trom time $t^{n}$ to time $t^{n+1}$ : the quallity $\Delta t=t^{n+1} \ldots t^{n}$ is known as the timestep. Note that every zome is defined at time $t^{n}$ and that all are moved in lockstep

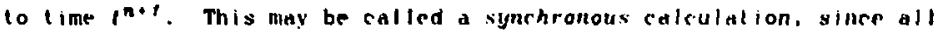
the zones are advanced syurhrotiously. The timestep $\Delta t$ does not depend on 2 . the zone index. Shortly Eqns. (1.1-1.2) will be axamined a litlle more closely and asynchronous calculations will be defined. with timesteps 4t, that may vary from one zone to the next. Asynchronous is used inlerchangeably with independent timesteps. When a parlicular zone is advanced from $l$ ime $t^{n}$ to $\ell^{n+}$. Il is said to be updated or ralculated. The tolal number of times that zones have been updated is the number of cone-ryetrs (represenled by SSIN) that the problem has done. In a synchronous calculation. SSSN is equal to the product of the number of zones times the number of cycles run (this product is denoted by $J X N)$. For an asynehronous calculation. SSJN may be less than $S X N$. The ratio (JKN/SSJN) may be called the campulation ratio. denoted by SRAT.

Fqn. (1.1) may he generalised in several ways. First, one may nute that it is a single equation in a scalar quantily u. By contrast. Ifere may be posed the wave equation 


$$
\begin{aligned}
& d i \quad d x \\
& d x
\end{aligned}
$$

dr.
$d e^{-}$
$d x$

It may be provided wilh inllinl and boumdars condilions analogous 10

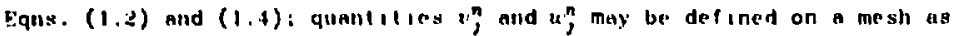
belore. And a patr of coupled finite difference equations play the role of Eqn. (1.3). In bydrodynamirs. Ihere will be not two but six or more such coupled equalions.

sercondly. It may be noted that in Equ. (1.1) there is only one space vartable 5 : there are conmonly as many as three, $x, y, z$ : and the temperature will arcordingly rarry three subseripts: $u_{j k l}^{n}$. I1 mav also be noted that the symbol \& in Eqn. (1.1) defilles a coordinate in problem with plane symelry: implicitly, u is delined for cartesian coordinates $y$ and $z$ al we, Eut does not depend on lhem. The problam might have bern posed in spherical Reometry, with $u=u(r)=u$ ir. and $a$ independenl of t and .: or in cyliudrical geometry, wills $u=w ! r=u\left(r=2:\right.$ and $u$ independent of . and $z^{13}$.

13 For a iwo dimelisianal probiem in eviludrical coordinates r.2, see leblalle $\$ 1$ soll $(1970)$; for a one dimensional problem in spluerical acometry. sece May White (1966). For lhree dimensional work. sec, $g$ leill

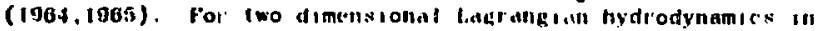
plane and cylindichl krometry, sese schulz, (1004). 
Two terms from hydrodyuamle :saue may be defined hl this poina: Eulfrian and Lagrangian hydrodyutilcs, Amoug the pliysical quantilies appearing in the hydrodynamic eqiations as dependent var iables ure the velocily, pressule, density, and internal energy densily. The position $r$, may be t'ken as dependent or itudependent. Hccording as the points $r$, are fixed in the moving lluid or lixed in the laborntory. In the tormer case, the Lagrangias formalism, the posilion $x$ is a dependent variable and the mass m, of the fluid zone $j$ is a fixed parameter. Here the quantity $x$, is the position of the point, which moves with lle flutd. In Eulerian hydrodynamics by contrast, the positions $r$, aye fixed paranelers, and the masses $m$, are depeident variables. Matler flows into and oul of zones, and this flow nust be calculated. In textbooks of hydrodynamics. the usual formalism is Eulerian's, and the Lagrangian equations are less commion's.

To returu to the system, Equs. $(1.1-1.2)$, and to indicate one more way in which it is not general. the initial cunditions in Eqn. (1.2) were specified on a line $T(x)=t_{0}$. This curve $T(x)$. called a Cauchy surfarc. might have been more general. a function not independent of $r$. The terms Cauchy Problem and initial Value Problem are synonymous. With InIlial and boundary condilions specilied by Eqn. (1.2) on $T(x)=t_{0}$ or on some curve $T(x)$ not a constant, the pertinent generalisations of Equ. (1.1) are always in some se.. p hyperbolicl6. It is known from the theory of partial differential equations' that if the Cauchy surface $r(x)$ is not a constant. neither $T(x)$ nor the function $f(x)$ defining the Initial conditions are completely free of restrictions. The nature and

14 Landau, Litshitz, (1959), f, 1, ff.

is Zel-dovilh. Raizer (1966). Section 2, p. 4, fl.

16 Garabed an $(1964)$. chapter 3 .

17 Garabedian $(1964)$, chapter 4 . 
causes of these restrictions will be made clear below, when the plail of the present work is oulined.

\section{Aloralion of Compula! ıonal Ertorl}

At each particular stage of the compulation, one must decide how iar in line to advance it on the next round of computalions. For erample, one must select II Eqn. (I.3) a value for the parameter $s t$ if one is to advance the problem from $t^{n}$ to $t^{n+l}=t^{n}+\Delta t$. In only the simplest of problems may the timestep be sot once and for all time at the start of the calculation. l'sually as events transpire. Ionger or shorter imesteps are appropriatc to different epoehs in the history of the problem. brief in times of rapid change. and of longer duration when Iitlle is haopenting.

Different zones of the problem may for reasons of stability and accuracy discussed below require quite incomensurate timesteps -differing pven by orders of magnitude. One is then apparently obliged lo step the problem not further than the briefest of these timesteps, in order to escape instability or avoid unacceplable inaccuracy in the most siringently limiled zone. It does nol matter that most of the zones in the fluid body being simulated will be compuled far more frequently that they require -- even recompuled when they are barely changing at all. One may in a one dimetisianal conlext plot the timeslep as a function of posilion. as in Fig. (2.2). This sultalion (and it is a common one) cries fom improvement. To the cxtent that the briefest $t$ imestep is unacceplably smajl becausc of stability considerations, one can resort 
lo Implicit difference methods, which usually are unconditionully stuble18. However. in problems of any conplexily at all experience with implicit equations indicates that the timestep is still controlfed severely by one or two zones for reasolss not of stability but of arcurary, One can use five or seven point integration formulas, in whirh a zone is allowed to interact not just with its neagest neighbors but wilh matter severul zones distant 10 . Here, one call expect the Courant condition 20 on the timestep to be relaxed by a fuctor of two or three. There are even explicil dilference methods which are unconditionally stable, such as that of du rolt and Frankel, for the diffusion equation ${ }^{21}$, a matler to be discussed below in Chapter IV.

What one would like 10 do if only one could is simply to skip calculaticns in those zones where the timestep can be long until enough lime has elapsed since their last updating lo fill out their own natural limesteps. Inspecting Fig. (2.2), zone number 10 has a limestep smaller by all order of magnitude than any other. This problem of 80 zones must allorale ten times as muen eftort to the body of the problem (zones 1-9 and 11-80, al the present) as it would require from stability and accuracy conditions prevailing in the majority of the zones. Because The region of brief timestep is so small. There is a potential savings of about a factor of ten in effort -- in problem running time.

In fact. much of this potential savings can be realised. It is possible to step zone 10 ten limes for every one time zones $1-9$ and 11-80 are stepped lorward in time, and it is posstble to do so in a way

18 Richtmyer \& Norton (1967), p. 16; Yanenko (1971), p. 12. is Joubert (1971.1972).

20 Courant. Friedrichs. Lewy (1928); J. R. loubert

31 du Fort. Frankel (1953). 
sich that the zone trequentiv calculated is not always sone fixed zone (zone 10, e.d.) but is whatever zone nomentarity needs the frequent attention. For as the shock progresses across the problem, each rone in turn requires a limeslep brieler than nil the others. With an aigorithm of no great complexily. each zone chn enjoy the treatmenl il deserves without undily delaying the rest of the problem. Or, If several zones al once require brief timesteps, that can be handled eastly. The method requires none of the global perspective of the human calculalor. but handles ils calculations and decisions on purely loral considerations, What lollows will indicate the approach and the modest precallions necessary to maintain stability and accuracy.

\section{The Experience of Celestial Mechanirs}

A remedy for the difficulties of hydrodynamics may be had by following the example of recent practise in some problems of celestial mechanics. This problem is Ireated in comprehensive generality for ordinary difterential equations by Gear ${ }^{22}$ and others, but my own acquaintance with it is via the particular case of celestial mechanics. and that example will provide a nicely concrete motivation for the contemplated programme in partial dilferential equations. Inlegration of the equations of motion of the ten major bodies of the solar system presents problems similar in some respects to shork hydredynamics. There is a great disparity in celestial time scales. from the 28 day orbit of the moon 10 the 90.465 day orbit of Pluto, a factor of 3000 . Methods of integration in celestial mechanics take advantage of the 
positions of the planels at many previous points in their orbits, and conseguenlly can move a planet around its orbil in dozen or so linesteps. Aut if the moon sets the timeslep at approximately 2 days, one is culled to step Pluto 40,000 times in its orbit. and that hardiy seems called for.

The experience of $s, J$. Aarseth and others ${ }^{3}$ indicates that indeed each planel can enjoy ils own natural timestep of about a tenth of its. year. In estimating the gravilational forces on one of the ten bodies one needs the positions of the other nine. These may be had by interpolation or extrapolalion as is convenient. The same strategy works for the solution of parlial differential equetions as for coupled ordinaries. There are some critical differences, however. Stabifity is Blways an uncertain mater until it is investigated and proven. There is at leasl one example of an unconditionally stable integration scheme for the heat equation being rendered at best conditionally stable by independent $t$ imesteps .

Hydrodynamics presents a new situation in as much as no one zone always has the briefest timestep. leaving others to be updated less olten. In the motion of the planets. Mercury will always have an 80 day perlod, and the Earth will always have one of 365 days. But no zone in hydrodynamics always plays the role of Mercury while some other zone plays the role of Pluto. One cannot permanently and ahead of time

23 The Work of $s$. J. Aarseth referenced is an extension of the described work from the solar system to the N-Body problem. specifically the simulation of globular clusters. The need for independent timesteps there is critical, and arises trom a few close encounters of stars. Close encounters require timesteps far briefer than those sufficient for the integration of the other bodies of the cluster. 
assign limesteps to different zones. Somewhal more sophisticated logical machinery is required 10 assign tumesteps and to select zones due for calculation. Neverlheless, to be uselul and general as a method, this logical apparalus must operate withoul help from the haman user of the melliod. alsd it must not consume too much time in compertison to the effort spent on actually doing the physics.

The strategy of Approach

As a general. il somewhat simple instance of the equations to be integrated, ote may take, with a.b,c, all positive:

$$
\underset{\partial t}{\partial u}+\frac{\partial^{2} u}{\partial t^{2}}=\begin{gathered}
\partial \partial u \\
c-c- \\
\partial x \partial s
\end{gathered} .
$$

The coefficients $a, b$, c. c may all be variable functions of $x$ and $t$ and more significantly. of $u$. If $b$ is zero. the equalion is parabolic. olherwise it is hyperbolicet. This is a scalar equalion in one variasle. $u$, and almost invariably praclical situations call for integrating several coupled equations. But this equation is for the moment quile sufficient to illustrate the pertinent considerations. Together with this equation, one must specify initial and boundary conditions on some Cauchy surface $T(x)$, as in Fig. $(1.1)^{25}$. For present purposes, all problems may be considered hyperbolic. and so initial conditions at point $P$ influence subsequent events in the region $D$ bounded by the two characteristics $q(x)$ and $s(x)$ : and in Fig. (1.2), the events at point $Q$ are determined by the conditions on the Cauchy surface 24 Garabedian (1964), Ch. 3. 25 Garabedian (1964), p. 104 
$T$ between points $R$ and $s$ and possibly (usually) by the conditions in the region $E$ bounded by $T$ and the characteristics $q$ and Ihrough the point Q.

In order for the problem to be well posed. Il is necessary that figures such as Figs. (1.1) and (1.2) exist. This is in fact a condition on the slopes of the rurves $T(x) . q(x)$. and $s(s): q(s)$ and s!s) must both be steeper lhan $T(. r)$. In usual circumiglances this could be passed over without menlion. since Cauchy condicions are conmonly preseribed on a line $1=0$. But as the computalion procends, II different zones have different timesteps. they will also be referred 10 different limes. Thus, at any stage of the calculation the ogeregale of dala stored for the sel of all zones represents Cauchy conditions specilying the further development of the problem. so that a problem which was initially well posed could evolve into one which is nol well posed. Such a pathological situation is illustraled in Fir. (1.3). Silppose that in Eqn. $(1.6)$, $u$ represents a temperoture, and that it point $P$ in Fig. (1,3) due to non-linear effects. the characteristics are significuntly flattened. Now the slope $(\partial q / d x)$ of the characteristic $q$ is just the reciprocal of the sound speed. so we may expect the curve $q(x)$ to bend over, and in fact it can intersect $T(x)$. Here there is trouble, for the point $Q$ is specified already, since il is on $T(x)$, which is to say $1 t$ is the result of prior essentially locnl evolution of the problem. But $Q$ is now alleged to depend on conditions in the neighborhood of $P$, and this is impossible. For computational purposes. Q lies in the past of $P$. and $P$ has succecded in propagating intormation into Q's past. There is no proper way lo handle this Irouble: the problem is no longer well posed. Because real equal ions are not 
17

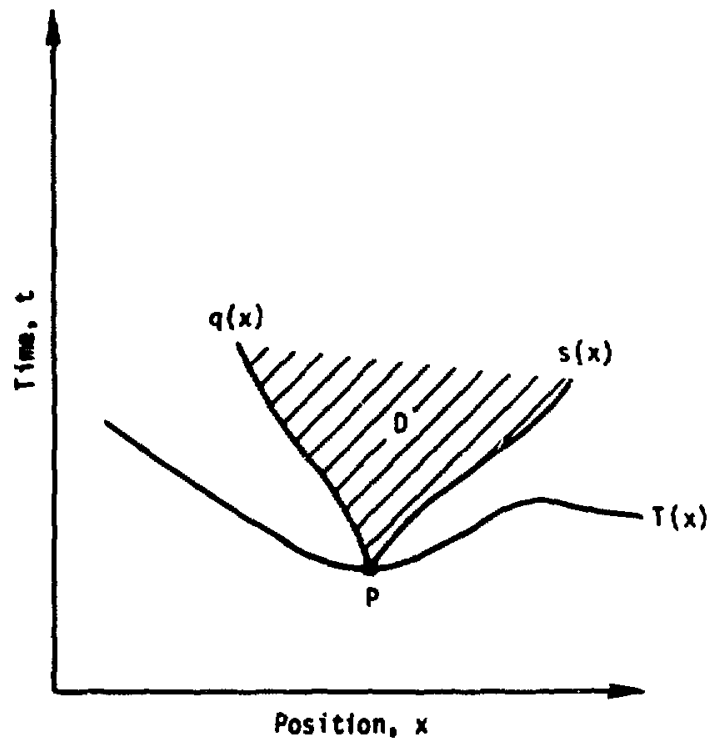

Fig. (1.1) Initial conditions 


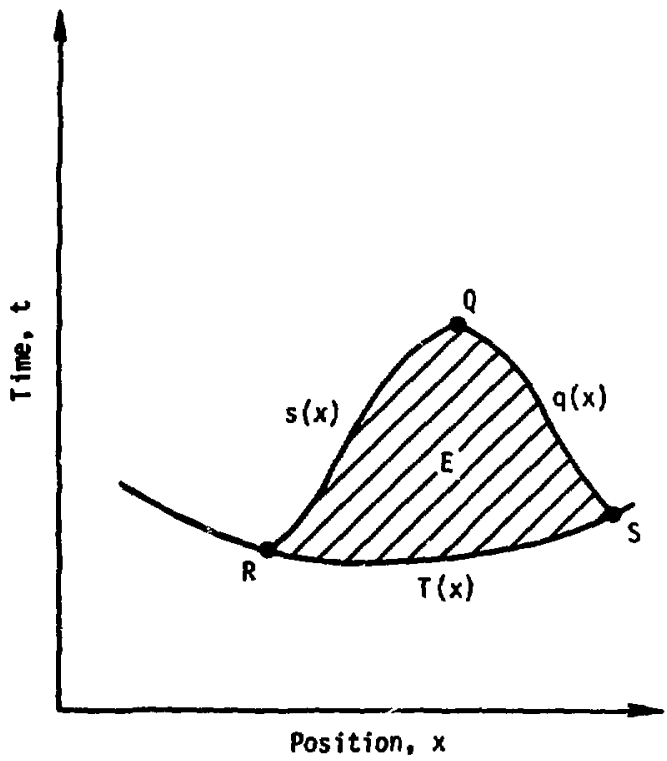

Fig. (1.2) Damain of Dependence 
conmonly bluear, it is not in keneral possible, pivel the illormation on

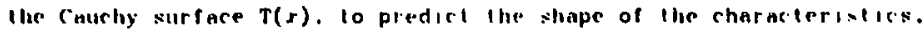
except by nelually solving the problem inciementally in time. And so. with Cauche surlaces concave forward in lime. one is always vulnerable to this kind of misfoltune. It is apperenlly possible lo protect oneself Irom 11 , as is repolled by Grandey. allhough his publs slied work dees not indicate low ${ }^{20}$, he indientes that st:ingent timestep rontrols will suffice?

This may be made clearer by indirating the possible methods of selecling the next zolles to be updated. sunce this cholce deformunes the character of the Cauchy surfaces $T(x)$. As each zone : updated. 10 it is ussigned a lime $T$. specifying some point on the curve $T(x)$. In the appronch of Grandey. the next zone to be compuled is always the zone most out of date. The zone of earliest or lcast time $T$. To the problam as a whole. at inis particular stage of the computation, can be assigned the time $t$ of this zone. Thus, all the $T^{\prime}$ s are larger than $t$. that is, parachronir with respect to $t$. Most of the time the next zone to be computed is tlie zone of least timestep, and this is the zone where events are developing at the grealest rate. It might be called the crisis zone. It is also the place most likely to originate trouble of the kind illustrated in Fig. $(1,3)$. Whenever a zone of longer timestep is momentarily the zone most out of date. It is updated far into the future of its neighbors of briefor limeslep. Thus, one may plot the Cauchy surface $T(x)$ and the timestep $\Delta l(x)$ on the same graph. as in $F^{\prime} i g$. (1.4) for the price of potential trouble, and the siringent limesteps

26 The work known as lariable Timestops is reported in the references of $R$. A. Cirandey and $C$. H. Davis.

27 R. A, Grandey, private communicalion. (1975) 


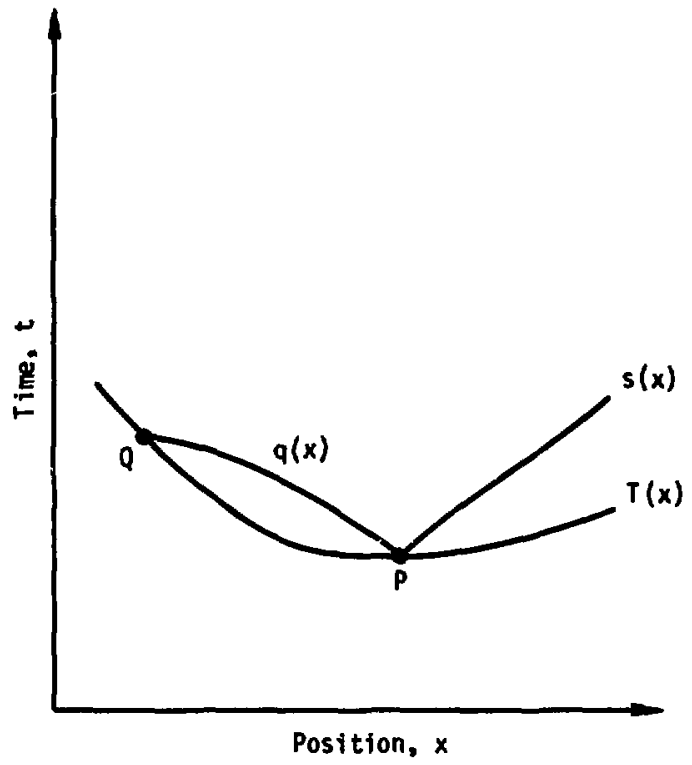

Fir. (1.3) Patholopical Initial Conditions 


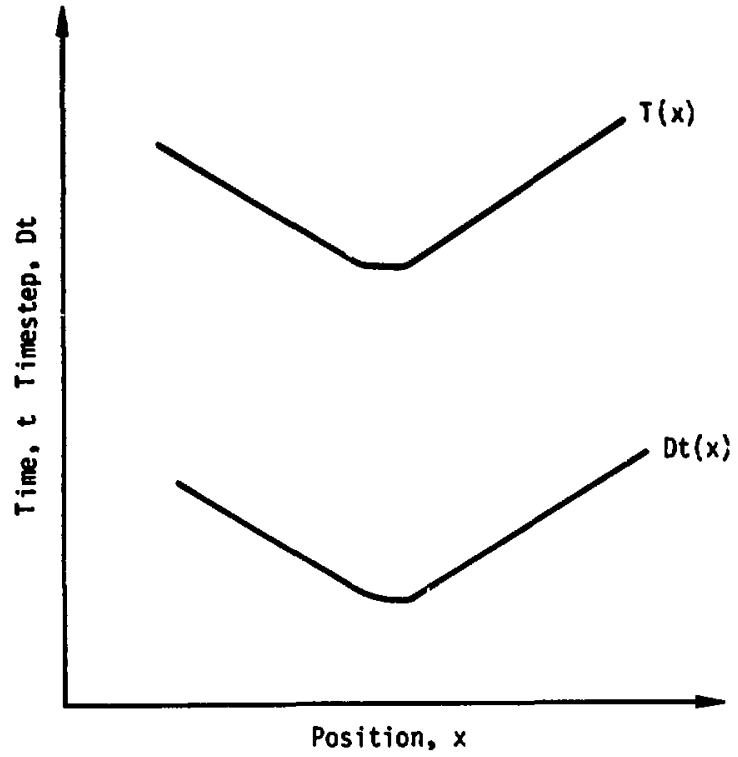

Fig. (1.4) Cauchy surfaces in the Method of Grandey 
needed to nvoid this trouble. che elljoys the cpportunity of tims IIIerpolating instead of extrapolat ink qualut ins in neighbor ing zolies as oue needs lhem whrll they are not isortioule wilk the zane of interest.

ta the work here delailed bejow. Ihe zonps of lonk characteristiv

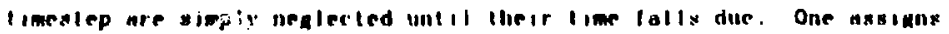

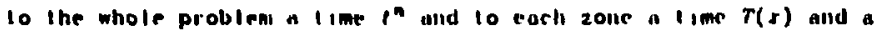
limestep sf(t). In advancing the problem from in to an intended next

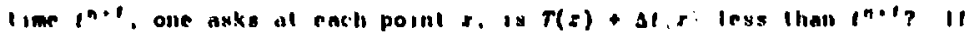
su. then the zome at point $r$ is due to be updaled. otherwise not. The zone of leagl linestep will be the zone of latesl proper I ime $T(s)$ : for that zone $r(x)=1^{n \cdot 1}$. Thus, all limes $r(x)$ are carlier than $1^{n+1}$. or prothronit to the problem time. If in calculatiby some zone one perds quantities fram a neighboring zone it may be necessary lo extrapolate them forward in tine. This can safely be done, subject to simple precautions. The chief of which is that adjucent zoncs have timesteps differing by no more than a factor of two (this restriction wil be motivated in detail at fiqn. (3,0)). It is this precaution which is responsible for the constant slope of $\Delta /(x)$ in Figs. (2.3) $10(2.4)$ adjacent to the zone of least timestep. The stralegy of the present work may be Ilustrated in Fig. (1.5) Four succesive stages in lie computalion are presented as surinces $T^{\prime} 10 T^{4}$. On the surface $T^{n}$ are indicaled points $P$ and $Q$ of lonk and short $t$ imesteps. respectively. It is possible, but in praclise quite unlikely. Ihat point p could originate a disturbance propagating into the past of point $Q$. The reason is that points which are potential sources of liouble tend to be thr points of briefest timestep. wuch as point 9 . and other points are 


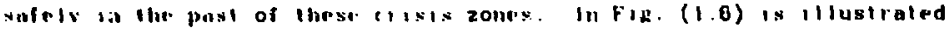
lie relalive slinpe of the atite $T(x)$ nibd $g(x)$ in the present work. Nole that the maximum pyopri I ime crobrs ill the zolse of minimum limsirp. This is sufficient 10 keep the problem well posed.

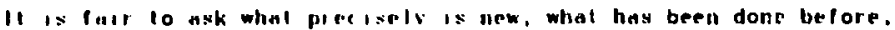
ald what is drawn from the comon practise of the tield. R. A. Grender litst altemptod nlint in known as rariable fimesteps, with mixed sticcess. and to insestigalion of that melhod's slability, convergence or wr Il posedness. For rensolos of well posedneks a diflerent approarh is laken hre. Will different melhods of approximalian (those reasons were just indicaled: the detalls of implementation are illustrated in chapter II and Reneralised in Chapter III) and a different sequence of logical control (for reasons of computational economy, discussed in Chapter HI). The methods of slability argument presented below are well enough known (though not widely used) but new in the ir application to independent timesteps.

In what lollows, the melliod of independent timesteps will be Ilustraled in chapter II by a simple example, one-dimensional von Neumann hydrodynamirs. In chapter 111 w II be presented rules spertlying a seneral approach to implementing independent times! aps in any difference scheme. Together with comments on specific instances of particuiar difference schemes. Chapters IV and $Y$ will detail stability analyses of synchronous (conventional) parabolic and hyperbolic difference equations. Chapler $l i$ will present these arguments modified by the presence of asynchronous (indepeadent timesteps) calculations. togelher with an error analysis of difference equations with independent timesteps. Chapter vil will present the experience of comparative 


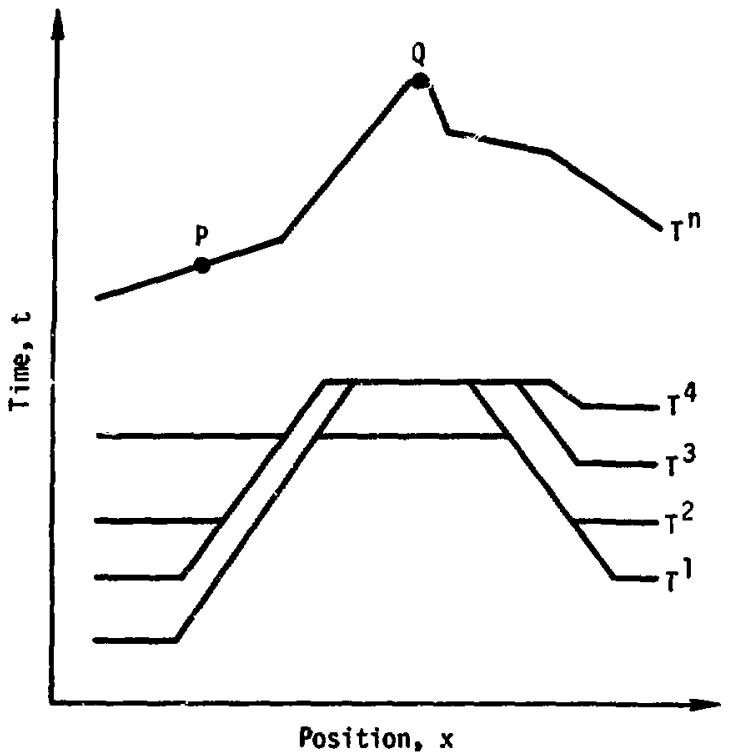

Fig. (1.5) Prochronic Cauchy Surfaces 


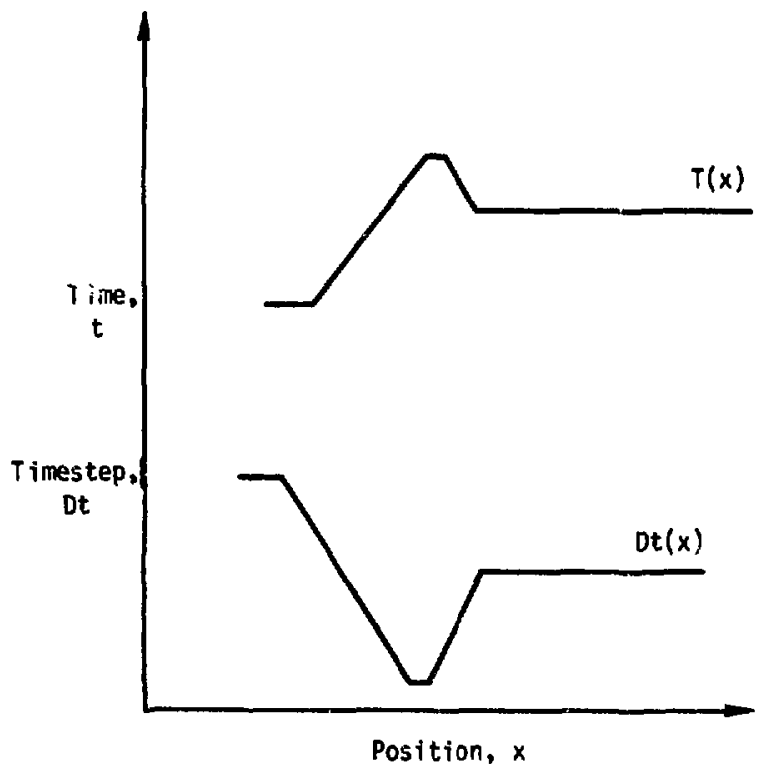

Fig. (1.6) Timesleps and Prochronic Cauchy Surlaces 
timing Irials. In which independent timesteps are seen 10 afford a ready wain in speed by $n$ factor by three to ten. 
('HAPTER II

AN ILLUSTRATIVE EXAMPLE OF INDEPENDENT TIMESTEPS

\section{General Consideralions}

11 is lypical in a one-dimensional program doiag Lagrangian hydrodynanics with the method of von Neumann' Richtmyer 10 use roughly 10010200 spatial zones and take from 100 to 10.000 timesteps. This is adequale lo describe, say. a dozen material regions and several shock transils. With half a dozen numbers describing each zone, for a problem of 100 zones run for 1000 cycles. There will be genera'ed $6 \times 10^{5}$ numbers

- these form the "answer" to the Cauchy problem.

Fig. (2.1) is a graphic summary of the kinemalic portion of such an "answer" (in the Lagrangian formulation) -- it plots the zonal coordinate vs. Iime for selected zones. It may be seen that various regions expand and are compressed in their turn as the problem crotves. Taking the number of inflection pounts as a very rough index of the degree of a polynomial required to itt these curves. It appears that a dozen sixlh or seventh degree curves are involved. Twelve seventh 
R vs.t Problem History Output of a Hydrodynomics Program

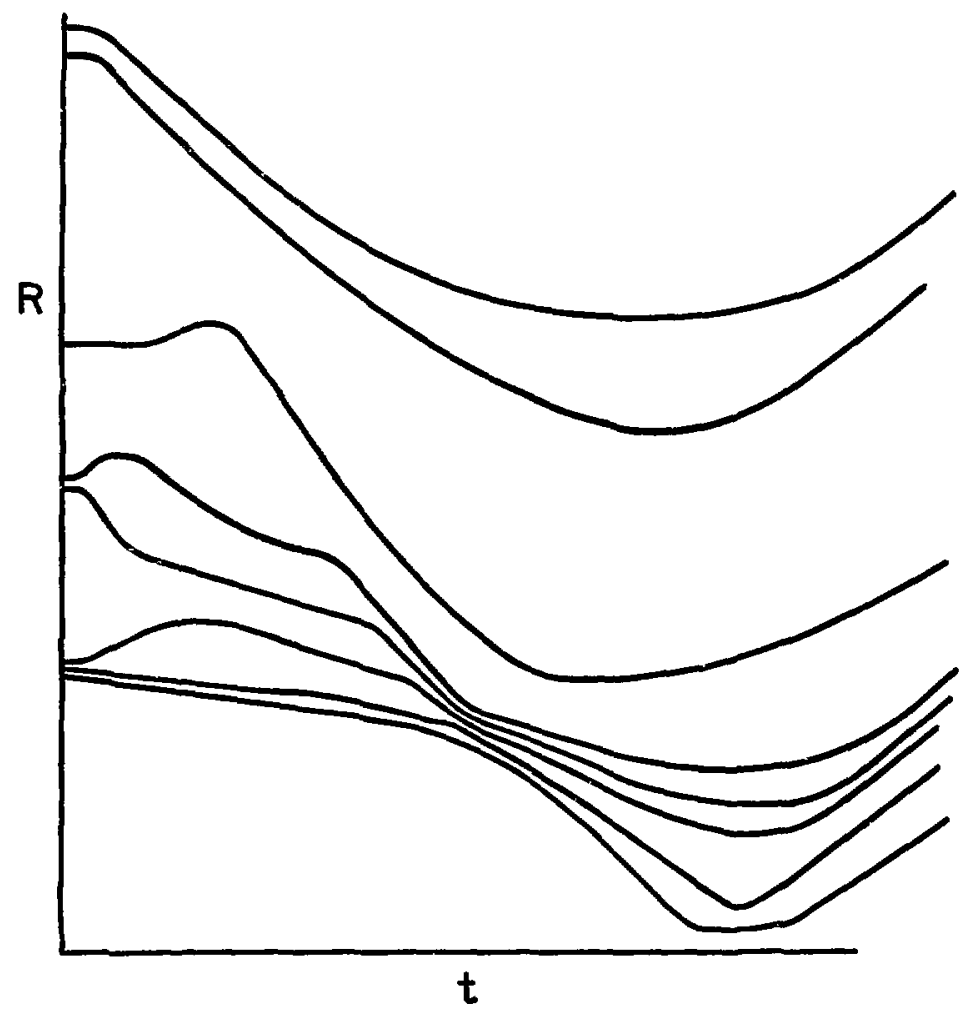

Fig. (2.1) A Problem History 
degree polynomials can be defined in $12 \times 8=9 G$ numbers, whereas code output is 100.000 position coordinates alone, not to mention pressures. ellergies, elc. This is a factor of 1.000 more "information" than one naively suspecled would be requiled. Ore thousand numbers might provide 100 curves -- a history for ench zone.

Since the code takes so mally more timesteps than one thought necessary, one may ask how the limesteps were set. A fimite difference program in hydrodynamics is limited in its timestep by a stability condition. the courant condition, and by some "reasonability" condition -- that no zone volume change by more than $10 \%$ or $20 \%$ in a single timestep. This second condition sets what may be called a physical timestep: It ensures the accuracy of the calculation. Each zone has its own individual Courant timestep and its own physical limestep; the whole problem takes the least of all these timesteps. In olher words. the zone with the smallest timestep of either kind sets the timestep for the whole probileem.

Conversations with L. D. Howard suggested one way to speed up a calculation. namely. to let each zone calculate at its own timestep. It is possible :o implement such a scheme, and the initial results were encouraging in that the method worked at all. and discouraging in that the experimental code the "hara"- computed only a little (0-50\%) faster than the standard von Neumann algorithm -- the "tortoise". Subsequent work was much more encouraging, as will be detailed in chapler vil. As the code was rewritten 10 do more physics, the logic required for independent timesteps occupied proportionately tar less of its time, and was able to effect the savings of a significantly greater effart. 
The Melliad of Individual Timesteps

DENEB, ahock bydrodynamics code 11 which tach zone steps forward In time nt its own natural rate, was croated to study the individual timesteps scheme. Fig. (3.2) plots the courant timesteps and the physical timesteps for a sanple problem. Here one ran see tho disparity in limestep from the briefest to the longest. This lest problem consists of two regions. zones 2 lhrough 42 and 43 through through 82. of different densities. The position al zone 2 is fixed, and a shock is moving from zone 8:2 towards zone 2 . At zone 42 , one can see the jump in Courant time due to the density dismoniluity: at zone 75 is the reflected shock, and the transmitted shock is at zone 10. The zone presently in the shock (zone 10) is being compressed rapidly, and it will set the timestep for the problem, a lactor, ten smaller than the natural timesteps for most of the other zones.

In fact, however. since (in DENEB) zone 10 hulds down the timesteps only of its neighbors, most of the problem does proceed at its own rate. The difference equations ore set up to compute the zone with the currently smallest timestep every cycle and (most of the time) skip zones of longer limesteps. The problem proceeds for 5.000 cycles as it normally would, but where one would have expected 400.000 zone-cycles of computation, only 33,000 have been done, so that on the average each zone is compuled less often than once every 10 cycles. There is no noliceable difference in accuracy relative to the calculation cone without individual timesteps, as is seen in the last section of this chapter . 


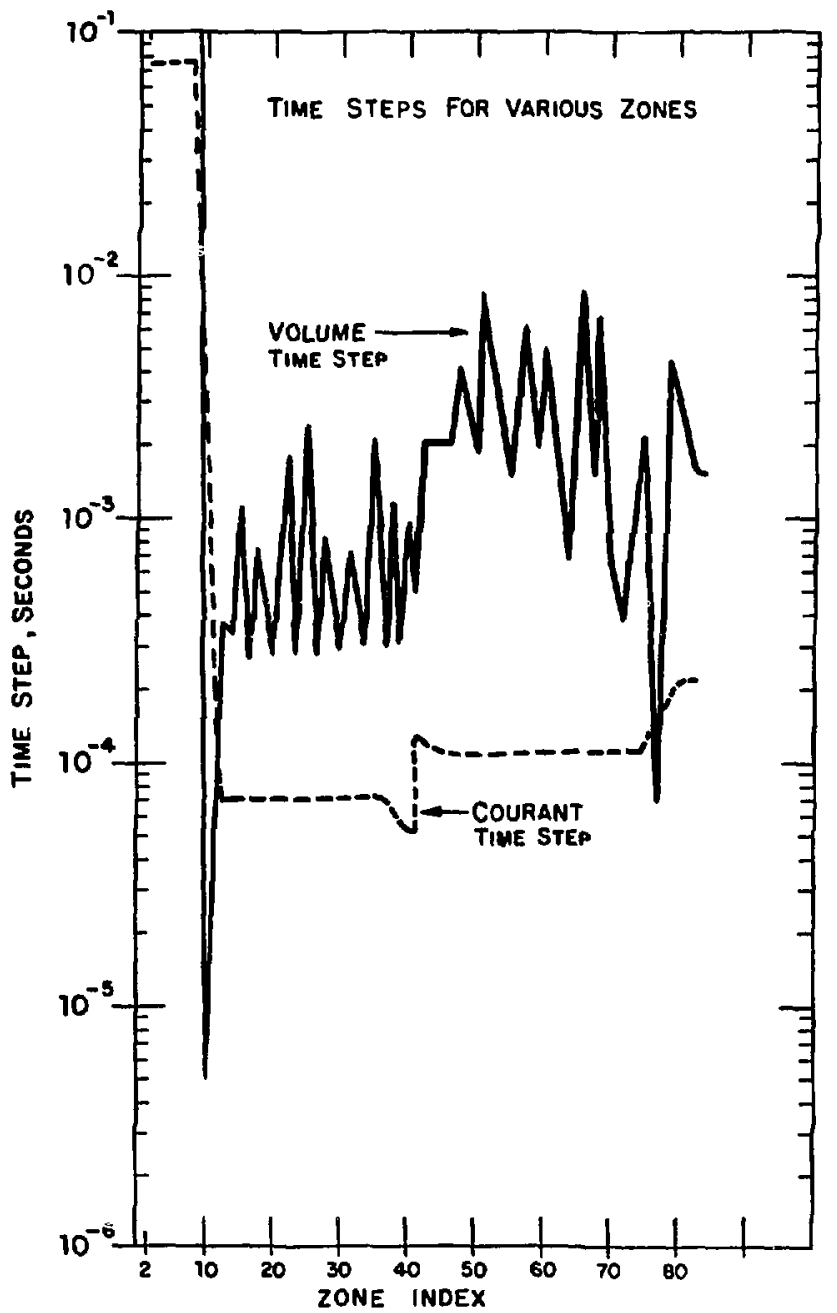

Fig. (2.2) Courant and Physical Timesteps 
There is no great strain on memory requirements by the difference scheme in DENEB. Hydrodynamics commonly stores at least nine numbers per zone (e.g. mass, posilion, velocity, specilic volume, artificial viscosity, material pressure, elfective pressure, inlernal energy, and nas law eanma). And for this scheme follr more numbers per zone are needed: the time when that zone was last updated, that zone's Individual limestep. "sentinel which says "compute me next cycle" or "skip me", and the rale of change of that zone's pressure. The computation sentinel is: the code's note 10 itself indicating whether that zone is due to be updated or not. The timestep stored for each zone is the maximum permissible: the actual step taken may be briefer. The time rate of change of pressure may be needed by neighboring zones in order to estimate that zone's pressure at limes other than when it was last updated.

Two programs were wrilten -- an asynchronous code with individual limesteps for each zone, and a synchronous code with a common timestep for all zones: both programs used the same difference equations taken Irom Richtmyer and Morton ${ }^{2}$. DENEB, with individual limesteps Ior each zone, generally requires less computing t ine than does RIGEL. which employs a single limestep. DENEB indeed spent much less time doing calculations of physics, as its computation ralio $(400.000 / 33,000=12.1)$ indicates. With physics as simple as this (no non-hydrodynamic energy transport, perfect gas equation of state). the physics tine saved by using individual timesteps was comparable to the time used in doing the extra logical work reguired to manage the

2 Richtmyer Morton (1967) See for example, p. 295. 


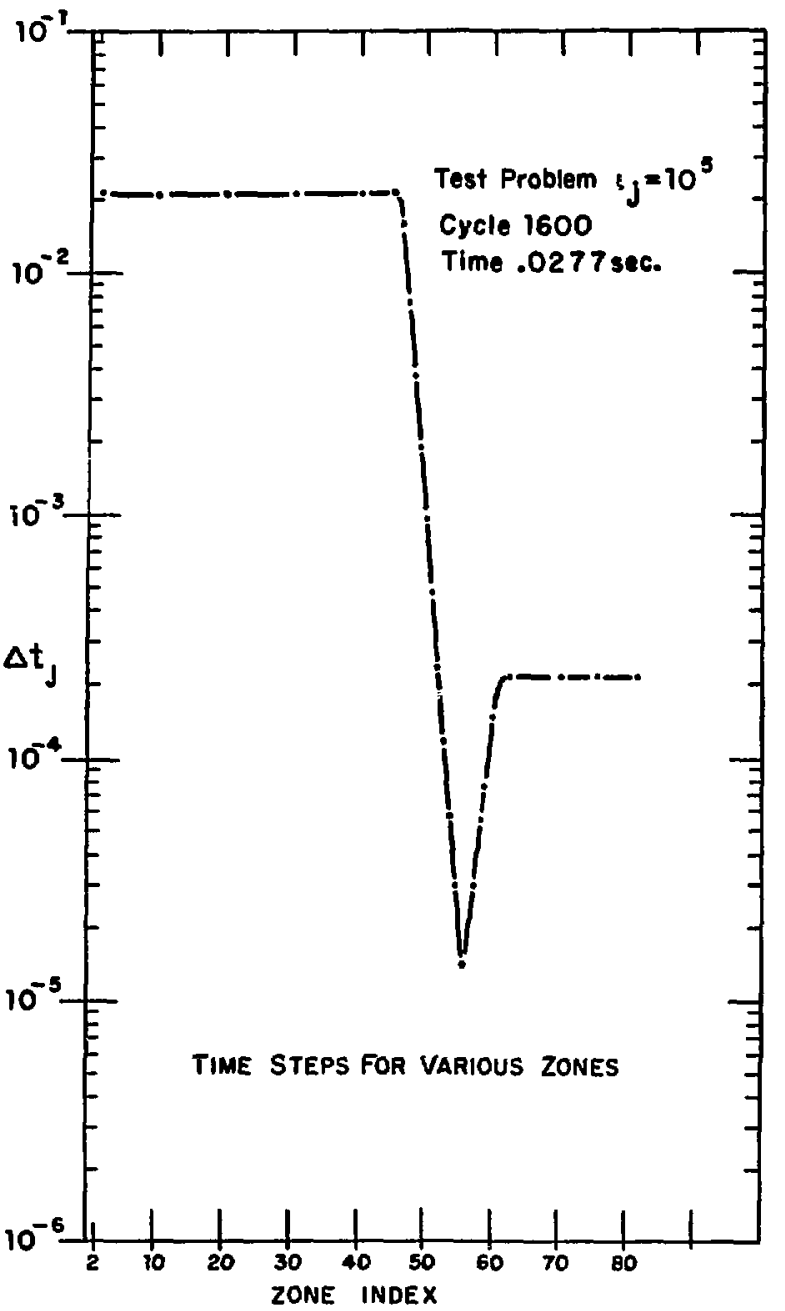

Fig. (2.3) Timesteps for Various Zones 


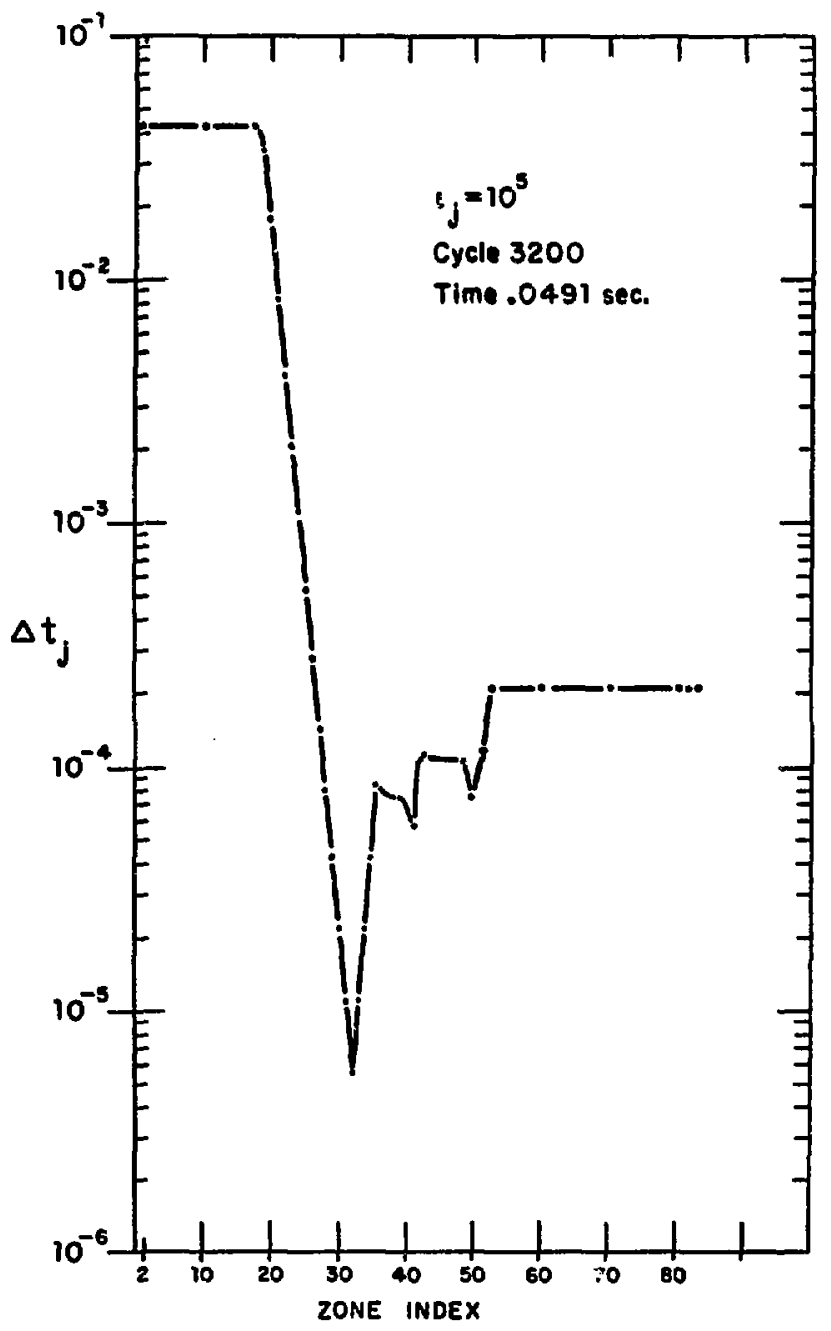

Fig. (2,4) Timesteps for Various Zones 


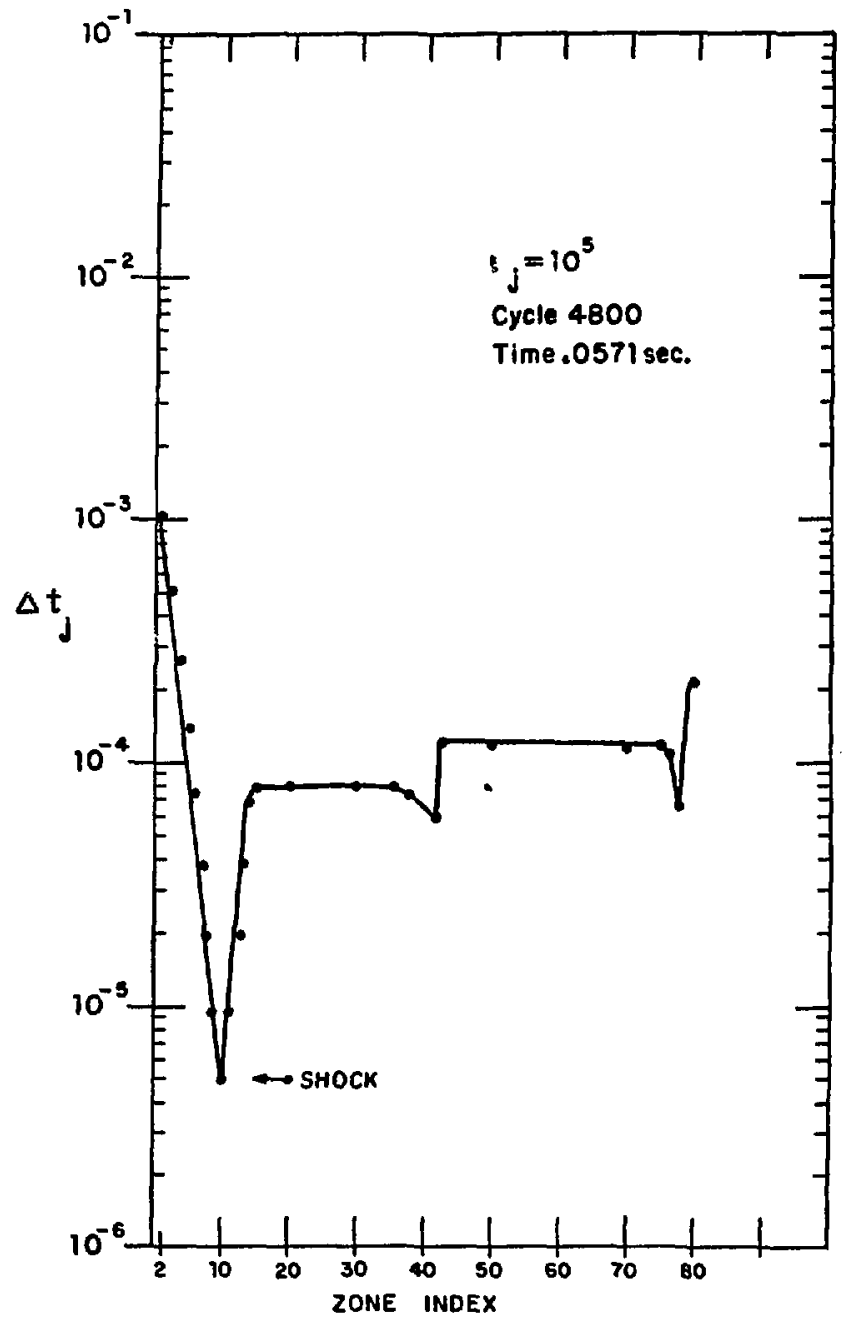

Fig. (2.5) Timesteps for Various Zones 


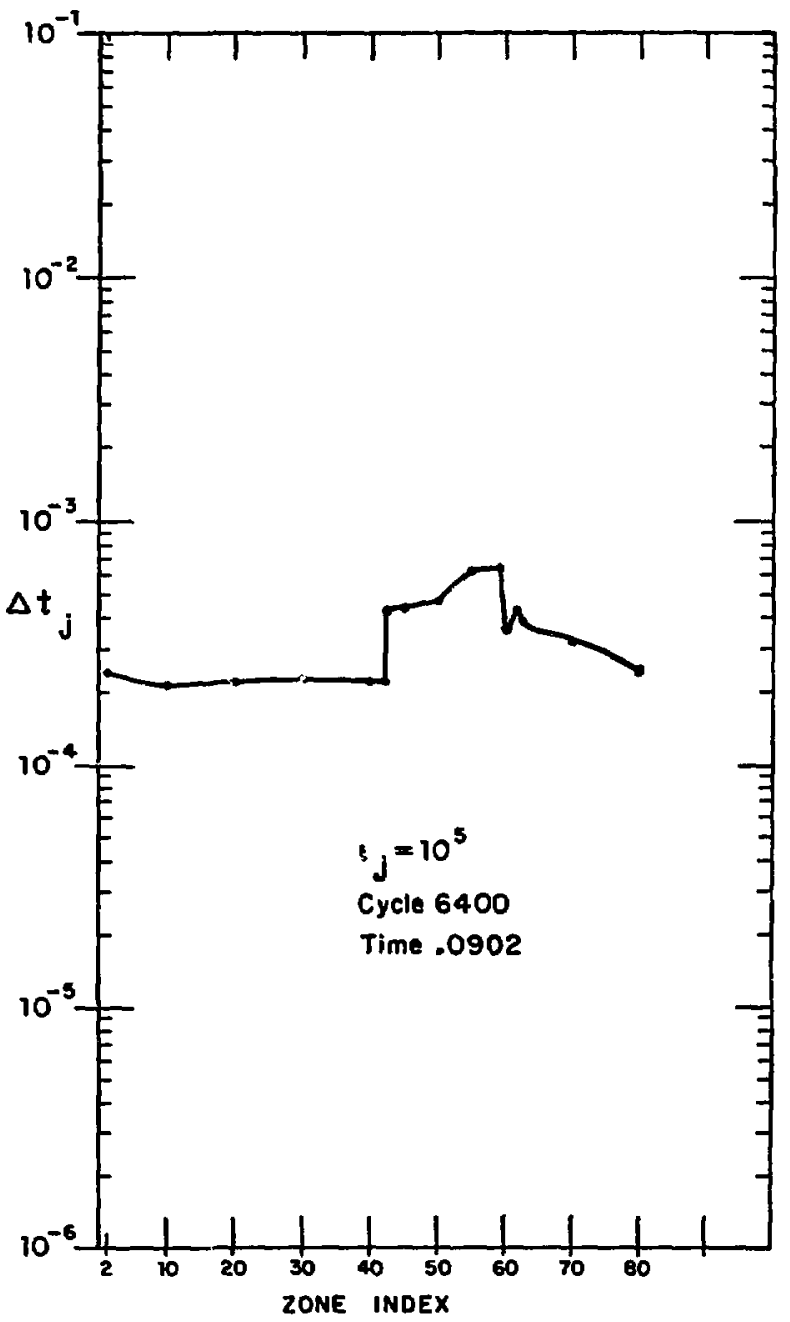

Fig. (2.6) Timesteps for Various Zones 
computation. Since these initial trials. this logical apparatus has been streamlined (it was very clumsy in DENEB), and with only little more physics added. The timing comparisons between the two methods can be quite striking.

As a graphic indication of what occurs in DENEB and RICEL, Figs. (2.3-2.6) plot at, us. j for various times in the lest problem of Fig. (2.7). showing the shock progressing across the problem. (This test problem is described in detail below.) In Fig. (2.3). the shock is at zone 56 , and the logarithmically regular interval in timestep between neighboring zonss may be noted on botin sides of the shock. (Hejghboring zones are allowed to have timesteps different by no more than a factor of two. resulting in the timestep spacing around zone 56 , as in Fig. (2.3). This restriction lowers the timesteps ahe ad of the shock. insuring that zones 50 through 55 are not "surprised" by the shock. an event which could leave those zones with negat ive volumes.) The zones ahead of and behind the shock have $t$ imesteps set by the courant condition. but the region behind the shock is much hotter and denser and develops a timestep accordingly brieler. In the shock itself, the Iimjting consideration is the volume timestep. In Fig. (2.4). the shock has crossed the region boundary, and the I imestep discontinuities mark the boundary and the two shocks now present in the problem. Fig. (2.5) is at the same time as Fig. (2.2). but plots the maximum permissible timestep for each zone (as do Figs. (2.3-2.4)), not the Courant or physical timesteps (as in Fig. ( $(2.2)$ ). The actual maximum $\Delta t$, is sometimer less than either the courant or the pliysical timestep. in order not to exceed $\Delta t, \ldots$ or $\Delta t,-t$ by more than a factor of two. Fig. 
(2.6) is plolted arter the shock has reflected from the fixed wall and the entire problem is in more or less unilorm expansion.

A method such as this one appears to be well suited to a problem in which tew zones require very trequent advancements in lime over very brief intervals. whils the vust majority of the zones can proceed forward in lime wilh mich more infrequent computalions. The isually striking overall savings in comptifation achieved by this method in ane spotial d vension mate it seem natural 10 try it in problems of two spatial dinension. shere the ratio of high frequency zones to low Irequency zones ought to be much smaller than the one dimensional ceses. It also seemed opportune 10 do more complex physics in one dimensional problems. .g. Io add heat conduction and other kinetic processes. The computalisn labor for limestep logic did nol increase, while such programs did indeed save much more computalion time in daing calculatisns of physics.

One point may be noted. tilat the independent limesteps code is everywhere at least courant limited. This limilation requires the program to include in its "answer" calculetional results at many more points than seem inluitively necessary to define the solution to the Cauchy problem. Nevertheless. independent timesteps codes with explicit transport run taster than synchronous codes with implicit transport (the lastest codes herelofore available). These results will be delalled in Chapter HI. 
The Diflerence Schemes

By exhibiting the thfference schemes in detasl. It is possible 10 show exactly what modificalions are necessary to implement independent limesteps in one dimensionth hydrodynamies. Both the synchronous von Neumann - Richtmyer method and the modifled asynchronous method are very similar in most respecls. Nine variables per zone are kept for physics:

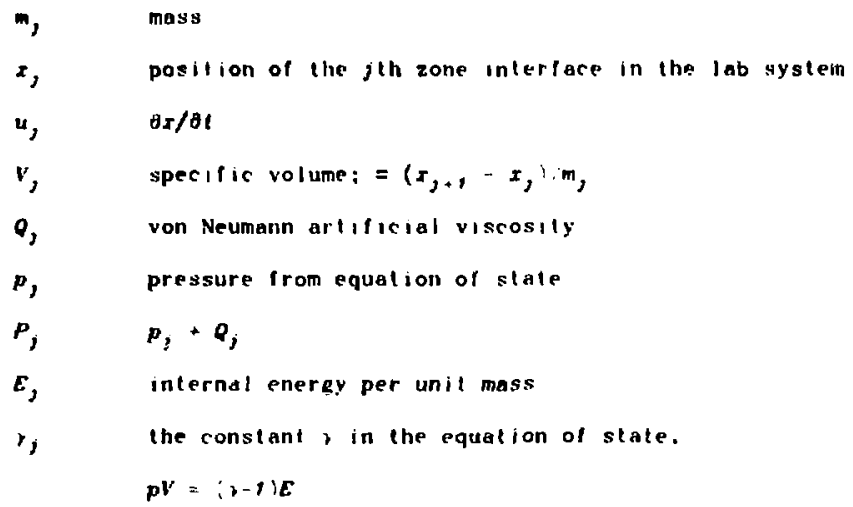

The mass, density, pressure, artificial viscosily, energy and gamma are kepl at the center of the zone. Position and velocity are kept for the $j^{\text {th }}$ zone at its boundary: $x_{j}, x_{j}$. Zone 1 is a logically convenient dummy, as is one zone outside of the olher boundaly. Thus. $x_{2}$ is the position of one boundary and $x_{J y 0}$ is the position of the other boundary. As in Fig. (2.7).

In addition. the limestep logic requires four variables per zone:

t) The time when the $j^{\text {th }}$ zone was last updated

st, the longest timestep permitted to the $j^{\text {th }}$ zone 
The Test Problem of Figures 2-6

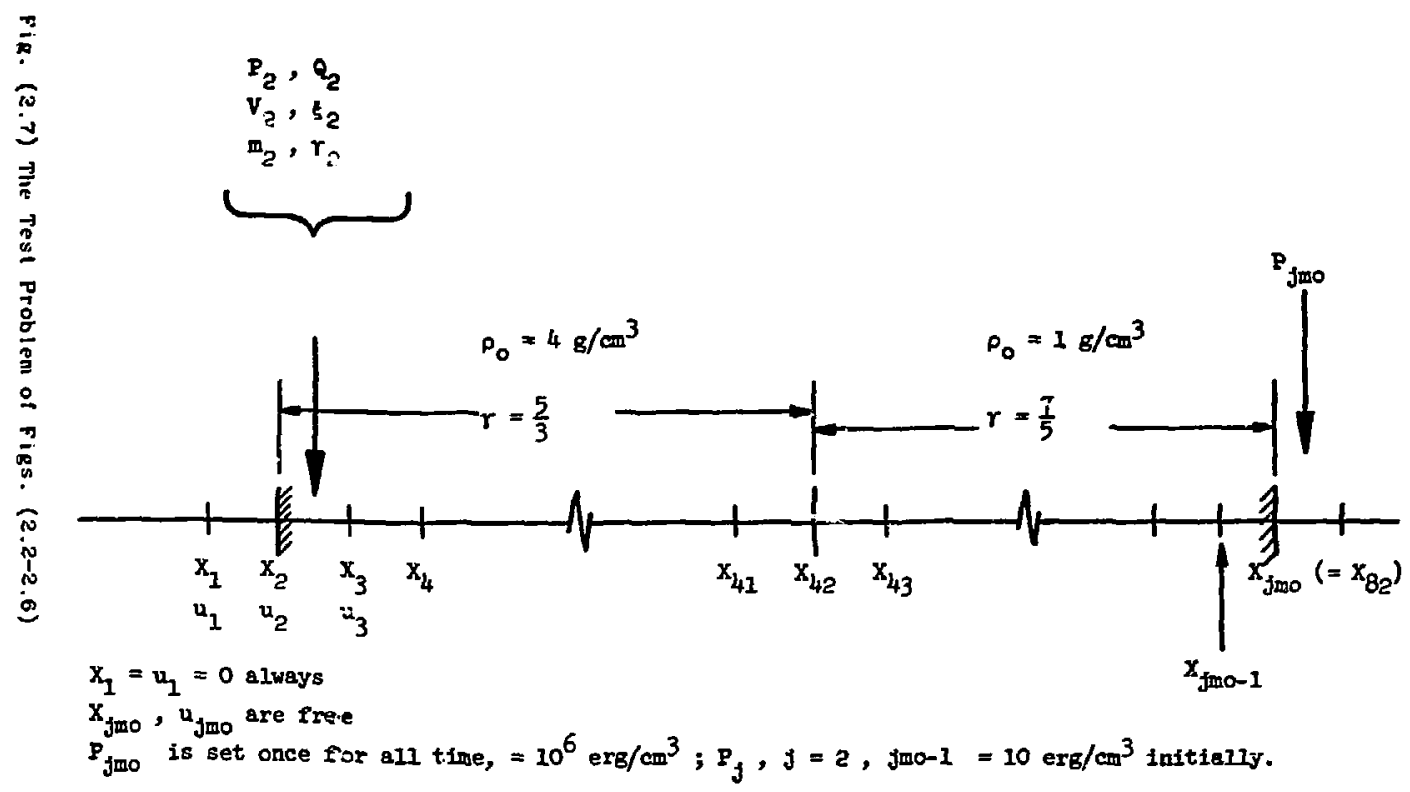

\& 


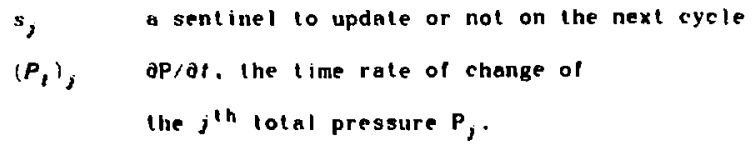

For simplicily and clarily of exposition. the calculation is in plane geometry. For the case of a common timeslep tor the whole problem. the difference equations are ${ }^{3}$ :

$$
\begin{aligned}
u_{j}^{n+1} & =u_{j}^{n}+2 \Delta t^{n}\left(P_{j}^{n},-P_{j}^{n}\right) /\left(m_{j}-t_{j}\right) \\
x_{j}^{n+1} & =x_{j}^{n}+\Delta\left(t^{n} u_{j}^{n+1}\right. \\
v_{j}^{n+1} & =\left(x_{j+i}^{n+1}-x_{j}^{n+1}\right) / m_{j} \\
\text { if } u_{j+1}^{n+1}-u_{j}^{n+1} & =0, \text { then } \\
Q_{j}^{n+1} & =2\left(u_{j+1}^{n+1}-u_{j}^{n+1}\right)^{2}, v_{j}^{n+1} \\
\text { else. } & \\
Q_{j}^{n+1} & =0 \\
P_{j} & =P_{j}+Q_{j}^{n+1} \\
E_{j}^{n+1} & =E_{j}^{n}-P_{j}\left(v_{j}^{n+1}-v_{j}^{n}\right) \\
p_{j}^{n+1} & =\left(r_{j}-t\right) E_{j}^{n+1}, v_{j}^{n+1} \\
P_{j}^{n+1} & =Q_{j}^{n+1}+p_{j}^{n+1}
\end{aligned}
$$

The equations are presented in the order in which they are solved. with the right hand side being evaluated and becoming the new value of the quantity on the lell hand side. For convenience, the pressure (P) includes both the materlal pressure and artificial viscosity, and the latter is updated belore line energy equation computation. while the material pressure $(p)$ is updated afterwards. 
The units employed are cgs metric. The equation of stale is that of perfect gas.

$$
\boldsymbol{p}=(\gamma-1) \boldsymbol{E}, \boldsymbol{V} \text {. }
$$

though ench zone may have ils own $r$, sel once for all lime.

The limestep is limited by two consideralions, stability and accuracy, which, as fig. (2.2) Hllustrates, are generally not 100 radically different. If $r$, is the local sound speed, we assign to euch zone two timesteps:

$$
\Delta t_{e j}=\left(x_{j+1}-x_{j}\right) / 2 c_{j}
$$

or one half the Courant time, and

$$
\Delta t_{v j}=0 . t\left|\frac{x_{j+1}-x_{j}}{u_{j+1}-u_{j}}\right| .
$$

the lime for a ten percent volume change. The timestep for the whole problem, $\Delta t^{n}$, is the least of the $\left[\Delta t_{c j}^{n}, \Delta t_{v j}^{n}\right]$. In RIGEL every zone is calculated at every timestep. In DENEB. a zone may be passed over for a thousand cycles if ils limesteps $\Delta t_{r j}$ and $\Delta t_{v}$ are both a thousand times longer than $\Delta t^{n}$, the smallest timestep of the problem.

One must be slightly more careful than merely to set $\Delta t ;$ to the lesser of $\Delta t_{r j}$ and $\Delta t_{w}$, If $\Delta t_{j}$ and $\Delta t_{j+l}$ are grossly different, one zone may be compuled many times while its neighbor does nothing. When Its neighbor finally "wakes up", it is ijkely 10 be too late. it has been observed in this situation that the neighbor zone may "wake up" to 
lind itself with a nepalive volube. To elimimate such possibilities, we insist that adjacent timesteps differ by at most a factor of two. The number two may seem arbitrary: it is. But it sufficed to allow the computation to proceed witheut untoward event; a value of four for this ralio proved 100 large. As a spcond requirement on the timestep, we let no $\Delta t$, increase more than twofold from one limestep to the next. Each limestep $\Delta t$, is thus consirulined by live conditions:

$$
\begin{aligned}
& \Delta l_{j}^{n} \leq \Delta l_{(j)} \\
& \Delta t_{j}^{n} \leq \Delta l_{l,} \\
& \Delta l_{j}^{n} \leq 2 \Delta l_{j+1}^{n} \\
& \Delta l_{j}^{n}=2 \Delta l_{j-l}^{n}, \\
& \Delta l_{j}^{n} \leq 2 \Delta t_{j}^{n-l}
\end{aligned}
$$

The first and second conditions of Eqn. (2.4) were enforced only as often as zone $j$ is computed: The remaining condilions were imposed on every zone every cycle.

Consider now a point in the computation at the end of the $n^{\text {th }}$ cycle. as the rode is about 10 set the limesteps $\Delta t^{\pi \cdot 4}$ and choose a next lime $t^{n+1}$ and choose zones to be advanced to that I ime. DENEa already has the timesteps $\Delta t$, for zones which were not calculated al $t$ ime $t^{n}$. and il has $\Delta t_{v}$, and $\Delta t_{t}$, for zones which were computed at $t$ ime $t^{n}$. For these last zones, sel $\Delta t,=\min i \Delta t_{v}, \Delta t_{r}$, , insuring the first and second conditions of Eqn. (2,4). Now the third, fourth, and Iifth condilions of Eqn. (2.4) may be imposed at all zones. This requires passing through the mesh once in each directioll. Having done this much. it is $t$ ime 10 choose a next 1 ime. $1^{n+1}$. For each zone there is a time t, when that zone was last calculated: $t$, can be as recent as $t^{n}$. The 
least (which is to say. the earliest) of the times $t,+\Delta t$, will be the new lime $t^{n+1}$, and the problem timestep (as dislinguished from any one zollal limestep) may be found (rom $\Delta t=f^{n+t}-f^{n}$. Clearly only olse zone absolutely must be calculated as early as time $t^{n+1}$. But it several zones fall due at nearly the same lime, it would be unreasonable to updule only one of them. because then the following limestep would have 10 be much smaller 1 . an the present olve. The code therefore calculates at cycle $n+f$ all the zones for which

$$
1,+\Delta t,-t^{n}+2 \Delta t^{n} \text {. }
$$

Fig. (2.8) illustrales this siluation.

Frequently. the nelghboring zones $j-f, j, j+f$ were all last calculated at the same $t$ ime, $t^{m}$, for some $m \times n$, and they all fall due at time $1^{n+t}$. In this case the straightforward difference equalions. Eqns. (2.1). may be used, but with the timestep here given by $\Delta t=t^{n+1}-1 \cdot$

Less often. zones $j$ and $j-f$, say, were last calculated al different times. $1, \neq 1, \ldots$ and the situation of Fig. $(2, \theta)$ occurs. Here the numbers $x_{j,}, P_{2}$, are al! relerenced 10 time $t_{,-1}$ : the quantities $x_{j}, \ldots x_{j}, P_{j}$ are al $t$ ime $l$, . The code must step the $j^{\text {th }}$ zone interface. (the quanlities $x_{j}, u$, ) from time $l_{j}$ to time $t^{n+l}$. But in oider 10 do this. The first of Eqns. (2.1) requires a pressure gradieni constructed from two pressures both referenced to Iime $t$,. This is not immedialely possible. since the pressure $P_{,-1}$ is at time $t_{j-}$, it is necessary 10 extrapolate the pressure in zone $j$-t forward to time $t$, before the difference Eqns. (2.1) may be solved at zone, to move $x$, and $u$, from time 1 , to time $1^{n-1}$. 


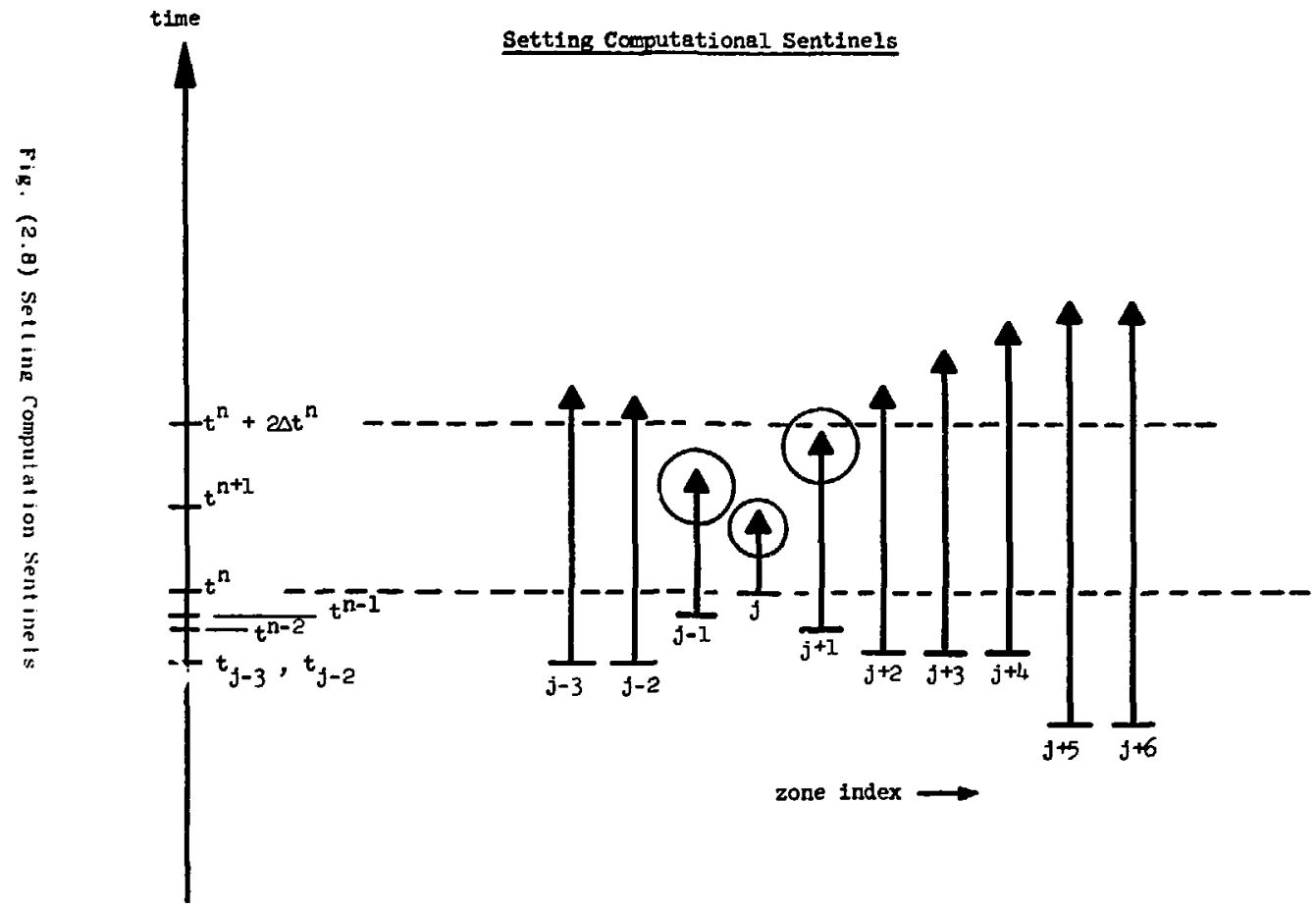


Figs. (2.9-2.10) illustrate the typical situation in the computation. The arrays $x_{j}$ and $u_{j}$ are zone-edged quantities and are not isochronsus. For instance, in Fig. (2,10), the numbers $x_{2}$ and $x_{3}$ are at different $t$ imes, as are the pressures $P_{1}$ and $P_{2}$. The zone centered quanlities. including the zone times $l_{j}$, are typified by the pressures in Fig. $(2 \cdot 10)$.

In this siluation, positions $x_{7}, x_{A}$ and pressures $P_{G}, P_{7}, P_{\theta}$ can be advanced to time $t^{n+1}$ in the normal way. Zone 2 , however, is more complex. Nonetheless, only a pressure $P_{2}^{0}$ is required al $t$ ime $t, 10$ advance $x_{2}$ and $u_{2}$ to time $t^{n+1}$. The position and velocity $x_{3}$ and $u_{3}$ may be advanced directly from time $t^{n-7}$.

The new $x_{2}^{n+1}, x_{3}^{n+1}$ and the mass $m_{2}$ yield a new specific volume $v_{2}^{n+1}$, and the change $v_{2}^{n+1}-I_{2}^{n-2}$, logether with the pressure $P_{2}^{n+1}$, yield - new energy $E_{2}^{n+1}$. The new artificial viscosity, $Q_{2}^{n+1}$, is obtained from $u_{2}^{n+1}$ and $u_{3}^{n+1}$. Thus, only the lotal pressure (which includes the artilicial viscosity) nead be extrapolated at time $t_{t}=t^{n-3}$. This extrapolation can be accomplished as lollows: if one keeps at each zone center a quanlity

$$
P_{t}=\frac{\partial}{\partial t}-\left(p_{i}+Q_{j}\right)=\frac{p_{j}^{m_{j}}+Q_{j}^{m}-p_{j}^{k}-Q_{j}^{k}}{t_{j}^{*}-t_{j}^{k}}
$$

where $1^{m} . t^{k}$ are the last two times zone $j$ was updaled. Then the extrapolated tolal pressure $P_{2}^{*}$ may be obtained in the example of Fig. (2.10) Irom the equation

$$
P_{2}^{*}=P_{2}+P_{1}\left(t_{1}-t_{2}\right)
$$




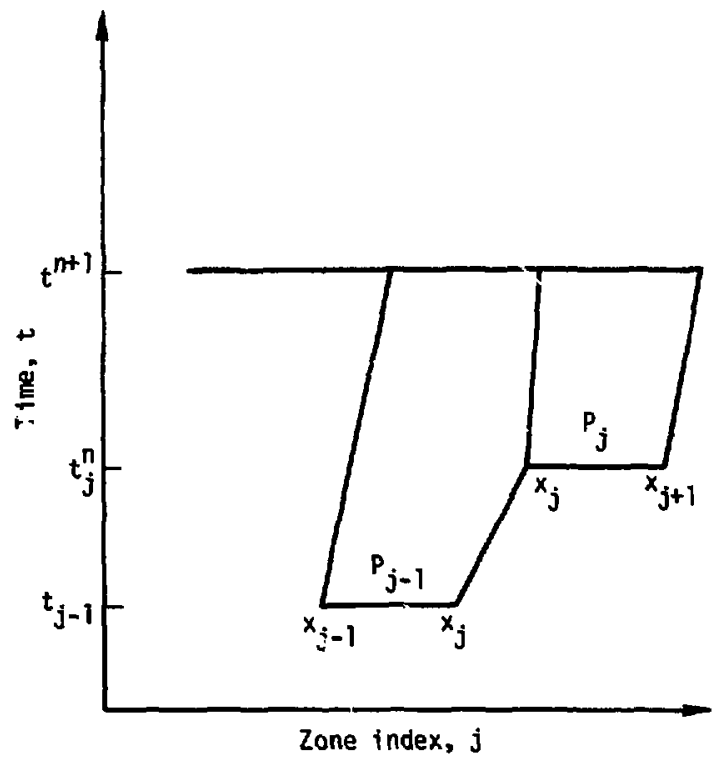

Fig. (2.9) Adjacent Zones with Different Timesteps 


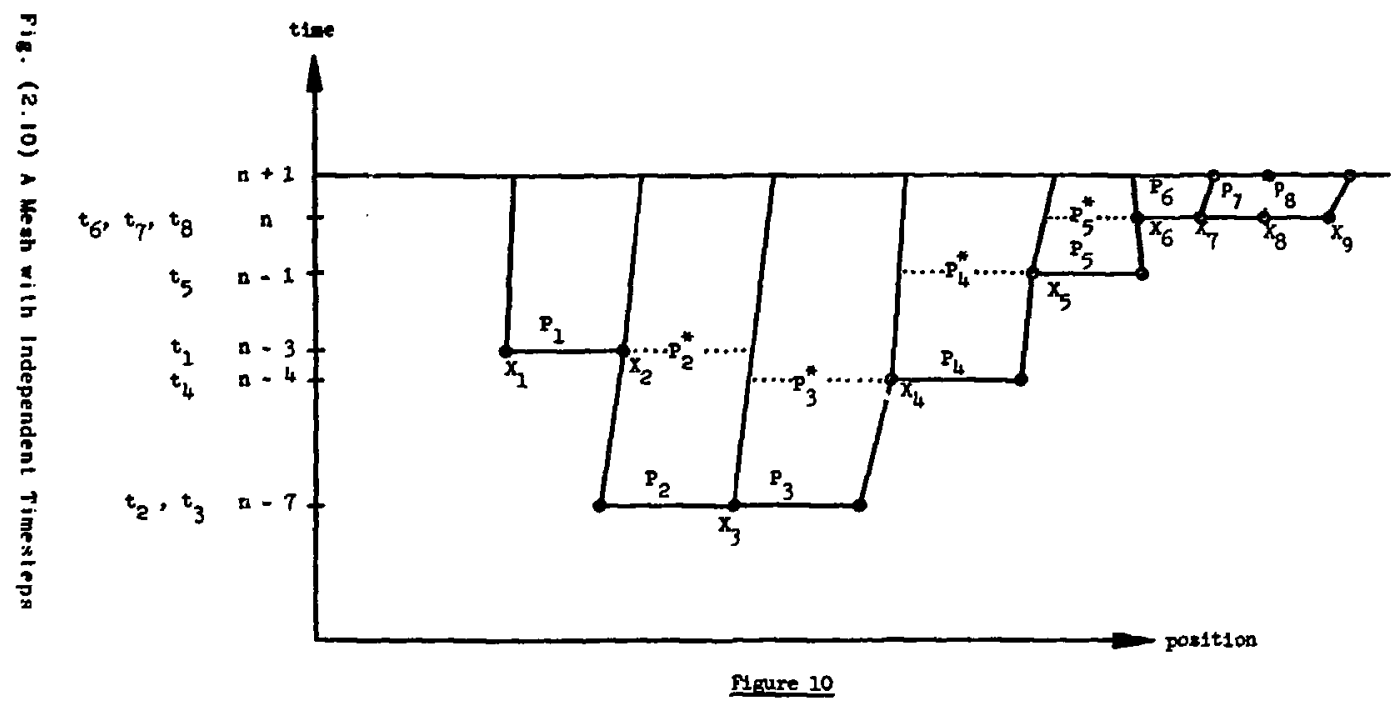

Zone $I$ through 9 are to be updated to the $t^{n+1}$. Flgure 10 showl how the arraye $p_{j}, x_{j}$ and $t_{j}$ are arranged in the woblem bistory and in the computer menory just befcre the update to $t^{n+l}$. 
In this manner the calculation may proced and abtain results differing not noliceably Irom those of " synchronous van Neumann - Richtmyer calculatioll, as the remurks of the next section will show.

\section{iest Problems}

Severa) early test problems were run, comparing DENEB (with individual timesteps for each zone), with RIGEL (taking a common timestep for the whole problem). In the case of a rarefaction of a perfect gas into a vacuum, the limesteps do not differ enough from one zone to the next for DENEB ever to gain any advantage, and DENEB runs more slowly. Both DENEB and RIGEL obtain the same results at all times to within about one percent.

Shock compression of a perfect gas engenders widely different timesteps, as noled earlier in this chapter, and here the difference in computation time is often considerable. Figs. (2.2) through (2.6) illusirate the zonal timesteps at various stages in a typical problem history. Fig. (2.11) diagrams the shock test problem. Two regions at an initial pressure of $10 \mathrm{ergs} / \mathrm{cm}^{3}$ comprise the initial conditions. Region I has a density of $4 \mathrm{~g} / \mathrm{cm}^{3}$. region 1 has a density of $1 \mathrm{~g} / \mathrm{cm}^{3}$. Regions $I$ and $I I$ have gas 1 aw gammas of $5 / 3$ and $7 / 5$, respeclively. Each region is of mass $50 \mathrm{~g}$ and comprises 40 zones. One outer boundary. Ihat of region 1. Is fixed in position for all lime. The other is Iree, bul has a pressure of $10^{6} \mathrm{ergs} / \mathrm{cm}^{3}$ placed on 11 . diving a shock into the problem. 
ohock

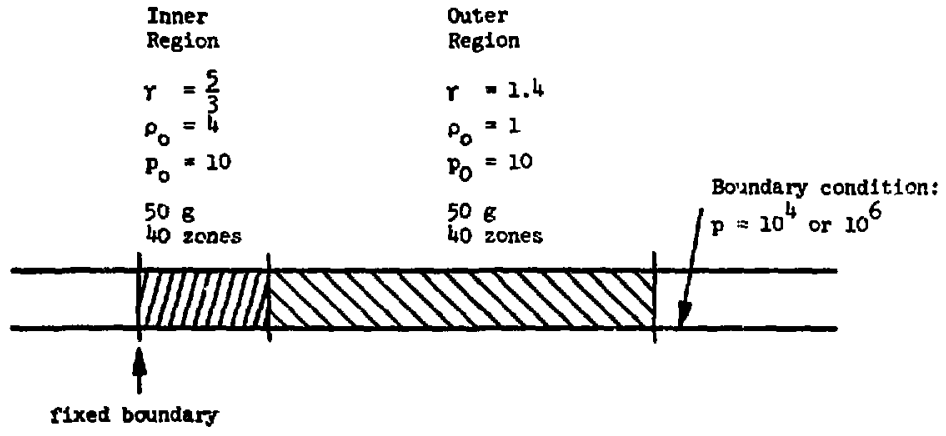

\section{A Test Problem}

Fig. (2.11) a Test Problem 
The shock is partially reflected and partially transmitted at the material interface. the reflected shock being ainplified by a factor at 2.I. The prablem has an andlulic solutions. The analy'ic solution. DENEB, and RICEL all agree 10 within aboul one percent. Tables (2.1-2.2) presest the conparalive resulls for Iwo problems, One is the problem just described. The other is identical excepl that the boundery pressure is $10^{4} \mathrm{ergs} / \mathrm{cm}^{3}$ anstend of $10^{\circ} \mathrm{ergs} / \mathrm{cm}^{3}$. The row headings are:

t inttial shork strength in region 2

t, trungmitled shock strength in region 1

$t_{2}$ reflected shock strength in region 2

$\eta \quad$ Initial compression ir, region 2

$\eta_{1} \quad$ transmitled compression

$n_{2}$ reflected compression

u Initial shock speed

$u_{1}$ transmilled shock speed.

The quantities from the codes DENEB ang RIGEL have an error associated with them. since there is some varialion in the pressure and density behind a shock: where this error is known. it is quoted with the results Irom these codes. The analytic results are usuelly presented to greater precision than that of the computational results of DENEB and RicEL.

R. Lelevier (1954) see pp. 25-27; LeLevier I reats the case of strong shocks in a problem with zero initial pressure. Actlally 11 is possible to treat shocks of any strenglh in a problem with finite initial pressure. For given initial conditions and ineident shock strenglh an implicil equation in the rellected shock streligth may be solved numerically. From the rellected shock sirengith all other quantities may be obtained explicitly. 
Table (2.1)

$\epsilon$

$E_{2}$

1

$\eta$

$\eta_{2}$

$n_{1}$

$u$

$u_{1}$

$\varepsilon$

$\begin{array}{ll} & \text { Analytic } \\ t_{2} & 2.1345 \\ \epsilon_{1} & 2.134: \times 10^{3} \\ \eta & 5.96 \\ \eta_{2} & 1.697 \\ \eta_{1} & 4 . \\ u_{1} & 109.5 \\ u_{1} & 84.3\end{array}$

Table (2,2)

\section{Analytic}

$2.134 \div \times 10^{3}$

86

4.

84.3
Analytic

2. 139

2. $139 \times 10^{5}$

5. 999

1.6997

4.00

1095.

844.
RIGEL

$2.14 \pm .02$

$2.13 \pm .04 \times 10^{5}$

6. \pm .1

I. 71

4.02

1110 .

850 .

Shork strength $=10^{3}$

\section{DENEB}

$2.14 \div .03$

$2.14 \pm .04 \times 10^{3}$

$6.0 \pm .1$

1. 705

4.04

110.

84. 


\section{CHAPTER III}

THE GENERAL METHOD OF INDEPENOENT TIMESTEPS

\section{On Nolation}

In a problem with a conmon timestep. notation regarding time and limestep is relatively simple: $t$ and $\Delta t$ will sulfice -- more

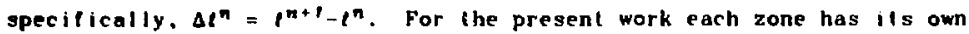
timestep $\Delta t:$ the actual time stepped by that zone may be briefer than $\Delta t j$. Let $t^{n}$. $t^{n+t}$. etc.. written without a sibscript $j$ refer to whole problem $t$ imes. When the computation has reached $t=l^{n}$ at some cycle number $n$, some zone has been advanced to $t$ ime $t^{n}$, and no zone has yet been advanced beyond $t$ ime $t^{n}$. Contemplating the advance of some zones to time $t^{n+1}$ we Iind that at this cycle (number $n$ ) these zones are referred to times $t$, not all equal to $t^{n}$. but to various $t_{\text {imes }} t^{n}$ with $0<m \leq n$. Nevertheless, it is convenient to label these several times $t^{n}$. The set of $t$ imes $t^{n}$ specifies the Cauchy surface at computation cycle $n$. All this may be illustrated in Fig. (3.1). It may be noted that $t_{j}^{n} \times i_{-}^{n}$, Although the set of times $t_{j}^{n}$ define the Cauchy surface at cycle $n$. The set of times $t^{n-1}$ do not define the prior raurhy surface 
at cycle n-t. The time $t_{j}^{n-1}$ is meant to reter simply to that time $t_{j}$ at which zone $j$ was last updaled prior to rycle $n+1$, regardless of what cycle that update occured at. The time $i^{n-1}$ may have fallen one or sevelat or hundreds of cycles befare cycle $n$. In the same way time $t^{n-2}$ is defined simply as Iwo updates beforp time in, In somewhat different words. The times $l_{j}^{n}$ are labeled at compulalion cycle $n$, and the limes 1,-i. 1, ;-2. etr.. are labeled in sequence barkwards by updates at zone $j-1$, not by cycles $n-1, n-2$, elc.

With this in mind. the timestips may be labeled. At is the time $\ell^{n+1}-l_{j}^{n}$, and so is different for different zones. In some places $\Delta \ell_{j}^{n}$ will refer 10 the step actually laken; in others, nolably in parts of the following section. to the maximum time allowed for that step. Where

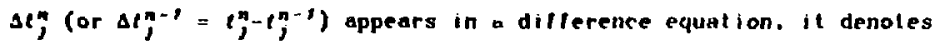
the step actualty taken. In considerations of what the limestep should actua!ly be. it denotes merely the bound al zone $j$ on that timestep.

\section{The Hethod}

Having provided in Chapter 11 an example of independent timesteps in the context of von Neumann hydrodynamics. it is time to indicate in a somewhat more general way how to implement independent timesteps in any difference scheme. For. if the method is applicable to just one or two difference schemes, it is only of theorelical curiosity value no matter how greal its practicul significance for its few applications. Its theoretical significance lies in its molivation (to instruct the machine how to approach its work along the lines of the humen calculator, i.e., 


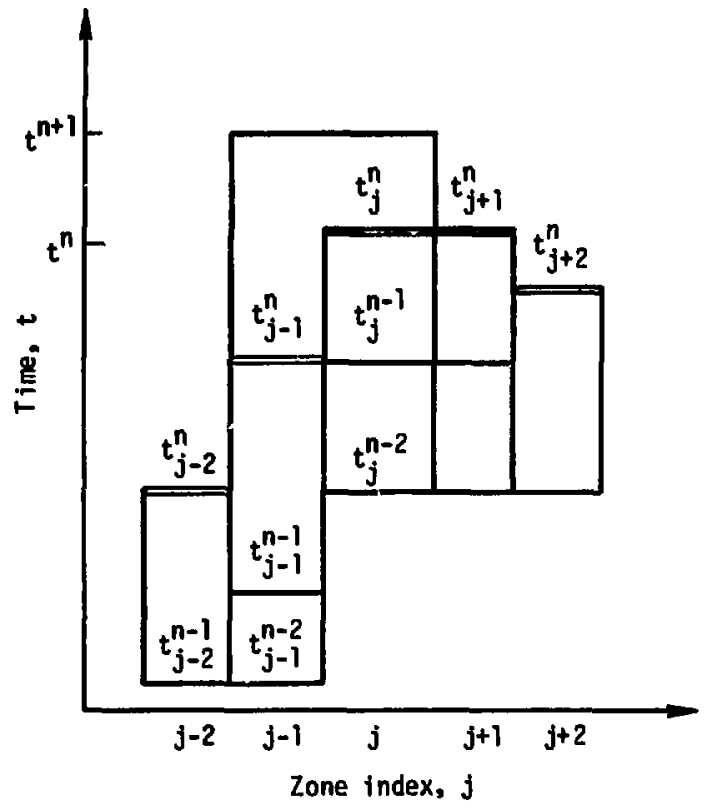

Fig. (3.1) Nomenclalule of Times and Timesteps 
lo allorate computational effort where it is needed instead of indiseriminately) and in ils broad applicability.

One is interested in predicting the time evolution of some physical quantily which we may designate as $u$. This is usually a vector quantity - not just lemperature, but an ensemble of quantilies: lemperalure. pressure, velocity, density, composition, energy, etc. The itinite difference equation can be concelved in the form

$$
u_{j}^{n+1}=F\left(u_{j}\left(t^{n}\right), u_{j+1}\left(t^{n}\right), u_{j},\left(\ell^{n}\right), t^{n+t} \cdot l^{n} \ldots e t c .\right)
$$

Here we have indicated the neighbors only in one dimension, $u_{j-}$, and $u_{j+1}$. But for our purposes, two and three dimensions are not qualitatively different. The function $F$ may be any procedure for generaling $u_{j}^{n+1}$ trom the given arguments, but note that it is an explicit operalion: $u_{j}^{n+1}$ does not depend on $u_{j+l}^{n+l}$ or $u_{j-1}^{n+1}$, the values of $u$ in the neighboring zones at the end of the timestep.

The arguments are all contemporaneous: all are evaluated at lime $t^{n}$. To implement independent timesteps, the quantities $u_{j}$ may have been evaluated at various times $t_{j}$. But the function $f$ still requires contemporaneous arguments, so we can rewrite Eqn. (3.1) for independent timesteps as tollows:

$$
u_{j}^{n+t}=f\left(u_{j}^{n}\left(t_{j}^{n}\right) \cdot u_{j+1}\left(t_{j}^{n}\right) \cdot u_{j-j}\left(t_{j}^{n}\right) \cdot t^{n+1} \cdot t_{j}^{n} \ldots . e t c \cdot\right)
$$

Note that now the neighboring quantities $u_{j+1}$ and $u_{j-1}$ must be Ireated differently from $u_{j}$. They may not have been evalualed at $t$ ime $t_{j} \pi$ when zone $j$ was last updated, but for the present update of zone $j$. 
the neighboring quantities are required at time $t_{j}^{n}: u_{j+1}\left(t_{j}^{n}\right), u_{j-}\left(t_{j}^{n}\right)$. These quantities are generated from the old values at the zones $j+f$ and g- $f$ and the ir time derivalives:

$$
u_{j+1}\left(t_{j}^{n}\right)=u_{j+1}\left(t_{j+1}^{n}\right)+\left(u_{1}\right)_{j+1}^{n}\left(t_{j}^{n}-t_{j+1}^{n}\right)
$$

The lime derivalives $u_{f}$. may be approximaled in whatever manner is conventent, and, as noted above. memory space must be reserved for the we quantilies.

Having indicated the lorm of the finite differencing. it remains to comment on the selection of timesteps $\Delta t$, and the decision when to update zone in order that the calculation may proceed stably and expeditiously. As in any complicated physical situation, there are various proceses occuring at different rates, and characleristic times associated with each. There are often (usually) stability condition(s) on the limestep arising from the difference equations. So, just as in a conventional situation, one is faced with the choice of the briefest of several candidate limesteps:

$$
\Delta t=\min \left(\Delta t_{1 j}, \Delta t_{2 j}, \Delta t_{3 j}, \ldots\right)
$$

The quantities $\Delta t_{1}, \Delta t_{2}$, etc., arise trom different processes, accuracy considerations. stability canditions, exactly as one would determine them without using independent timesteps. The timestep $\Delta t$, need be evaluated only as often as its arguments change. and this means in practise only as orten as zone $j$ is updated. It happens that for explicit difference equations, stability is usually not offected by the presence of independent timesteps. (To my knowledge. there is no 
rolltrary exnmple, but as murh cannol be said for independent timesteps in implicil equations. A matcer to be mentioned al greater length below.) Stabilily will be proven quile rigorously in Chopter Vl for the common diffusion and hydrodynamir difference equations with independent limesteps. It is a matter of some significance that independent limesteps should not affect the stabilily conditions for the common explicil difference equations so lar encountered. However, there is not any readily evident simple proot that this is true in general: so each difference equation, or clase of equations. mus! be considered on its own merils.

There is an additional condilion on limesteps which are independent. Il arises not so much to essure stabilily as to insure that the problem remain well posed. Successive limesteps in one zone are constrained to increase if at all by no more than a lactor of two. and neighboring timesteps to difter by no more than a factor of two. The number "2" was chosen orbitrarily at first, as a guess at the limils beyond which one might not rreasonably stray. These conditions may occasionally be relaxed. but for the moment they may be stated thus:

$$
\Delta t=\min \left(\Delta t_{j}^{n} \cdot 2 \Delta t_{j}^{n-1}\right)
$$

$$
\Delta t=\min \left(\Delta t_{j}^{n} \cdot 2 \Delta t_{j+1}^{n} \cdot 2 \Delta l_{j-1}^{n}\right)
$$

The reason for the restriction of Eqn. (3.5) on successive timesteps is that extrapolated valses of $u_{j}$ will be required, and it is risky to extrapolate for a time nuch greater than the interval over which $\left(u_{t}\right)_{j}^{n}$ was itself approximated. Relaxing the restraint of Eqn. 
(3.5) in fact led to trouble of precisely the nature indicaled. This restriclion will be $u$. as a premise in the stability arguments in Chapter VI. so it may not be relaxed casually.

The motivation for Equ. (3.6), the restriction on neighboring limesteps, is a little different and less quantitative. If, for instance, some zone $j$ is updaled many limes while zone $j+1$ is updated nol al all. then the two zones may lose conlarl with cach other. A natural apprehension suggests itselt , hat the original long estimute for at,.., was nal realistic: oubsequent events in zone, have rendered it quite dated and even quite dangerous. The imagined situalion may be diagrammed as in Fig. (3.2). Both zones, suppose, were computed at lime $t^{0}$ and both $t$ umesteps were set then also. Zone $f+t$ will not fall due until $t^{\circ}$, bu' zolve $j$ will need to be updated al $t$ ime $t^{2}$. As events transpire, let us say zone; requires updaling fove limes before zone $j+l$ receives any attention. One cannot really bet leve that all that activity in zone $j$ can leave zone $j+t$ unaffected. So it is reasonable to require that zone $j+t$ Iall due at least at $t$ mes $t^{4}$ and $t^{6}$. or. equivalently. to put the restriction as in Eqn. (3.6). Once again. this restriction grew out of experience: for relaxing Eqn. (3.6) completely soon leads to griel. The value of "2" for the rallo of adjacent timesteps is not critical, but a ratio of approximalely this value must be used. The experience leading 10 Eqn. (3.6) and its sale relaxalion will be discussed at the end of this chapter. In fact however. the restriction as stated here (Eqn. (3.6)) is economically the most useful and (for programing purposes) the simplest form. 


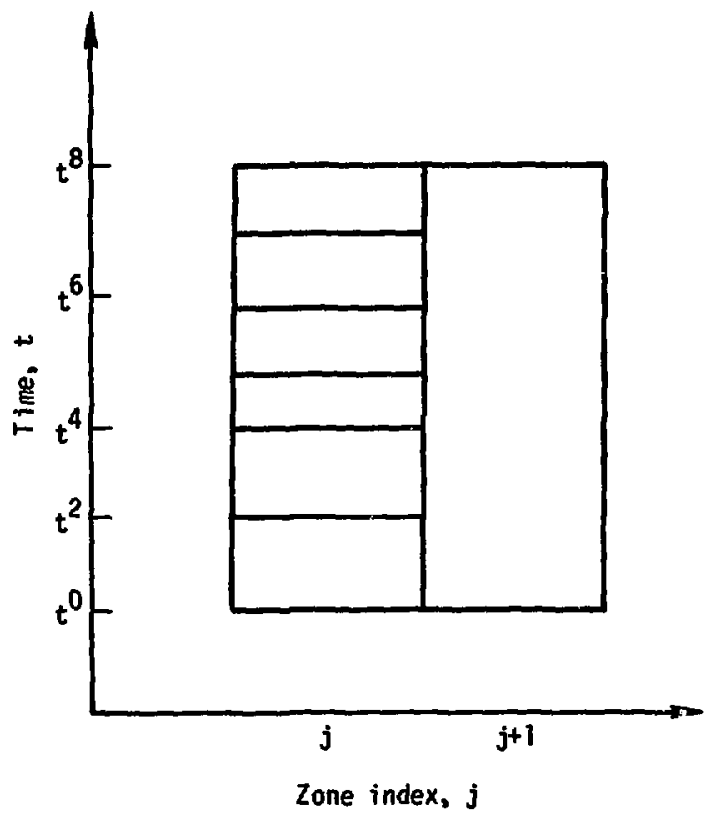

Fig. (3.2) Disparale Neighboring Timesleps 
All that now remains to complete the general specification of calculations with independent timesteps is the rule for selecting zones due for updating. The remarks in Chapter II ar quite general and nol at ull restricted lo hydrodynamics. As war liustrated in Fig. (2.8). we require the tipdating of those zones for which

$$
t^{n}+\Delta t^{n}, t^{n+1}+2 \Delta t^{n}
$$

The reasons for the stringent condilion of Equ. (3.7) Instead of say.

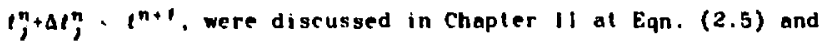
illustrated in Fig. (2.8)

\section{Examples in One Dimension}

The principal example in one dimension. and the only one to be examined in great detail. is that of Chapter II, one dimensional von Neumann hydrodynamics. The experience here summarized is included for several reasons. $1 \mathrm{t}$ is pertineit to indicate the range over which independent timesteps have been tested, and also lo note places where special considerations were (or were nel) necessary.

The bulk of the experience to date has been III ot dimensional calculations. coupled hydrodynamics and one or several, frusion processes. The method of dufort and Frankel was examined and deserves some comment simply because the standard manuals alt note it in passing with only only the briefest indication of its special char ter. A considerable effort was expended atlempting to implement independent 
limesteps in an implicit difference scheme for the diffusion equation. and not wilhout some sucress: but the results were such as to render it Impractical except as a curiosity. And Iastly is mentioned two dimensional explicst heat diffusioll, explored both to prove that, as expected, nothing essentially new is encounttered here, and 10 get some Idea of the compulational economics of independent limesteps in two dimensions.

To deal first with one dimesisional problems, the hydrodynamies of Chapter If is simpler than common praclical problems in several respecls. Il assumes plane geometry. and calculatiolls are often carried out in cylindrical (and. lor astrophysical problems in spherical) geometry. Usually ull three geometries are coded together, and selling an index to a value of 1,2 . or 3 is all that is nepded to select the desired geometry. The implicalions for independent limesteps are marginal. The tirst equalion of Egn:(2.1) is changed. as is the third: the lorce equation becomes

$$
\frac{u_{j}^{n+1}-u_{j}^{n}}{\Delta t^{n}}=2 \frac{P_{j-1}^{n}-P_{j}^{n}}{m_{j}+m_{j}-t}\left(x_{j}\right) \cdot-1
$$

and the specific volume

$$
v_{j}^{m+1}=\frac{\left(x_{j+1}^{n+1}\right)^{\prime}-\left(x_{j}^{n+1}\right)^{\prime}}{(m,)^{\prime}}
$$

where $i=1,2$, or 3 , depending on the geometry. Neither of these changes affects the use of independent timesteps. The situation here is typical of cifference equations for diffusion as well, which can be 
constructed straightlorwardiv in any geonetry in the presence of independent I imesleps.

When hydrodynamics is coupled to ditfusion. The difference equations may be written as a modilication of Eqn. (2.1). here in plase geomelry. Where in Equ. (2.1) pressure was considered a function of eneray and apecific volume. here temperature alno wifl be trealed this why. Enerey is differenced by analogy to the enersy equation of Eqn. (2.1) and lemperature is looked up in equation of state tables. One could easily do it the other way, differencing the temperature and ireating the energy by menns of an equation of state as a function of temperature and specific volume. A new quantity. the energy flux, is defined by an equation of the form of Eqn. (3.17): Its gradient appears in the energy equation eqn. (3.20). When a zone falls due for compulations. some of the equations (3.10-3.21) are done at zone $j$, and some bolh al zones $j$ and $j+t$. The zone centered quantitiss, volume. pressure, energy, temperalure, are updated only at zone $j$. The zone edged quantities, position. velocity, flux, are updated at zone edges $j$ and $j+1$ : at both edges of zone $j$. So 11 should be noted that a zone edged quantily (e.g. $x_{j}^{n}$ ) is not necessarily contemporaneous with its companion zone centered quantities $\left(e . g . E_{j}^{n}\right)$. The zone edped quantities are contemporaneous with the more recently updated of the zone centered quantities at zones $j$ and $j-1$. One may $I$ ist the difference equations:

$$
\Delta t_{j}^{n}-t^{n+1+t^{n}}
$$




$$
\begin{aligned}
& u_{j}^{n+1}=u_{j}^{n}+2 \Delta t_{j}^{n}\left(\frac{P_{j-1}\left(t_{j}^{n}\right)-P_{j}^{n}}{m_{j}+m_{j-1}}\right) \\
& x_{j}^{n+1}=x_{j}^{n}+u_{j}^{n+p_{\Delta l}^{n}} \\
& v_{j}^{n+1}=\frac{x_{j+i_{j}-x_{j}^{n+1}}^{n}}{m_{j}}
\end{aligned}
$$

$$
\begin{aligned}
& \text { if } u_{j+1}^{n+1}-u_{j}^{n+1} \text {, } 0 \text {. then } \\
& q_{j}^{n+1}=2\left(u_{j+1}^{n+1}-u_{j}^{n+1}\right)^{2} / v_{j}^{n+1}
\end{aligned}
$$

eise.

$$
Q_{j}^{n+1}=0
$$

$$
\begin{aligned}
& P_{j}=P_{2}+Q_{j}^{n+P} \\
& E_{j}^{n+1}=E_{j}^{n}-P_{j}\left(V_{j}^{n+1}-V_{j}^{n}\right)+\Delta t_{j}^{n} C_{j}^{n} \\
& p_{j}^{n+1}=p\left(V_{j}^{n+1} \cdot E_{j}^{n+1}\right) \\
& T_{j}^{m+1}=r\left(m_{j}^{m+1} \cdot E_{j}^{n+1}\right) \\
& \theta_{j}^{n+1}=\varphi\left(\left(T_{j}^{n+1}-m_{j-1}^{n+1}\right)>\left(x_{j+1}^{n+1}-x_{j-p}^{n+1}\right)\right) \\
& \sigma_{j}^{n+1}=\left(\omega_{j}^{n} ; ;-\phi_{j}^{n+1}\right) / m_{j}
\end{aligned}
$$

So. when zone $j$ falls due. Eqns. (3,10,13-19,21) are soived at the center of zone $j$, and Eqns. $(3,11,12,20)$ are solved at zone edges $j$ and $j-1$. In Eqn. (3.21) the difference of energy fluxes across zone $j$ is saved os the quantity $C_{j}^{n+1}$. Eqns. $(3,11,20)$ require zone centered quant it ies trom neighboring zones, pressures $P_{1}, P_{1}$, and temperatures $T_{j-1}$ and $r_{j+1}$. These are required at time $t_{j}^{n}$ although they may have been computed at some other time. Therefore, they are extrapolated to 
that time $t^{n}$, and tor this purpose one must save both of their time derivalives. This fairly convent ional set of coupled equations can be differenced quile straightforwardly with independent limesteps.

Il is somelimes convenient to require one's difference equations explicilly to observe some conservation law. for example, conservaiion of energy. Il is fair to note that this, 100, can be done in the presence of independent timesteps. The approach is to construct the difference equntions in a way that takes exactly us much energy out of one zone as is passed to the neighboring zone. If all zones are updated synchronously in lockilep, this is of course very eas?. It they are updaled asynchronously. It is not 100 much more intricate. For. suppose that zones, and $j+t$ are contemporaneous at some $t, j$ and that a litte later zone $j$ lalls due belore zone $j+f$, and is updated accordingly. Then there is some energy transferred into zane $j$ but not yet taken out ol zone $j+f$. This lloating energy balance may be simply saved zone by zone. logether with a sentinel which indicates at ench zone edge for which of the two zones there bounded the 1100 is being sayed.

The work of dufort and Frankel' deserves some discussion whel economies of computalion are sought. They constructed and published in 1953 (early in the modern history of Inice differences) a difference approximation for the diffusion equalior which is ciuile remarkable. II is explicit and unconditionally slable and can even be generalized to Iwo or three dimensions withoul displaying any essentially new behavior. It is mentioned in all the standard differefiee manuls ${ }^{2}$ for 1 ts peculiar stability and convergence properties. This $k$ ind of equation may be 2 dufort \& Frankel (1953). 11.

\footnotetext{
Richtmyer \& Morton (1967). P. 176: or innenko (1971), p.
} 
quoted in several forms having slightly different accuracy. but essentially the same character:

$$
\begin{aligned}
& \frac{u_{j}^{n+1}-u_{j}^{n-1}}{2 \Delta t}=A\left(u_{j+1}^{n},-u_{j}^{n+1}-u_{j}^{n-t}+u_{j}^{n}-t\right) \\
& \frac{u_{j}^{n+t_{-}-u_{j}^{n}}}{\Delta t}=A\left(u_{j}^{n}, \ldots-u_{j}^{n+1}-u_{j}^{n-t}+u_{j}^{n}-t\right)
\end{aligned}
$$

For present, urposes it is enough to observe that meither presents anything ew 10 independent timesleps. The lemperatures $u_{j+1}$ and $u_{,}, 1$ must be supplied at time $\ell_{\text {; }}$ by the usual independent timesteps formula, Eqn. (3.3): then the calculation may proceed normally.

\section{Dillusion in Two Dimensions.}

Diffusion in two dimensions is worth some altention both because it is essentially similar to the one dimensional case and because it pays greatly to code narelully Eqn. (3.6), which restricts neighboring zonis to have Iimesteps differing by no more than a factor of two. This aspect of the coding will serve to illustrate the sort of considerations one encounters in managing the logic of asynchronous calculations.

The equation to be solved is:

$$
\begin{gathered}
\partial u \\
-\partial \partial u \\
\partial t \\
\frac{\partial x \partial x}{\partial x}+\frac{\partial \partial u}{\partial y \partial y}
\end{gathered}
$$


and its common explucit backward differenced finite representation is

$$
\begin{aligned}
& \frac{u_{k, j}^{n+1}-u_{k}^{n}, j}{\Delta t}=\left\{c_{k, j}\left(u_{k, j+1}^{n}-u_{k, j}^{n}\right)+c_{k, j, j}\left(u_{k, j-1}^{n},-u_{k, j}^{n}\right)\right. \\
& \left.+k_{k, 1}\left(u_{k+1,1}^{n}-u_{k, j}^{n}\right)+k_{k-1,},\left(u_{k-1,}^{n}, u_{k, j}^{n}\right)\right\}
\end{aligned}
$$

A word of explanation is in order, for the simitarity of Eqn. (2.25) to (3.24) may appear strained. The 0 in Eqn. (3.24), the heat conductivity, may be a function of lemperafure. It appeass in Eqn. (3.25) as factor in the coefficients $G_{k}$, and $k_{k,}$, which also include the difference approximations $\Delta x$ to the denominators of the space derivatives in Eqn. (3.24) The tirst two terms on the right of Eqn. (3.25) approximate the derivatives, and the last two terms approximate the $y$ derivatives. Out of those derivatives have been factored the numerators, the temperature differences. All other factors have been collected in the coefficients $C$ and $K$. It is the temperatures at the neigtiboring zone centers that may be asynchronous to the temperature $u_{k, j}^{n}$ in the zone being updated currently. The indexing conventions may be seen in Fig. (3.3) The zone centered quantities are referred to the paint $Q$ in this tigure: the point quantilies to the zone's upper right corner. The conduclivjties are zone edged quantities and stand belween zones as shown in Fig. (3.4)

For reasons of economy. the common method of approximating Eqn. (3.24) is nol with Eqn. (3.25) but with all alternating-directions-implicat technique (AOI), and as this is well known ${ }^{3}$. it need not be described again here. Thus, the explisit 
68

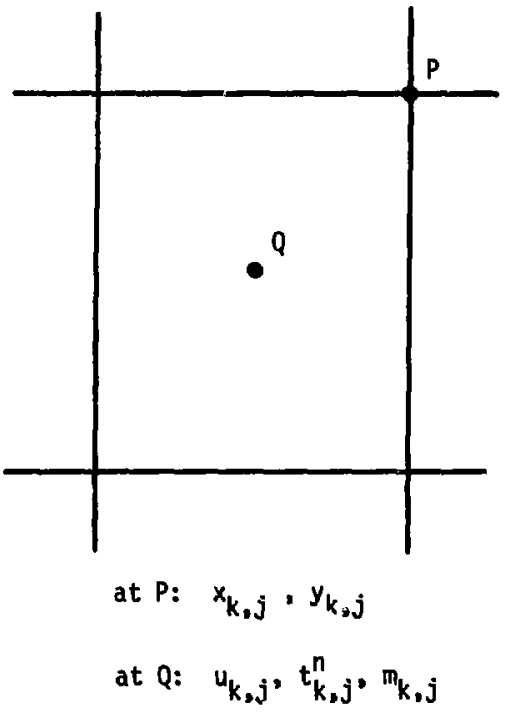

Fig. (3.3) lidexiul: conventions 


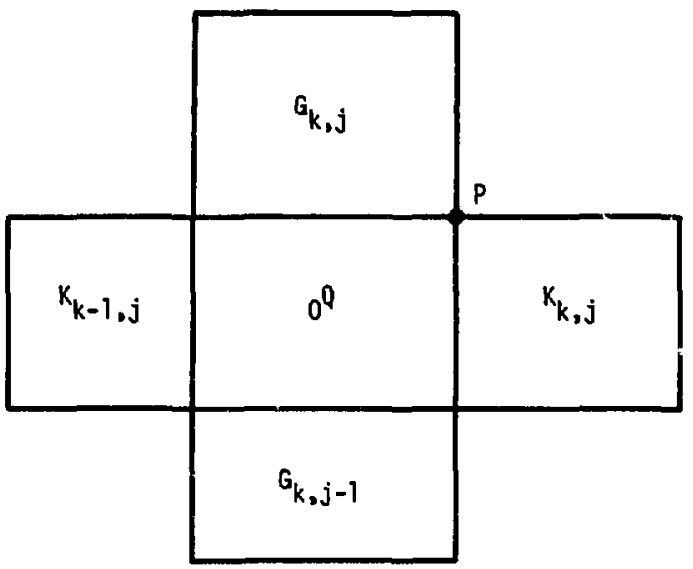

$G_{k, j}$ stands between zones $k, j$ and $k, j+1$

$k_{k, j}$ stands between zero $k, j$ and $k+1, j$

Fig. (3.4) Conductivily Coefficients 
difference equation with independent timesteps must compete not with conventional explicit but with AD1 equations. To indicate what must be done to implement independent (imesteps in Eqn. (3.25), the neighboling temperatures must, of course, be brought by extrapolation to a time contemporaneous with $u_{k, j}^{n}$. And the timestep $\Delta t$ must be replaced by the quantitiy $\left(t^{n+t}+t_{t}^{n}\right)$. This much corresponds quite ctosely lo Eqns. $(3.2-3.3)$

Eqns, (3.4-3,7) are the same in nny nsynchronous calculation, but their coding can yield greal dividends if it is done with care. Eqn. (3.7) must be inspected for every zone every cycle, as it selects those zones due for computation on the next cycle. Eqns. (3.4-3.5) need only be solved as often as the zone at $k, j$ is itself updaled, not very of en on the duerage. The condition in Eqn. $(3,6)$. which requires neighboring limesteps not to be too disparale. can be handied several ways. One could at every cycle readjust all the timesteps $\Delta_{t}$, or, one could let matlers in zone $k, j$ rioe unatlended until one of its four neighbors" limesteps is reset, and them enforce condition $(3,6)$ at zone $k, j$. Now if on some cycle the new minimum timestep appears at zone $k 1, j t$, is necessary to apply Eqn. (3.6) at its four neighbors. And for each of these. only it their timestep is reduced by Eqn. (3.6) does one continue the enforcement of Eqn. (3.6). This specification is recursive if it is extended to cover the whole mesh starting from each zone, but experience shows that it may be terminated after dealing with the adjacent neighbors. The reason for indicatiug the method of coding Eqn. (3.6) is that if done this way. It is encountered only a little more often thun zones are updated, whereas thaively coded it can be execuled for every 
every zone at every cycle, and ihis can have a suanificant eftect on runuing $t$ imes.

The conventional explicit, explicil with independent limesteps, and ADI melhods may be compared (here for their accuracy; in Chapter VII for their running (imes) in their solution of similar problems. A useful test problem lor any scheme is an initial temperature distribution of the form $u=\cos (x) \operatorname{cas}(y)$. wh the temperiture held at $u=0$ on the (square) boundaries. It has a known solution. but suffers from the disadvantage that the characteristic timesteps are identical always and everywhere. so the independent limesteps coding solves the problem in exactly the same way as the conventional explicit version, without, in fact, ever doing any asynchronous calculations at all. Another problem. in which corner zone is held al a fixed high temperature of $10^{60}$ and all other zones start out at a uniform temperature of $1^{\circ}$, provides a good comparison of methods. These inilial conditions are illustrated in Fig. (3.5). The problem is defined on a mesh 30 zones by 30 zones, each: one centimeter square.

For numerical purposes all monotonic lemperature dependent conductivities are elike. As the heat propagates out irom ine source. there are great disparities of limesteps, and the more so if the heat conductivity is laken as proportional 10 some power of the lemperinture. If o goes as the first power of $u$ or hikher, one zunc must warm up almost completely beiore ils conductivity is great enough to bcgin warming the next zone. The time scale may be different for different conductivities, but the numertcal scquence of events is pietiy much the sanie for all. Zones warm up one at a time, and the zone currently 
warming up will set the timestep. Electron thermal conductivity is a typical physical process displaying this numerical behavior

Figs, (3.6) and $(2,7)$ are oulput from ADI and independent timesleps calculations with the same initial and boundary conditions. The number of cycles required to calculate the time evolution of the problem is nboul the same (contrary to what nue would expect). and is determined not by stability conditions but by accuracy constraints. What is plotted in these figures is the temperature distribution, und these pictures are futrly early in the problen. At the stop 1 ime, $5.26 \times 10^{-5}$ sec.. the calculations have renched in zone $(6,6)$ a lemperature of 7.143.7.105. and $7.125 \times 10^{30} \mathrm{~K}$ by the explicit, independent limestep, and ADI methods respect Jvely, a spread of $0.5 \%$.

Fjgs. (3.5-3.12) are all output from two codes, ADI and TDH. ADI is an alternating-directions-implicit two dimensional heat diffusion code. Iorward differenced. TDH is an explicit backward differenced two dimensional heat diffusion code using the method of independent timesteps. Various functions of (x,y) are plotted as surfaces using lhe system plotting routine PICTURE. A function of two variables $(x, y)$ det ined by the FORTRAN array, $f(x, y)=F(J, K)$. is plotted by PICTIRE as a surface. with $x^{\circ}$ and $y$ cordinates equal to the integer indices $J$ and $k$, and the ordinate $z$ (scaled) equal to $F(J, K)$. The pount of vipw is chosen to show as much of the surlace as possible, such that the lemperature source appears variously at the far right or near left corner. The first line of labelling at the bottom names the code (ADI or TDH). the problem name (POINT SORS), thr vartable plotted (II (=u): (U) $\left(=u_{l}\right): D\left(=\Delta t_{k j}\right)$. T.J $\left(=t_{k j}^{n}\right):$ and operating system statistics. On the - spitzer (i96:2). p. 1:3:3. 
third Iine appear the cycle number. time, and timestep. On the third lime under SSJN and JXN are the number of zone-cycles of compitation actually done, and the product of the mesh size (900) and the number of cycles. For ADI, SSJN is wiways equal to JXN. For TDH, SSJN is usually much less than JXN. SRAT is the computalion ratio, JXN/SSJN. The Iasl two integers, under K,Lwst, are the indices of the zone with the brielest timestep. On the rourth line, after "SCALE", is "LOG" or "LIN". according os the verticul scale in the picture is logarithmir or linear. After "FI" is printed the angle in radians from the line $J=1$ to to the point of virw of the picture. On the fourth line, as MAX and MIN. are the maximum. t minimum values of the plotted function at "ir. lop and bottom of the piclure box.

In Figs. (3.8) and (3.9) ure plotted logarithmically the time derivalive $(\Delta T / \Delta t)$ of the temperature as calculated by $A D I$ and by TDH. In Figs. (3.10) and (3.11) are plotted the limesteps $\Delta t_{k}$, . The comparison is instruclive. for the minimum timesleps are found in a "trench" in the plolted surlace. at the edge of the growing heated region, and are not sel by the stability condition. Behund this region. the timesteps are set by the Courant condition for this difference equation in the explicit calculation. and in the implicil one by the equation $\Delta f=0$ O5u, $(\partial u \cdot \partial f)$. This adjusts the timestep so that no lemperature is expected to change by more that $5 z$ per cycle. Alhead of the heated region. The limesteps are unilormll quile Iarge. The implicit code is constraincal to step ill zones at loughly the sane brief timestep as the explicit code: thev bollh advaluced the problem $5.26 \times 10^{-5}$ sec in about 3500 cycles. 
Fig. (3.12) shows the Cauchy surface at this stage in the explicit calculation. Zones ahead of the heated region have not been compuled at all, and those near il and behind it are mare or less up to date. This graph is in linear scale. Comparison of Fig. (3.12) and Fig. (3.7) will show how far ahead of the heated region the calculations have been brought up to drite by the enforcement of the condition of Eqn. (3.6)

\section{Implicil Equations}

11 was reasoned at one point that in an attempt 10 speed up calculations one should slart with the fastest difference equations avaliable, namely, implicit ones. And proceeding along the lines indicaled at the beginning or this chapter yielded some successes wilh implicit equations. In a one dimensional problem describing a bar heated al one end. no difficulties arose until the lemperalures everywhere approached equilibrium. Then an instability of unknown cause manifested itsell. and the temperature distribution would blow up in isolated areas, but not everywhere. The mystery was compounded by the fact that not just a simple lest code behaved this way. but also a complicated problem including hydrodynamics and multi-temperature difrusion.

The implicit equations requirs solving a sertes of recursion relations for the temperatures at the folure time $t^{n \cdot t}$ :

$$
u_{1}^{n+1}=c_{3} u_{3+1}^{n}+D_{j}, \quad, j \cdot 1 \cdot \ldots
$$

The coefficients $C$, and $D$, are given at zome, as rumetions of 

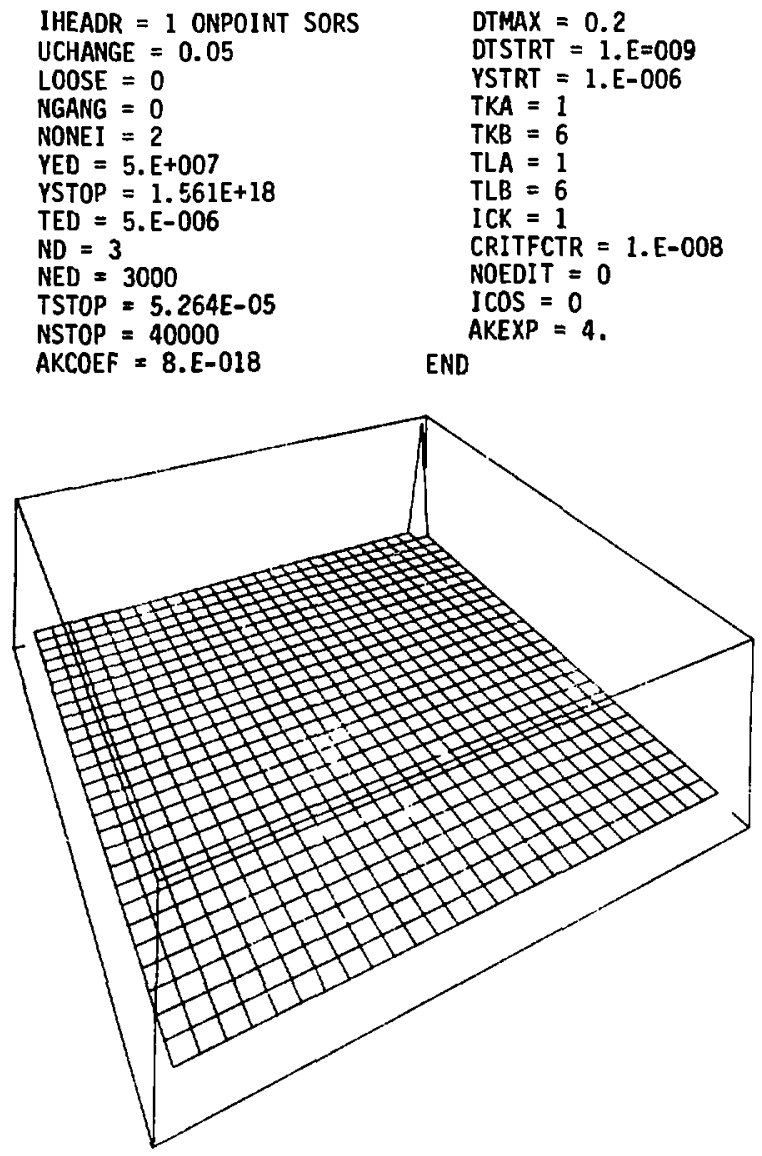

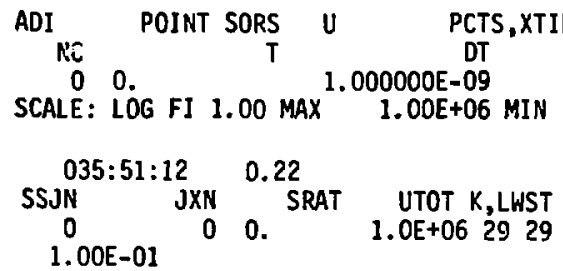

Fig. (3.5) Initial Conditions of a Two Dimensional Problem 


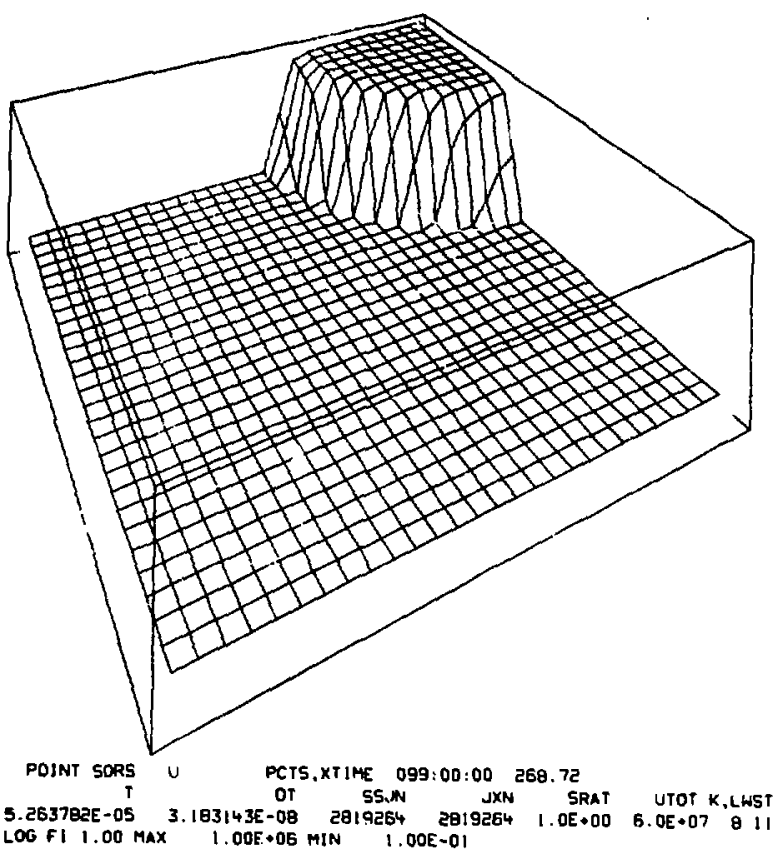

Fig. (3.6) Temperature from an ADI Colculation 


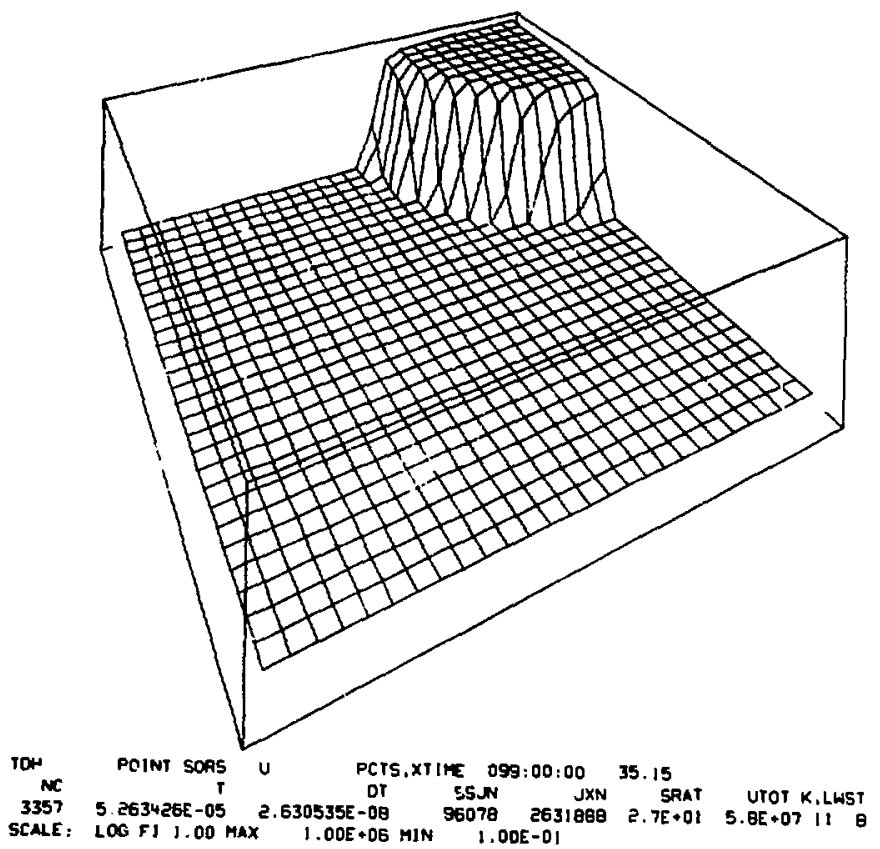

Fig. (3.7) Temperalure from a MITS Calculation 


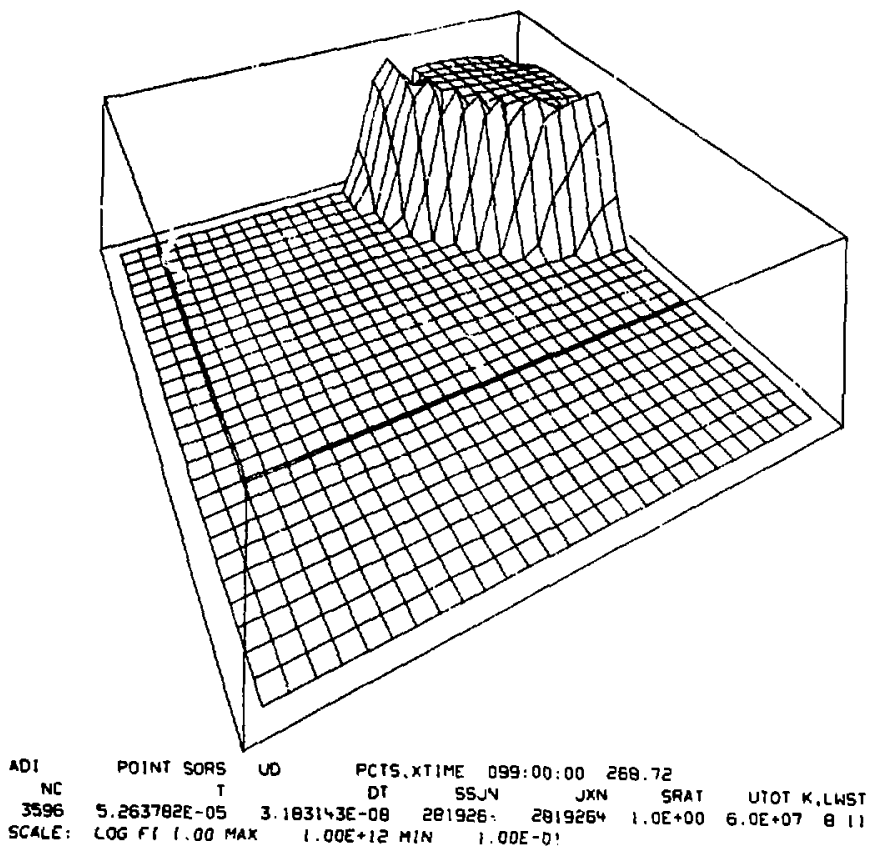

Fig. (3.B) Rate of Change of Temperature: ADI 


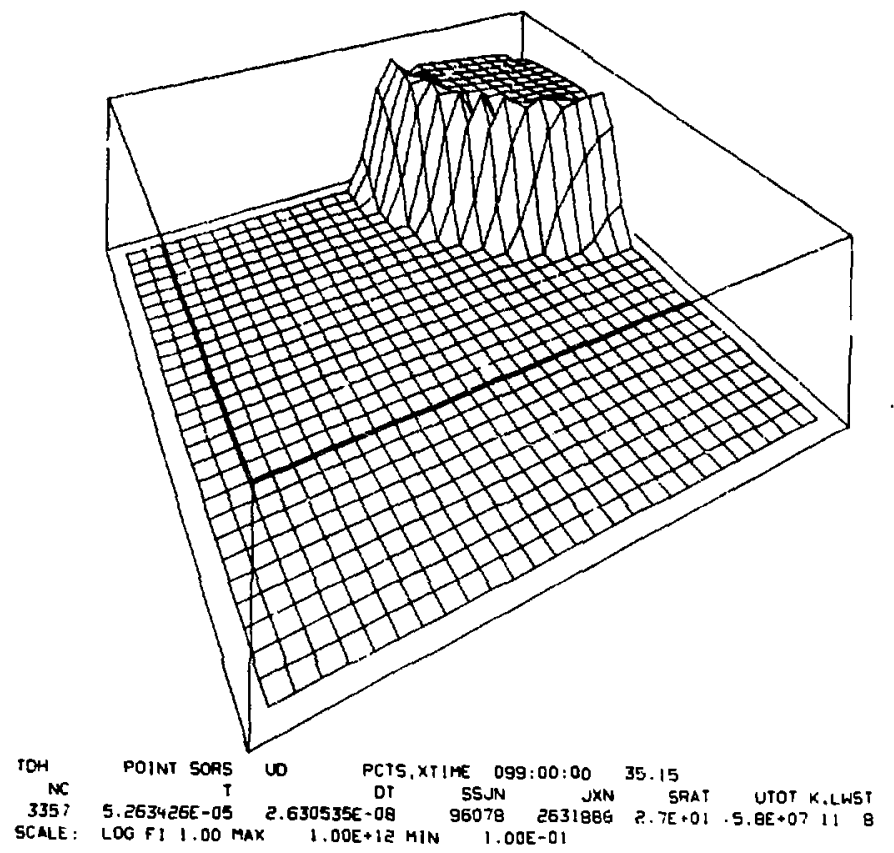

Fig. (3.9) Rate of Change of Tomperuture: MITS 


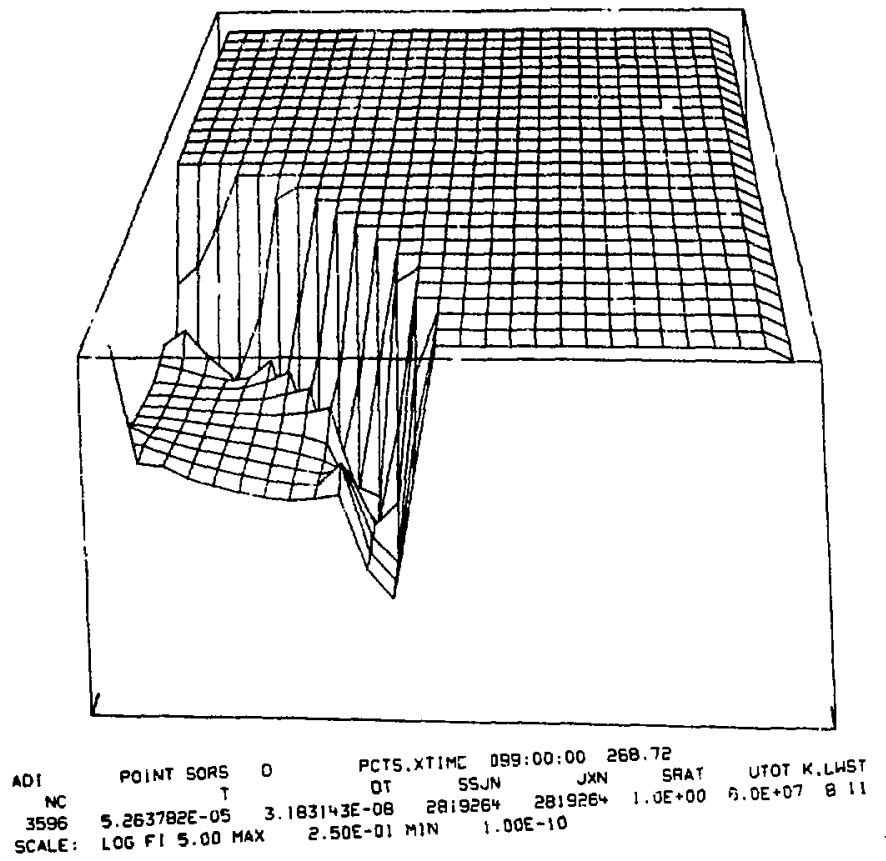

Fig. (3.10) Timesteps in an ADI Calculation 


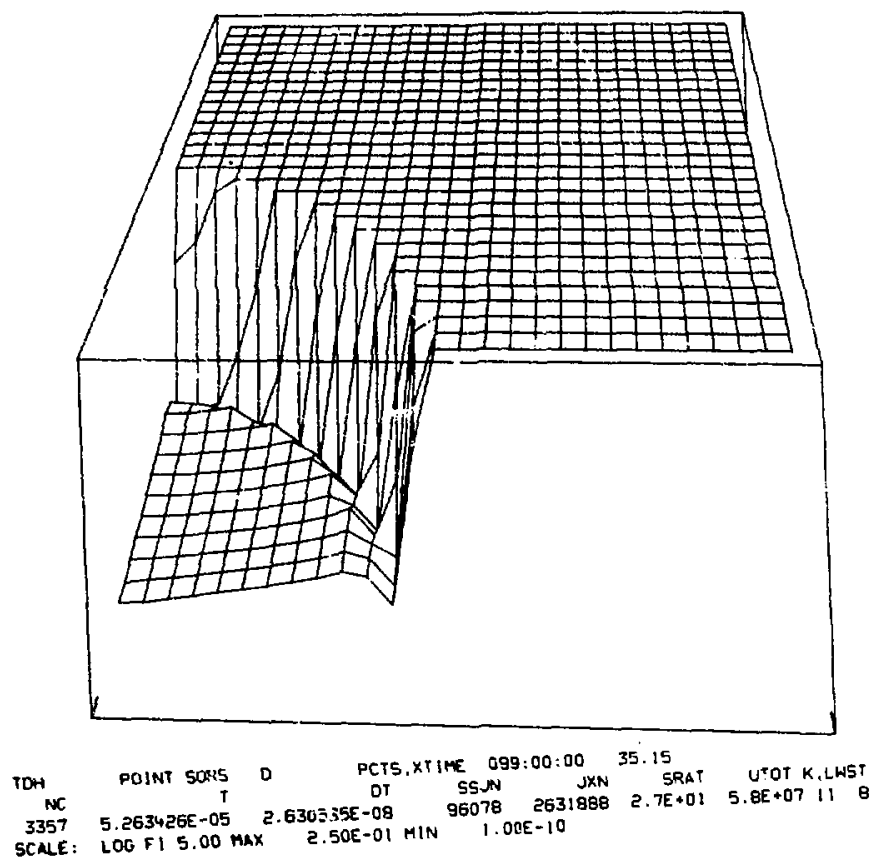

Fig. (3.11) Timesleps in a MiTs calculation 


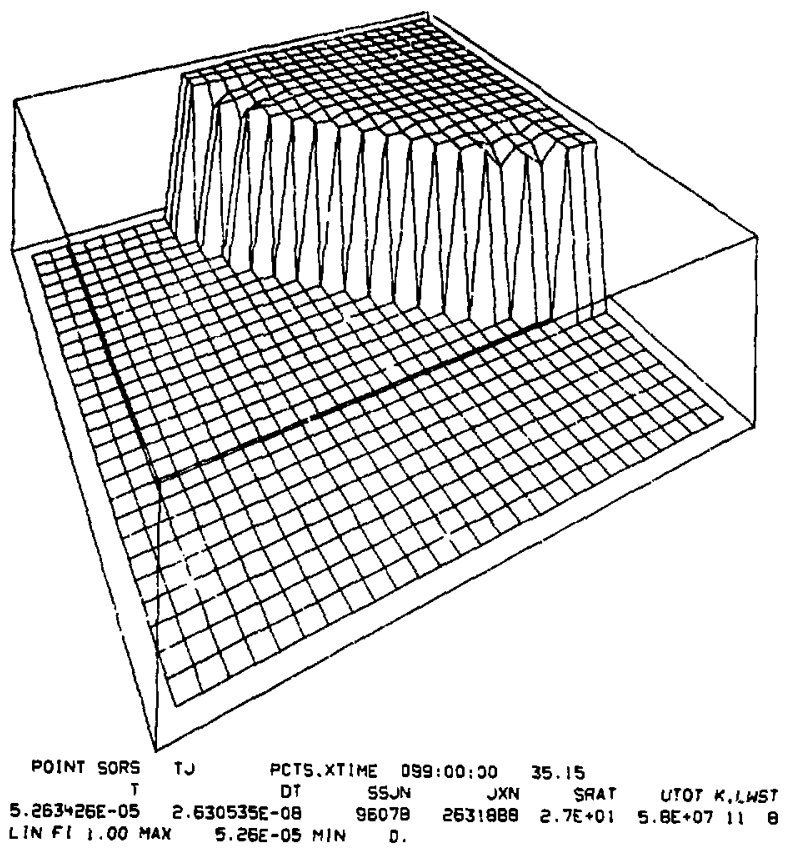

Fig. (3.12) Cauchy surface in a MITS calculation 
quantities known at zone, and quantities required from the neighboring zones:

$$
\begin{aligned}
& C_{j}^{n}=f\left(u_{j}^{n} \cdot u_{j}^{n}, t \cdot u_{j}^{n} \cdot 1 \cdot C_{j}^{n}-,\right) \\
& D_{j}^{n}=f\left(u_{j}^{n} \cdot u_{j+1}^{n} \cdot u_{j}^{n} \cdot 1 \cdot C_{j}^{n}, \cdot D_{j-1}^{n}\right)
\end{aligned}
$$

And so. when a neighboring zone was not computed. its $C$, and $D$, were extrapolated from old values and their time derivatives. It is remarkable thot this procedure worked at all, becuuse independent timesteps do violence to the motivating philosophy of Implicil equations. The implicit solution is of the forn

$$
u_{j}^{n+1}=f\left(u_{i}^{n}, u_{2}^{n} \ldots u_{j-t}^{n} \cdot u_{j}^{\eta}\right)
$$

and each lemperature $u_{j}^{n+l}$ at the future time depends on all the lemperatures $u^{n}$ at the old time $t^{n}$. It is from this that the implicit method derives its stability. as will be made clearer in Chapter IV. Interrupling the recursion Eqn. (3.26) al any point complelely destroys the dependence of the form of Eqn. (3.28). Thus, implicit diffusion with independent timesteps is not nearly the simple matter that mxplicit equat ions are.

\section{Considerations in Implementing Independent Timesteps}

It is pertinent to speak more of the details of managing asynchronous calculations. For once the simultaneous quantities have been generated at some zons, its calculations proceed pretty much as usual. But the solution of Eqns. (3.2) may be interleaved with the 
solutions of Eqns, (3.3-3.7), inslead of proceeding in the order given. For example. it may be convenient to find the lime derivalives dudt on physical grounds and then get the limesteps, and only then proceed to update the $u^{\circ}$ s al $t$ ime $l$. 11 is a maller again of convenience where in thrs cycle one entorces the netghbor retsrictions on the limesteps and selects those zones to be updated next. The present experience is that Il can be done in various ways without peculiar difficulties in any approach.

The neighbor constraint on the limesteps, Eqn. (3.6), can oflen be relaxed. os was mentioned above. Specifically. where there is not much aclivily (which is to say where all the lime derivalivalives are small). It can be relaxed, but Il must be enforced in the vicinily of those zones of briefest limestep (where the lime derivalives are not smali). This involves more coding than one would usually care lor, and grealest savings in computation lime come nol from eliminating physics in just a few more zores, but from reducing the Jogical "overhead" one must pay to manage independent limesteps al all. For example, suppose zone, has the least timestep and, in accordance with Eqn. (3.6), zones $J+1, j, 2$. elc. have limesteps each increasing by a factor of two, as far as zone $j+n$. In the time that zone $j+n$ is updated once. zone $j$ is updated $2^{n}$ limes, zone $j+t 2^{n-1}$ times, and so on. The tolal number of zone cycles of computation is $2^{n}+2^{n-1}+\ldots+2+1=2^{n+1}$. An equivalent number of zone cycles of physics would have been done if zone $j+t$ was held at the timestep of zone $j$ and zones $j+2, j+3, \quad j+n$ were all held at the much longer timestep of zone $j+n$. Although the enforcemest of fign. (3.6) has greatly lowered the timesteps of some zones, Il has, in effect. only cost the computational effort of lowering the limestep in 
one zone. In Fig. (2.4) thr regular (nild sterp) slope of like sti) culve is ralsed by fiqu. (1.6) restrainum the limesteps in the vicimily of thre shock zone of that problem. 
CHAPTEK IV

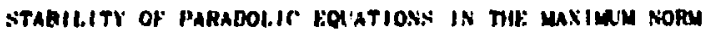

\section{The Clegsical stability Anelysin}

The method of elability andivin bo fourite componentw whicti wax developed by von Neumang and Rirhtayer' is quste wuftirienl lo deal will noel problems. As it happine. Ihe welhod of indrpendent limestrps is quile refractory to ins approash. and it ons necenenry to regort to

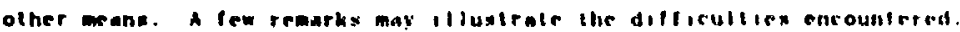
The solution uiz, of any problew in one dimension ran br reperacticd ax

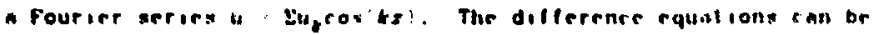

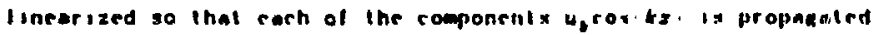
lormata an time independently of lle olhesy. Siability requiren prool that the volution remoins bounded as the mesh in refined. If marli

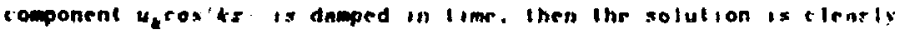
Ilable. If any componerit is anplitiod. Ihet threr arr crounds for suppecting instabitity (but not. It may be toted, proof of inwlability in $\operatorname{tac}()$.

1 von Sirumann \& Richtmyer (1950). 
One substifutes in the Iincarized difference equalions a solution of the form

$$
u_{j}^{n} \cdot e^{n+14 s}
$$

nind solves for e. The amplificasion fattor. The diffictly is ihat thid method assumes in the apptoximntions of its premises precinely bll the prope I les which indepindeut limesteps never possess, namely constant coeticients in llie difference equations aud a mesh that is tways and evergwhere liviforn in as and nore mportantly in 31 . For suppose in the difference equation

$$
w_{i}^{n+1}, \cdot+1 u_{j}^{n}, 2 u_{i}^{n} \cdot u_{j}^{n},
$$

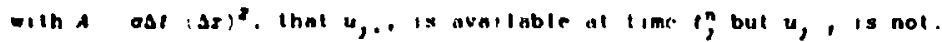

The lemperature at zone, $f$ may be approximaled by

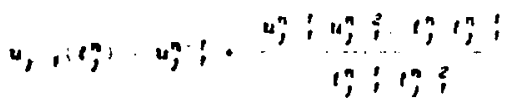

This is the linear extrapolation forward from the lwo previous values al

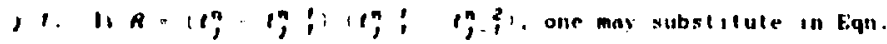

$(+.2) \cdot \operatorname{aron}$

$$
u_{i}^{n+s}-u_{j}^{n}-\lambda\left(u_{j}^{n},-2 u_{j}^{n} \cdot u_{;}^{n} ; \cdot R_{i} u_{j}^{n} ; u_{j}^{n} ;\right)
$$

Into this may be subntiluted tign. (4.1), and simplifying, there results nu equation in 6 : 


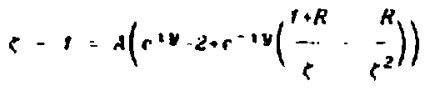

with $y$ - kdx. This may be rearranged to exhibit a rubic in amplifichlion ractor:

$$
C^{3}+C^{2}\left(2 A-A r^{\prime} y-1\right)\left(A r+y_{1}(1+R)+A R c^{-1 y}=0\right.
$$

Now the roots of this equation are not intrcessible, but before considering them 11 is sobering to note that $R$ was tacitly assumed equal 10 unily. For, If Equ. (4.1) is 10 be lested as a solution to any lorm of Eqn. (4.2). It must be that $u$ is amplified by the same factor $c$ at every zone and over every limestep. and this requires limesteps of equal size. not only in odjacent zones, but also in succession in the samp zone. So, any results based on Eqn. (4.6) are suspect for values of $R$ nol equal to one.

While this is one of the more tractable equations in an amplifisalion factor, It still requires a numerical soluliou. Eiven the mrthod of Routh and Hurwitz will not easily conline ils rools 10 within the unit circle. Its roots are plolted in fig. (4.t) in the complex plane. The unit circle and the positive real axis are shown for scale. As the parnmeter $y=k 1 x$ is varied frem to $2 \pi$. Ihr poots tall on iwo loci. one balloon near unity, and the olher, a deformed circular lorus with approximate radius proportional to $A$. When 4 is roughly equal to 0.25 . this locus tirst strays outside of the unit circle. thus Indirating the limits of stability. As encouraging as this was, it was 


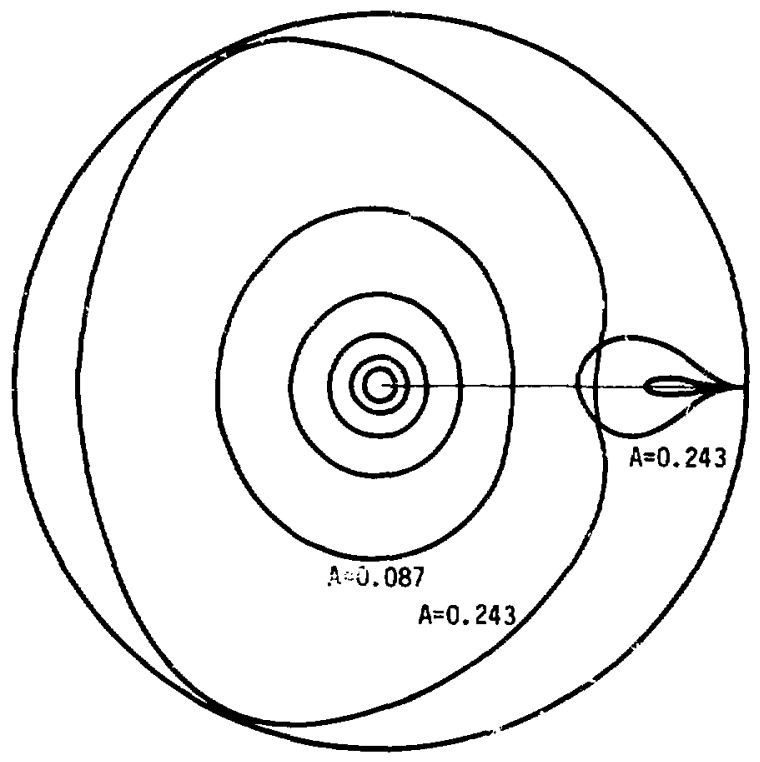

Fik. (4.1) Amplification Faclors 
Tell to be no more lhan suggestive. nnd other assurninces for stability were soughl.

\section{The Equelion of DuForl and Franke!}

If 1953 was published a rather remarkable finile diflerence npproximation to the heal equalion ${ }^{2}$. Il is quile explicil and unconditionally stable. The fact that its convergester is condilional on The way in which the mesh is relined does not make clear its truc characier, and lillte more is sald aboul it in the various finile difference handbooks. The equation published in 1953 is aclually one of a broad class of difference equations which arr explicit and uncondilionally stable, I wo of which were quoted al Ens, (3.22) and (3.23). Because of ily slability. It was lell that such an equation.

$$
\frac{u_{j}^{n+1}-u_{j}^{n}}{\Delta t}=\frac{a}{\Delta x^{2}}\left(u_{j}^{n}, \cdot, u_{j}^{n+1}-u_{j}^{n-1}+u_{j}^{n},\right)
$$

might provide the best starting point lor independent limestops. Such an expectation was not conlirmed, but this equation turned out to be very instruclive and to provide good illustralions of precisely whal slability is. The common ralionalization notes that since in these equations the temperature $u_{j}^{n \cdot 1}$ at the luture lime $t^{n \cdot}$ depends only on present and past temperatures at the three zencs, J.J.j+t. The timestep cannot be extended 100 far without asking for troubie. This is indeed true, and the reasons why will indicate that the concept of stabilily is not as difficult as romonly supposed. In actua: Iacl. Eqn. (4.7)

2 dufort Frankel (1953) 
vields very bad npproxtmations to the hent equation for timesteps la: compared 10 lhose permited by slabilily consideralions 10 simple backward differencsd explicil equations. Moreoser. Ihe solutions, while bounded and therefore formalls quile slable, exhabil thoroughly unarceptable patholopies.

Equ. (f.7) may be solsed explicilly for $u_{j}^{n+1}$. with $A=\sigma s x^{2}$ :

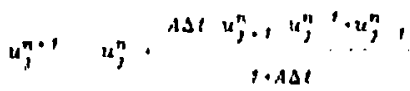

In the IImat of Iarus limesteps.

$$
u_{j}^{n+1} u_{j}^{n}, u_{j}^{n}, u_{j}^{n},
$$

A litle erephic work sufficos to explain what was happening. In fig. (4.2). if $u_{j}^{n}, u_{j}^{n}, \ldots$ and $u_{j}^{n}$ dre as shown, $u_{j}^{n+p}$ upprodehes point $Q$ asymptolicallv as $d t$ increases without IImil. Point $R$ is the averagr of $u_{j}^{n}$, and $u_{,}^{n}, \ldots$ and pount $Q$ is as far above $R$ as $u_{j}^{n}$, is below $R$. The calculated solution of a Dufort and Frankel tepe cquation exhibits ripples of a quile unphysical nature, which. hewever. do not grow without bound in time. and thus are tormally strible. It should also be clear that at late times the true solution $p^{n+1}$ can be arbitrary, but the calculated value of $u^{n+1}$ will bear no relation to it at all. if the calcutalion consists of one long limestep.

Thus, armed with an example of an equation uhich is stable but nevertheless not satisfactory, a sinilar inspection of the common backward differenced explicul equation 
9.

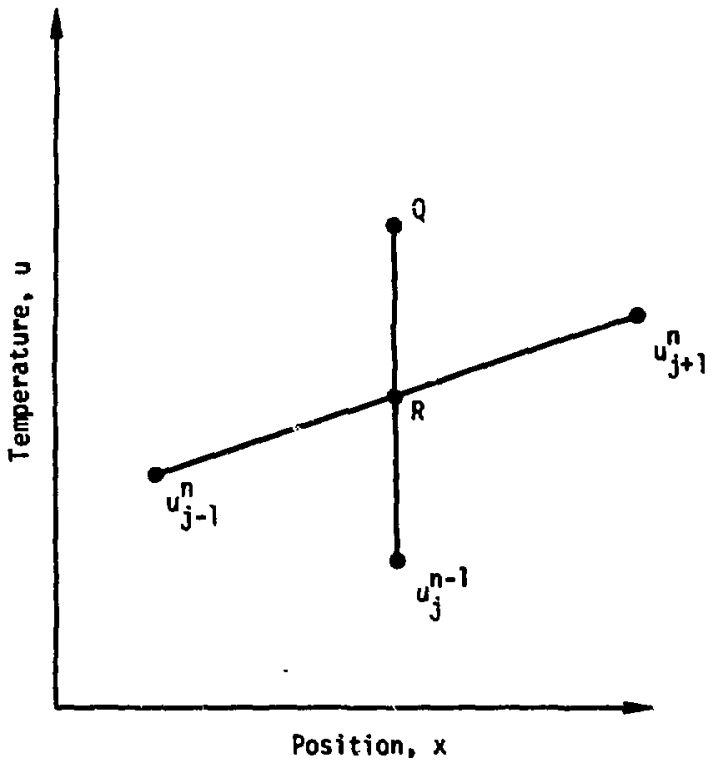

Fig. (4.2) The solution to the Du rort-Frankel Equation. 


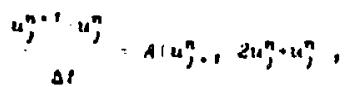

sulfered to revenl the reasons for its stability randition. If one supposes $4, \ldots w_{j}^{n}$. nnd $w_{j}^{n}, 10$ have ar ilrary values. the diagram in Fia. (4.3) may be constructeril. Here there is no pollit $Q$ for w, ithereases wilhoul lim: I ns al increases willoul IImil:

$$
u_{j}^{n+1} u_{j}^{n} \cdot \operatorname{2as} t\left(\begin{array}{cc}
u_{j}^{n}, \ldots+u_{j}^{n}, & \left.u_{j}\right) \\
2 &
\end{array}\right.
$$

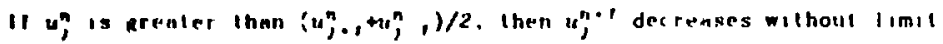
The stabilily condition is known to require lhat taf, 0.5 , which is 10 say that instability orrurs as soon as up, crosses point $R$ in Fig. (4.3). but the difference equations we stable os long as $u^{n-1}$ lies between $u^{n}$, and the avernge of $u_{,}^{\prime}$, and $u_{j}^{n}, \ldots$

\section{SIabilily in Grneral}

Faced with the phenomena deseribed above. one naturally returns 10 the definilions of slability to inquire just whal one is desting with. Following Richtmyer Morton ${ }^{3}$ (the Russian nomenclaluret is generally ol odds with this). one construets an approximalion to ux.' and as the difference mesh is refined, if the approximalion 10 u.t. remains finite. Then the method is sald to be stable. othetwisp tot. Note that 
94

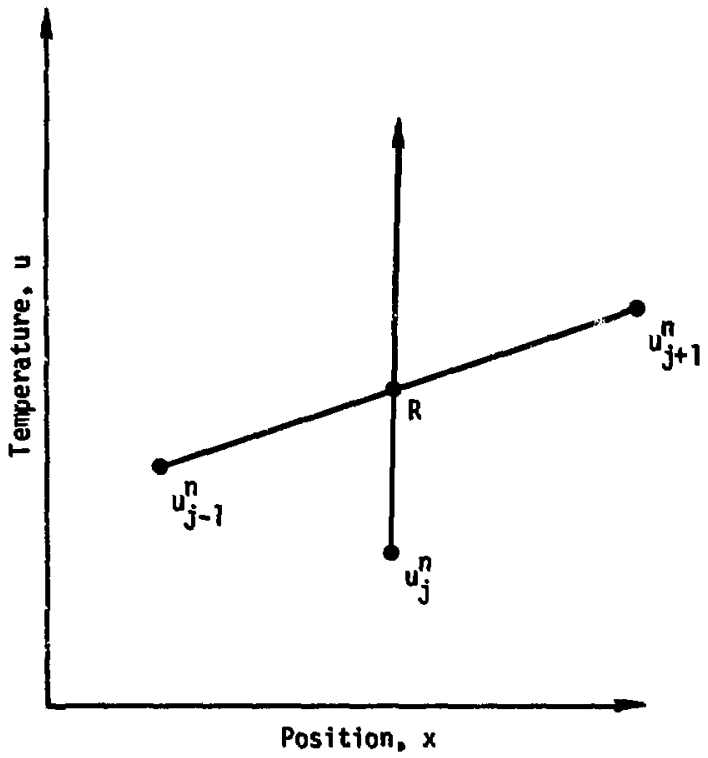

Fig. ( 4.3$)$ Solutions of En. ( 4.10$)$ 
the approximate $u(x, t)$ is not required to decrease as the mesh is refined, only not to increase without timit.

In spenking of refining the mesh. Jue has in mund a series of ever

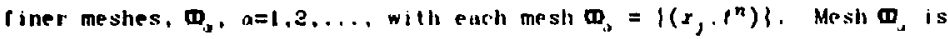
characlerised by $i t s$ mesh spacings, $\Delta x=x,+, j$, and $\Delta t=t^{n+1}-t^{n}$. Mesh

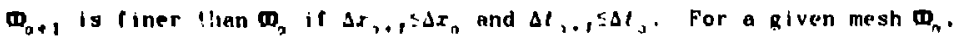
there is an approximation (calculated by means of the finitedifference equation on that mesh) to the quant ity $u(x, t):\left(u_{j}^{\prime \prime}\right)$. For mesh $m_{a+1}$, and its approximation $\left(u_{j}^{n}\right)_{3+1}, j_{x+1} \geq j_{x}$ and $n_{x+1} \geq n_{x}$. The point $u(x, t)$ and ils dependent variables $u(x, t)$ are reached in ever more and ever finer increments. The definstion of stability speaks of the series $\left.\mid u(x, t)_{a}, a=t, 2 \ldots\right\}$, and requiras that this series converge (uniformly on all $x$ and $t$ to some finite value. It does not have to be a monotonic decreasing series. Condilional stability generally asserts convergence of the series $\left\{u_{a}\right\}$ given only the stronger additional premise that for each mesh $\boldsymbol{W}_{,}, \Delta x_{a}$ and $\Delta t$, are connected by some stability condition, as for example for some constant $K, \Delta t / \Delta x \leq K$ or $\Delta t ;\left(\Delta x^{2}\right) \leq K$. These conditions were first stated by Courant, Friedrichs, and Lewy ${ }^{6}$ and are of ten called Courowt canditions.

The problem may be specified precisely by naming the equation to be solved.

$\partial u, \partial \ell=F\left(u, \partial_{i} ; \partial x, e f c,\right)$

its initial and boundary conditions.

5 courant, Friedrichs, Lewy (1928) 


$$
\begin{aligned}
& u(x, 0)=f(x) \\
& u(0, t)=g ! t) \\
& u(x, t)=b ! t ?
\end{aligned}
$$

and an approximale solution $v(x, t)$ logether with its tinite difference equal ion:

$$
y(x, t+\Delta t)=s(x, t, \Delta x . \Delta t)(x, 1)
$$

$s$ is some for the moment unspecifled finite difference operalor. The approximation $"$ is subjec! to the initial and boundary sonditions of Eqn. (4.13). To define stability it is necessary to consider $y(x, 1)$ as an element of comptete vector space in which there is a norm ${ }^{6}\|v\|$. There are two common norms usefut for our purposes. the inaximim sorm and the $l i$ norm. The maximum norm is defined by

$$
\|v\|_{\text {wAX }}=\max _{x}(\{x\} \mid)
$$

and the $l 2$ norm by

$$
\|v\|_{i 2}^{2}=\int \mid v i x \|^{2} d x
$$

The operalor $s$ is said to have a bound $s$, if for any permissible function $v(x)$,

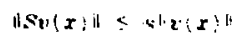

This bound s may be writlen as isth. A difference equalion is really a a A Banach space: see Rirhtmyer \& Morton (1967), p. 30. 
schemin of operalors $s(x, . \Delta x, \Delta \ell) . \Delta x$ may be laken as a function of $\Delta t$. since we are inlerested in the behavior of approximations as one varies $\Delta t$, and in practise, $\Delta x$ and $\Delta t$ are connected by some fixed relationship. Thus the operators $s$ may be considered as functions of $\Delta t$ : fo: having specified $\Delta t$, one has a rule at every point $(x, t)$ for specifying $\Delta x$, ind so $s$. As at is lowered, with nat $=$ l held constant, one expects $S^{n}(\Delta t)$. The operulor which brings $v(x, 0) 10 v(x, t)$. 10 give an ever beller approximation $10 u(x, l)$. The approximalion by means of $s^{n}(\Delta t)$ is called s'able if there is some number $K$ such that for any $\Delta t$ in the finile range specified by

$$
\begin{aligned}
& 0=\Delta t=T_{\text {max }} \\
& 0<n \Delta t=T
\end{aligned}
$$

il is the case that for all oermitted $f(x)$

$$
\left\|S^{n} f(x)\right\|=\|v(x, l)\| \leq k\|f(x)\|
$$

\section{Slability in the Maximum Norm}

The Insight gained from the equalion of DuFort and Frankel can be lormalized in a method mentioned in passing by Richtmyer \& Aorton?. The Fourier analysis may be taken as proof of stability in either the L2 norm or the maximum norm, but it is much easier for present purposes to prove slability for parabolic equalions in the maximum norm. Moreover.

7 Richlmyer Morton (1967). p. 12. It is surprising that these authors did not acknowledge the power and generality of the method they mention so briefly and decline to develop fully. 
the proof supplied here is rigorousty true for equations that are nonlinear and which have variable coeftirients. and for neither of these cases will the Fourier analysis guarantee stability. Hyperbolic equations are best malysed in the $L 2$ norm. but again, by methods other than Fourier analysis.

Il will be convenient 10 delille an averaging function: $g(a, b)$ is an averaging function of its two arguments $a$ and $b$ if

$$
|g| \leq \max (|a i \cdot| b \mid)
$$

This definition is a litle more broad than the intuitive idea of an average. but il captures precisely that properly of averages which is used as a premise in the following arguments. The discussions of Figs. (4.2-4.3) hinged on the point at which $u_{j}^{n+1}$ overtakes the average of its neighbors, $u_{j-,}^{n}$ and $u_{j+,}^{n}$, and this is the place where instabilily sets in. Averaging functions will figure prominently in all the stability arguments in the maximum norm.

11 is useful to think of difference schemes as operators: the operator $c$ applied to the function $u^{n}=u\left(x, f^{n}\right)$, gives the new function $u^{n+1}$ at the time $i^{n+1}$ :

$$
u^{n+1}=C u^{n}
$$

The form of all stabilily arguments in the maximum norm is quite simple: an example mey be stated in the following theorem:

Theorem 4.1 For a difference scheme $u^{n+1}=C u^{n}$, and a function 
89

$a_{j}^{n}$, if $a_{j}^{n}$ is an averaging function $a_{j}^{n} u, \ldots, u$, of is arguments. and if

$$
\left|u_{j}^{n+1}\right| \leq \max \left(\left|u^{n},\right| \cdot\left|a_{j}^{n}\right| \cdot\right.
$$

422;

then the scheme is stable in the maximum norm.

For the proof, one may note first that from ton. (4.20).

$$
\left|a_{j}^{n}\right| \leq \max \left(\left|u_{j}^{n},\right| \cdot \mid u_{j}^{n}, t\right)
$$

(4 231

It lo l lows from Ens. (4.22) and (4.2:3) that

$$
\left|u_{j}^{n+1}\right| \leq \max \left(\left|u_{,}^{n}\right| \cdot\left|u_{,}^{n},+1 \cdot\right| u_{j}^{n},|,|\right.
$$

424

and so that

$$
\left\|u^{n+1 \|} \cdot\right\| u^{n} \|
$$

42.5 ;

whence the bound on $H u^{n} \|$ (it $u^{n}, \cdot u^{0} \cdot$. proving stability as expressed in Kin. (4.19).

Te note without proof that gix.y: ax a $y$ is an axerahine function it 0.9:1.

There follows readily from Theorem $(t .1)$ :

Theorem (4.2) The difference scheme

$$
u_{j}^{n+1} u_{i}^{n} \cdot A_{1} \sigma_{j}^{n} u_{j}^{n}
$$

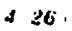

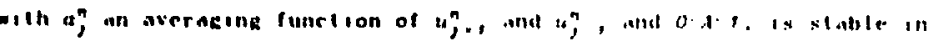


the waxinum norm. The quantily $A$, is eenerally $20 \Delta t a x^{2}$. where $a$ is ine diflusion constant and at and $\Delta x$ spreify the mesh size. This is fust llie common slabilily condition. Nole that il is a local argument; the mesh size may be variable, and the nveraging function a and the diffusion coeficient $a$ may both be very nonlinenrly dependent on $u$, but Theorem (4.2) silll quite rigorously proves stability. One may see this in the rommon explicil backward differenced equation:

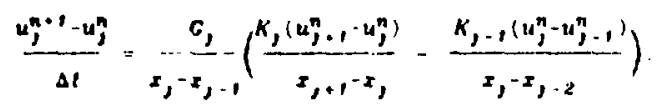

Here $\sigma$, is the diffusion coeficient, specitied at the zone edge, and is - Iunction of the temperalures $u_{j}^{n}$. The quantilies $G$, contain information about the geometry. (plane. cylindrical. or spherical) and the mesh size. Eqn. (4.27) may be rearranged:

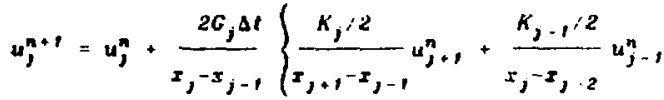

$$
\begin{aligned}
& \left.-\left(\frac{k_{j} / 2}{x_{j+1}-x_{j-1}}+\frac{k_{j-1 / 2}}{x_{j}-x_{j-2}}\right) u_{j}^{n}\right\}
\end{aligned}
$$

Here the auxiliary quantities $B_{j}$ and $C_{j}$ may be defined:

$$
B_{j}=\frac{\kappa_{j} / 2}{x_{j+1}-x_{j-1}} \text {. and } c_{j}=\frac{\kappa_{j-1 / 2}}{x_{j,-x_{j}-2}}
$$

and the averaging Iunction $a_{j}^{n}$ of Eqn. (4.26) here is given by 


$$
a_{j}^{n} \quad \frac{\theta_{1} u_{j+1}^{n}+c_{,} u_{j}^{n},}{\theta_{j}+C_{j}}
$$

and $A$, is given by

$$
A_{j}^{n}=c, \Delta t \frac{B_{1}+C_{j}}{x_{,}-x_{,},}
$$

Thus, the difference Eqn. (4.27) is Indsed of the same form as Eqn. (4.26).

\section{Implicil Dufferences Equalions}

It is not difficult to extend this metiod to the forward differenced implicit equations. In order to demonstrate the quitt broad general application of stabilily analysis by means of a bound in the maximum norm using simple arithmetic itequalities. the treatment of implicit equations is included here. This will provide the means of justifying the assertion of Chapter Ill from another point of view why independent limesteps are not sulfable for implicit equations. Il may be pruven that

Theorem (4.3) A difference scheme $u^{n+1}-\left(u^{n}\right.$ is stable ill the maximum norm of there exists an averaging function $n_{j}^{n}: u_{j}^{n}, \ldots u_{j}^{n}$, such that

$$
\left|u_{j}^{n \cdot \prime}\right| \leq \max \left(\left|u_{j}^{n}\right|, \mid a_{j}^{n \cdot t} i\right)
$$


For the prool. note that in the premise the average is not taken at time $t^{n}$ but at time $1^{n+1}$. Eqn. (4.31) slates in effect that $u_{j+1}^{n+1}$ smaller in absolute value than one of $u_{j}^{n}, u_{j}^{n+i}$, and $u_{j}^{n} ; j$. But one may proceed recursively from zone $j$ to the boundaries and bound $u_{j}^{n}$ by either some $u_{k}^{n}$ or by a value of $u$ al the boundary, and this is precisely to say that

$$
\left\|u^{n+1}\right\| \leq\left\|u^{n}\right\|
$$

proving stability.

As a corollary. one may note:

Theoren (4.4) Dilference schemes of the form

$$
u_{j}^{n+1}=u_{j}^{n}+A\left(a_{j}^{n+1}-u_{j}^{n+1}\right)
$$

are stable in the maximum norm for $0<A<\infty$, If $a^{n+1}$ is an averaging function of $u_{j}^{n+!}$, and $u_{j}^{n+?}$.

For proof, one may note that $u_{j}^{n+l}$ is given in Eqn. (4.33) by an averaging function of $u_{j}^{n}$ and $a_{j}^{n+1}$. Ihus fulfilling the premise. Eqn. (4.31) of Theorem (4.3). One may also nole thal.

$$
u_{j}^{n+1}=\frac{u_{j}^{n+1 a_{j}^{n+1}}}{n+4} .
$$

and thet for the entire range O.d.e. $u_{j}^{n-1}$ lies between w $^{n}$ and $a_{j}^{n+1}$. As before. A is taken as $20 \Delta f \cdot \Delta x^{2}$, and the scheme. Enin. (4.J3) is stable for all limesteps. Than is just the fully lorward differenced implicil equalion. Note that in this scheme each w,', is bounded not by one of 
$u_{j}^{n}, u_{j}^{n}, \ldots u_{j}^{n}, \ldots$ but by some element of the murh larger set $\left\{u_{1}^{n} \cdot u_{2}^{n}\right.$ $u_{j}^{n} . \quad . u_{j}^{n} \mid$.

The Crank-Nicholson scheme muy be wrilten as follows:

$$
u_{1}^{n+1}=u_{j}^{n}+A\left\{\left(g a_{j}^{n}+\left(1-g: a_{j}^{n+\cdots}\right) \cdots\left(g u_{j}^{n}+(1-g) u_{j}^{n+1}\right)\right\}\right.
$$

Here $0 . g, 1$. and $a_{j}^{n}$ is wh nverage of $u_{j}^{n},$. and $u_{j}^{n}, \ldots$ as before, Eqn.

$(4,35)$ may be rewrilten as

$$
u_{j}^{n+1}=u_{j}^{n} \frac{t-A g}{1+A(1-g)}+\frac{A}{t+A(t-g)}\left(g a^{n}+(t-g) a_{j}^{n+1}\right.
$$

The right hand side averages $u^{n}$ and $\left.\left(g a^{n}+(1-g) a^{n}\right)^{+}\right)$it and only if $0.5 \leq g$. In this case, $u^{n+1}$ may be bounded by one of $u^{n}$, and $\left(g a_{j}^{n}+(t-g) a_{j}^{n+1}\right)$; or equivalently by one of $u_{j}^{n}, u_{j}^{n}, \ldots u_{j}^{n}, \ldots u_{j}^{n}, f$,

$u_{j}^{n+!}$ : and one may proceed recursively as before until one bounds $u_{j}^{n}$ by some $u_{t}^{n}$ or a value of $u$ on the problem boundary. The number g specifies how Iar "forward" the difference equation is: when $g=0$, the equation is backward filterenced, and when $g=1$, it is tully lorward ditferenced, For the Crank-Nicholson scheme, $g=05$. 


\section{CHAPTER V}

STABILITY OF HYPERBOLIC EQUATIONS IN THE LZ NORM

\section{An example with Varıable Coefficients}

The usually superb convenience of fourier analysis of stability is nol universal. There are problems resistant to 1 , and one here described leads to a stability analysis laler sultable for independent timesteps. The strategy is known as the energy mpthod. and has been known for some time'. This chapter will deal with stability of hyperbolic equations without independent timesteps, and the next wil! detast how the arguments in this chapter are modified by independent I imesteps.

The example following was related to me by $K$, Mar $x^{2}$. One differences the cylindrical wave equation in the straightforward manner explicitly. This equation has coeficents variable in $r$. and ils behavior is known Irom experience to be slable with the usual Courant condition for such equations. However, the Fourier melhod falls to prove slability. This 
is generally (and here errolievisly) laken lo be diagnostic of instability. It may be remembered from the discussion above in chapler IV that stable solution of the difference equation is merely forbidden 10 grow withoul bound: 11 is not required to decay.

The cylindrical wave equation.

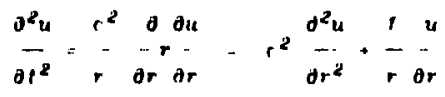

may be differeneed,

$$
\frac{u_{j}^{n+1} 2 u_{j}^{n}+u_{j}^{n-1}}{(\Delta f)^{2}}=c^{2}\left\{\frac{u_{,}^{n}, 1-2 u_{j}^{n}+u_{j}^{n}, 1}{(\Delta r)^{2}}+\frac{u_{j}^{n}, 1-u_{j-1}^{n}}{2 r, d r}\right\}
$$

where $\Delta t$ and $\Delta r$ specily the mesh size. The Equ. (5.1) is to be npproximaled by Eqn. (5.2) on some domain $0 . a \leq r: b$, not including the axis of coordinales. One may subsilule

$$
u j-r e^{n+u t}
$$

and with a litlle algebra oblatn

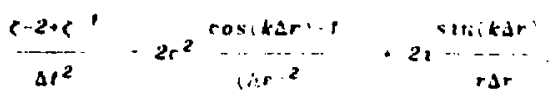

from which

$$
r^{2}-2 c r+1=0
$$


and witll

$$
A=c^{2} \Delta t^{2} / \Delta r^{2}
$$

Now the two roots $\zeta_{1}$ ard $\zeta_{2}$ must satisfy

$$
r_{1} r_{2}=1 . \quad c_{1} c_{2}=-2 C
$$

If $r_{1} \zeta_{2}=1$ and $\left|\zeta_{1}\right|=\left|\zeta_{2}\right|=1$. then $r_{1}=\zeta_{2}{ }^{\circ}$. But $\mid 1 r_{1}=\zeta_{2}{ }^{\circ}$. then $c_{1}+\zeta_{2}$ is real. This cannot be the cose. since $G$ is not real. Therefore. one of $\left|\zeta_{1}\right|$ : $\mid \zeta_{2}$ ! must be greatnr than unity, and some Fourier component of the solution grass with tume. leaving the stability of Fạn. (5.2) unproven.

\section{Plane Waves}

Before tackling cylindr jcat saves with the energy method, it it instructive ic exhibit this strategy in ils application to plane waves. because here Il may be seen in the greatest clarity, Cylindrical raves and hydrodynamic difference equalions $m$. later be reduced to this case. In one dimension. in plane geometry. The wave equation is

$$
\frac{\partial^{2} u}{\partial t^{2}}=c^{2} \frac{\partial^{2} u}{\partial r^{2}}
$$

and its common finjte form is, 


$$
\frac{u_{2}^{n+1}-2 u_{2}^{n}+u_{1}^{n+1}}{\Delta t l^{2}}=\frac{2 r^{2}}{r, \ldots r, \ldots}\left\{\begin{array}{ll}
u_{2}^{n}, \mu_{1}^{n} & u_{2}^{n}-u_{2}^{n}-1 \\
r, \ldots-r, & r, r,-1
\end{array}\right\}
$$

It is convenient to rewrule this as a par of first order equations. To this end one defines quantities $v$ and $u$ by

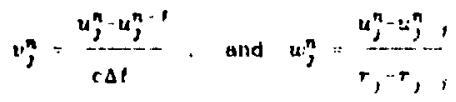

Eqn. (5 9) may be written as

$$
\frac{\left.v^{n+1}-v^{n}\right)}{c \Delta t}=\frac{2\left(u, j,+w_{2}^{n}\right)}{r,+1, r, t}
$$

One may construct from Eqn. (5.10) an equation in $u$ :

$$
\frac{w_{j}^{n+1}-u_{j}^{n}}{r \Delta t}=\frac{v_{j}^{n+1}-v_{j}^{n+i}}{r_{j}-r_{j-1}}
$$

It is convenient to define

$$
A_{j}=\frac{r_{j+1}-r_{j} t}{2 c \Delta t} . \quad B_{j}=\frac{r_{j}-r_{j-1}}{c \Delta t}
$$

Equs, (5.11) and (5.12) may be rewritten

$$
\begin{aligned}
& A_{j}\left(u_{j}^{n+1}-v_{j}^{n}\right)=u_{j}^{n},-u_{j}^{n} \\
& B_{j}\left(u_{j}^{n+1}-w_{j}^{n}\right)=z_{j}^{n+1}-u_{j}^{n+!} ;
\end{aligned}
$$

The first of these may be multiplied by $\left(x^{n+1},+e^{n},\right)$ and the second by 
$\left.i w_{j}^{n+1}+w_{j}^{n}\right)$ to obtain a pair of equations:

$$
\begin{aligned}
& A_{j}\left(\left(v_{j}^{n+1}\right)^{2}-\left(v_{j}^{n}\right)^{2}\right)=\left(w_{j+1}^{n}-w_{j}^{n}\right)\left(w_{j}^{n+1}+v_{j}^{n}\right) \\
& B_{j}\left(\left(w_{j}^{n+1}\right)^{2}-\left(u_{j}^{n}\right)^{2}\right)=\left(v_{j}^{n+1}-v_{j}^{n+1}\right)\left(u_{j}^{n+1}+w_{j}^{n}\right)
\end{aligned}
$$

If Eqns. ( 5.15$)$ are summed from $j=10 j=J$, one has

$$
\begin{aligned}
& \sum_{j=1}^{j}\left\{A_{j}\left(\left(v_{j}^{n+1}\right)^{2}-\left(v_{j}^{n}\right)^{2}\right)+B_{j}\left(\left(w_{j}^{n+1}\right)^{n}-\left(w_{j}^{n}\right)^{2}\right)\right\} \\
& =\sum_{j=1}^{J}\left\{\left(\left(w_{j}^{n+1}+w_{j}^{n}\right)\left(w_{j+1}^{n}-w_{j}^{n}\right)\right)+\left(\left(w_{j}^{n+1}+w_{j}^{n}\right)\left(v_{j}^{n+1}-v_{j-1}^{n+1}\right)\right)\right\}
\end{aligned}
$$

The right hand side of Eqn. (5.16) may be summed by parts:

$$
\begin{aligned}
\text { R.H.S. }= & \sum_{j=1}^{t}\left\{\left(v_{j}^{n+1}+v_{j}^{n}\right)\left(w_{j+1}^{n},-w_{j}^{n}\right)+v_{j}^{n+1}\left(w_{j}^{n+1}+w_{j}^{n}-w_{j+1}^{n+1}-w_{j+1}^{n}\right)\right\} \\
& -v_{j}^{+1}\left(w_{2}^{n+1}+w_{2}^{n}\right)+v_{j}^{n+1}\left(w_{j+1}^{n+1}+w_{j+1}^{n}\right)
\end{aligned}
$$

The last, unsunged terms, may be termed $B T^{m}$. the boundary terms. Ont may def ine

$$
R^{n}=\Sigma\left(A_{j}\left(v_{j}^{n}\right)^{2}+B_{j}\left(u_{j}^{n}\right)^{2}+v_{j}^{n}\left(u_{j+1}^{n},-w_{j}^{n}\right)\right)
$$

and rearranging Eq̣n. (5.17) and substlituling into Eqn. (5.18), one has

$$
R^{n+1}=R^{n}+B T^{m} \text {. }
$$

As stabjlity problems at the boundary are usually of a different and allogether more tractable character than stability in the interior of 
the mesh. it will simply be assumed ihat $B T^{\text {n }}$ has no effect on stability. The boundary term may be set to zero for present purposes, and so

$$
R^{n+1}=R^{n}
$$

The quantity $R^{n}$ has a form appearing very much like that of the square of finite 12 norm, and in fact, it may be shown to define a norm equivalent to the Lie norm. which may be called the wave norm. Eqn. (5.19) proves stabilitg in the wave norm under conditions which will be explored forthwith. It sho.d be noted that nowhere were constant or Iinear coefficients assumed for the difference equations.

\section{The Nave Norm}

Let $Z$ represent a vector function with $t$ wo components $x_{\text {, }}$ and $y_{j}$ at each index $j$ tor $j=1 . \ldots J$; similarly. let $U$ be a function with components $v_{j}, w_{j}$. One may deline an inner product in the space of these functions :

$$
(Z . U)=\Sigma\left(A_{j} x_{j} y_{j}+B_{j} y_{j} w_{j}+\frac{l}{2}\left(x_{j} \Delta_{+} w_{j}+v_{j} \Delta_{+} y_{j}\right)\right)
$$

Here $\Delta_{+}$is the forward difference operator: $\Delta_{+} w_{j}=w_{j+1}-w_{j}$. The $A_{j}$ and $B_{j}$ are positive coeficients, and conditions will be imposed on them in order that Eqn. (5.20) in fact define an inner product. For Egn. (5.20) to qualify as an inner product. it is necessary that ${ }^{3}$

$(Z, U)=(U, Z)$

3 Herstein (1964), p. 152 . 


$$
\begin{aligned}
& (z, Z) \geq 0: \text { and }(z, z)=0 \text { iff } z=0 \\
& (a Z+b l, T)=a(Z, T)+b(U, T)
\end{aligned}
$$

Eqn. (5.21) is easily verified, and Eqn. (5.23) is deall with momenlarily. Eqn. (5.22) yields the familiar Courant conditious. For Eqn. (5.22) to hold, it is necessary that

$$
A_{1}>1, B_{j} \cdot 1
$$

Recalling the definition of $B$, one has

$$
\Delta_{j}=\frac{r_{j}^{-r} j-1}{c \Delta t} \times t
$$

and similar condition results from $A_{j}, t$. In order to prove the necessity of Eqn. (5.24) one may rewrite Eqn. (5.19). with HUHz $=$ $(U, U)$. as

$$
\begin{aligned}
& R^{n}=\|U\|_{-N}^{2}=\sum Q_{j}^{n} \\
& =\frac{1}{2} \sum\left\{\left(A_{j}\left(v_{j}^{n}\right)^{2}+\theta_{j}\left(w_{j}^{n}\right)^{2}-2 v_{j}^{n} w_{j}^{n}\right)\right. \\
& \left.\quad+\left(A_{j}\left(v_{j}^{n}\right)^{2}+B_{j+1}\left(w_{j+1}^{n}\right)^{2}+2 v w_{j+1}^{n}\right)\right\}
\end{aligned}
$$

The boundary term is different than in Eqn. (5.17) if one is to conslruct from Eqn. (5.25) the quantity $R^{n+1}-R^{n}=B T^{n}$. The squared norm Eqn. (5.25) was constructed rom Eqn. (5.18) by apportioning the terms $B_{j}\left(w_{j}^{n}\right)^{2}$ not all at zone $j$ in the summation, but hulf and half at zones $j$ and $j-1$. The two terms in Eqn. (5.25) under the stmmation sign are each positive definile, il the $A^{\prime}$ s and $B^{\prime} s$ are all greater than unity. Together, as indicated in Eqn. (5.25), they are denoted by $Q_{j}^{n}$. Eqn. 
(5.19) bounds $R^{n}=\|l n\|_{N}$, and this gives a bound on the individual quantities under the sum of Eqn. $(5,25)$ if those quantities are themselves all positive. Relaxumg Eqn. (5.24) not only means that $R^{n}=\|l\|_{N}$ no longer defines a norm, but that the quantities $v$ and $u$ may increase without bound, which is precisely instability.

To complete the proof that Eqn. $(5.20)$ defines an inner product. If in Eqn. (5.23), 7 is thr set of quastillies $(r, j, s)$, one has on writing out in full, and omilling the subseripl $j$.

$$
\begin{aligned}
(a Z+b U \cdot T)=\Sigma & (A(a x+b v) r+B(a y+b u y) s) \\
& \left.+\frac{1}{2} \sum(a x+b v) s_{+} s+r \Delta_{+}\left(a y+b u^{\prime}\right)\right)
\end{aligned}
$$

The first lerm is given by

$$
\sum a A x r+b A u r+a B y s+b B w s
$$

and the second by

$$
\frac{t}{2} \sum a x \Delta_{4} s+b v \Delta_{4} s+a r \Delta_{+} y+b r \Delta_{+} w
$$

Together, they are

$$
\begin{aligned}
& a \sum A x r+B y s+\frac{f}{2}\left(x \Delta_{+} s+r \Delta_{+} y\right) \\
& +b \sum A v r+B u s+\frac{1}{2}\left(v \Delta_{+} s+r \Delta_{+} w\right)
\end{aligned}
$$

or jus t

$$
a(Z . T)+b(U . T)
$$

proving Eqn. (5.239. One may now define the wave norm: 
To qualify as a norm. it must sat isfy

$$
\begin{aligned}
& \|a Z\| \leq|a|\|Z\| \\
& \|Z\| \geq c:\|Z\|=0 \text { iJ } Z Z=0 \\
& \|Z+U\| \leq\|Z\|+\|U\|
\end{aligned}
$$

Equation (5.28) tollows imnediately from Eqn. (5.23), Eqn. (5.29) in the some as (5.22), and Eqn. (5.30). The Iriangle Inqquality. Iollowy from the properties of inner products. The Le norm may be defined by

$$
\| Z H_{l_{2}}^{2}=\Sigma\left(A_{1} z_{3}^{2}+B, v_{3}^{2}\right)
$$

It remains to show under whet circumstances an araument in the wave norm implies the same conclusion in the La norm, for we have already proven stability in the wave norm. al Eqn. (5.19). Equivalence of these two norms requires the existence of positive constants ${ }^{*} K_{1}$ and $\kappa_{2}$ such that

$$
K_{1}\|Z\|_{L 2} \leq\|Z\|_{R N} \leq K_{Z} \|_{L Z}
$$

That such constants must syist may be seen from the positive def inileness condition. for, one may wrile.

$$
\|Z\|_{E N N}^{2}=\Sigma\left(A, x_{j}^{2}+\theta_{,} y_{j}^{2}+x, \Delta_{+}, y,\right)
$$

or

- Richtmyer Morton (1967), p. 31.

3 Maclane Birkhofl (1967) p. 392. If.

- Richtmyer Morton (1967). p. 57. 


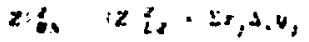

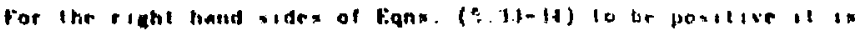
neressary ltwal

$$
\text { "zat, 15, s., }
$$

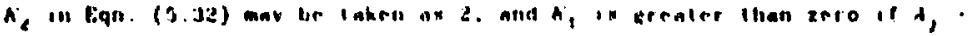

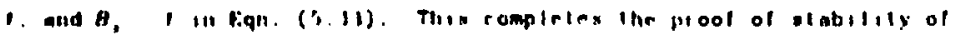

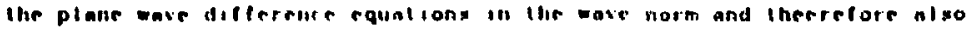
in the li2 norm.

\section{Cylandraral waven}

The case of cylindrical waser may be irduced to that of plane Deven. Fan. (5.2) anv br wition in tuil

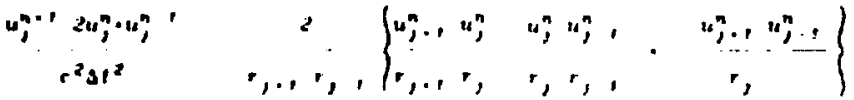

$$
\begin{aligned}
& 5 \quad 35
\end{aligned}
$$

To dral with the left hasd side lirst, one misy def ine

$$
\frac{r,\left(u_{j}^{n} u_{j}^{n}\right.}{r \Delta t}
$$

and write 


$$
a_{j}\left(v_{j}^{n+1}-v_{j}^{n}\right)=r_{1}\left(\frac{u_{j,+1}-u_{j}-r_{j}}{u_{j}-u_{j-1}}\right)+u_{j+1}-u_{j-1}
$$

with $A_{1}=\left(r_{1+1}-r_{1-1}\right) / 2 e d t$. a before. The right hand oide may be reerranged as

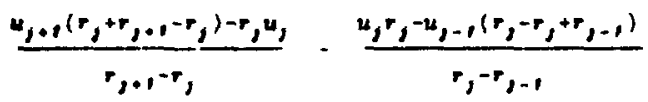

or.

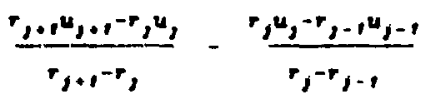

Definine

$$
\omega_{j}=\frac{r_{j} u_{j}^{n}-r_{j-1, u_{j-1}^{n}}}{r_{j-1}}
$$

the difference equation (5.35) way be writlen as

$$
A_{j}\left(v_{j}^{n+1}-v_{j}^{n}\right)=w_{j, 1}^{n}-w_{j}^{n}
$$

A first order difference equat un in w may be constructed.

$$
\theta_{j}\left(w_{j}^{n+1}-w_{j}^{n}\right)=v_{j}^{n+1}-v_{j}^{n+1}
$$

wilh $B_{j}=\left(r_{j}-r_{j},-1 / c \Delta t\right.$, as before. Eqns. (5.39) and $(5.40)$ are identical to Eqn. (5.18). although $w_{j}$ and $w_{j}$ have been defined a little differently for the cylindrical case. The detinilion of the wave norm. 
of course, proceds es before, and the courant condition on the timestep is obtained in the same way.

\section{Hydrodynumies}

Hydrodynemics may also he reduced to the plane ware treatment. One ablaius a wave norm based only oll the pressures, and we lacitly assume that instability wil always include instability of the preasures ${ }^{7}$, Thus, stability of the pressure equation is taken to imply glability of the entire system of equations. Only the plane case is considered here. as the other gcometries introduce nothing qualitatively new.

The difference equations may be exhibited:

$$
\begin{aligned}
& \underline{u^{n+1}-u^{n}}=\underline{P}^{P,-1^{-P},} \\
& \Delta t \quad m,+m,-1 \\
& x_{j}^{n+1}-x_{j}^{n}=u_{j}^{n+1} \Delta l \\
& v_{j}=\left(x_{j}^{n},-x^{n}\right), m,
\end{aligned}
$$

The rest of the equations wil only bear indirectly on what follows.

The quantities $x, u, r$, are the (Lagrangian) posttion, velocity, and specific volume. $P_{j}$ is the pressure, including the artificial

7 It must include instability of pressures: for the Lagrangian coordinates to diverge requires that the pressures vanish, by the equalion of state, but this is forbidden by the boundary conditions. For any other quant ity to diverge requires (again through the equation of state) that the pressures also diverge. 
viscosity. Eqn. (5.41) written at zolle, end agein al zone jet any be cowbined to cive

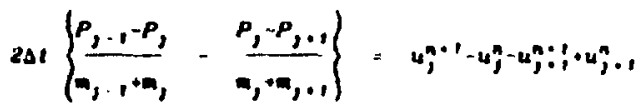

The aound speed $c$ may be defined by

$$
V^{2} d P=-c^{i} d V
$$

Here in the defin. an of the sound speed is where tipe elfect of difference equations in enercy and the equation of state for the presuure are telt. The volume change dV in Eqh. (5.43) is envisioned as

$$
m_{j}+m_{j}=\left(u_{j}^{n}: !-u_{j}^{n+1}\right) \Delta t / m,
$$

Cqns. (5.43) and (5.44) may be combined to give

$$
\begin{aligned}
u_{j-1}^{n+1}-u_{j}^{n+1} & =\frac{m_{,} v_{j}^{2}}{c^{2} \Delta l}\left(p_{j}^{n+1}-P_{j}^{n}\right) \\
u_{j+1}^{n}-u_{j}^{n} & =-\frac{m_{j} v_{j}^{2}}{c^{2} \Delta t}\left(p_{j}^{n}-p_{j}^{n-1}\right)
\end{aligned}
$$

These may be combined with Eqn. (5.44) to give

$$
2\left(\frac{P_{j+1}-P_{j}}{m_{j}+m_{j+1}}-\frac{P_{j}-P_{j-1}}{m_{j}+m_{j-1}}\right)=\frac{m_{j} V_{j}^{2}}{c^{2} \Delta t^{2}}\left(P_{j}^{\left.n+1-2 P_{j}^{n}+P_{j}^{n-1}\right)}\right.
$$

One may now define two quantities $y$, and $w_{j}$ by 
117

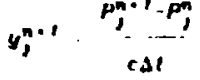

$$
\begin{aligned}
& w_{j}^{\prime \prime}=\frac{P^{n}-P^{n}, 1}{m,-1+m} .
\end{aligned}
$$

(5 49)

and reduce Sign. (5.46) 10 a pair of first order equal ions:

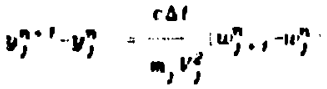

$$
\begin{aligned}
& 2 c \Delta t \\
& u_{j}^{n+'}-w_{j}^{n}=\ldots+\cdots,\left(y_{j}^{n+1} \cdot y_{j}^{n+1}\right)
\end{aligned}
$$

(5.50)

And with

$$
A_{j}^{\prime}=\frac{c \Delta t}{m_{,} v_{j}^{2}} \text {. and } B_{j}^{\prime}=\frac{2 c \Delta t}{m_{j}+m_{1}-1} \text {. }
$$

one has again exactly Eqn. (5.14), the plane wave equations proven stable above. 


\section{CHAPTER VI}

STABILITY AND CONVEACENCE:

IN THE: PRESENCE OF

THE MSTHOD OF INDEPENDENT TIMESTEPS

\section{Parabolic Equalions: Stebility}

The Iast two chapters provided stability analyses of parabolic had hyperbolir difference equations. While there are more common and intuitively imple techniques for slability analysis. Independent limesteps render these appronches a bit difficult and unconvincing. It was telt clearer 10 present the analyses of Chapters iV and $v$ for equat jons with a common timestep and to wast unt I now to show how the argument needa to be modified to accomodale individual timesteps. Parabolic equalions will have slability properties hardly different in the presence of independent timesteps. Hyperbolic equations will be a little more intricate. It is also necessary. if one wouid warrant a difference lechnique for general use, to say somelhing about ils truncation error. Which is to indicate its consistency with its 
differentini equation. Having ustablished roliststency and slability, there are far ious theorems which ensure rubvergence: 1... Ihat with refinement of the nash the ralculation gives a solution which which is not only linile (stability is no more ihan this) but which npproximatea the Irue answer.

In the common exp!ic:! tifferaue sclietne (Eqn. (4.10) or (4.27)).

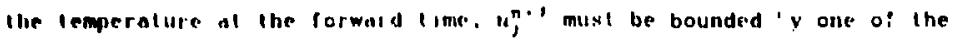

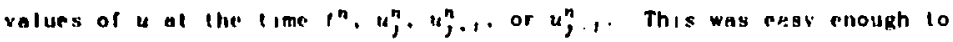
do. but suppose. as in FiR. (6.1), one of $u_{j+1}^{n}$ or $u_{j}^{n}$, was rol avallable at I ime $i^{n}$ and an estimate was supplind from earlier values:

$$
\begin{gathered}
u_{j}^{n+r} u_{j}^{n} u_{j}^{n+1} \cdot u_{j}^{n} \\
t^{n+1} \cdot t_{j}^{n} \\
\Delta: n
\end{gathered}
$$

with

$$
u_{j},=u_{j-1}^{n-1}+\left(t_{j}^{n}-t_{j-1}^{n-1} \frac{u_{j}^{n+1}-u_{j}^{r}-i}{t_{j-1}^{n-t}-t_{j-1}^{n-2}}\right.
$$

11 is, of course, easy to bound $u_{j}^{n, 1}$ by one of $u_{j}^{n}, u_{j+1}^{n}$, or $u_{j}, 1$, but how is one to bound $u_{j-,}$, the estimate of $u_{j-1}^{n}$ ?

The answer lies in looking at how $u_{j}^{n}$ was itself calculated, and how the time tj-; was selected for that calculation. It was then decided that zone $j-t$ could go unatlended for some length of lime $\Delta f^{n} 2$

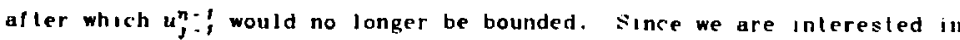
using the same process 10 get $u_{j-1}^{*}$ at $t$ ime $t^{n}$, the original constreint on $\Delta t j^{n-2}$ must be $t$ ightened. For the estimate of $(\partial x: \partial t)$ at $x_{j}$, and $t_{j-2}^{n-2}$ must now be safely usable as late as $t^{n}$. Now the limesteps in 
zones, and $j-1$ can differ by no more than a factor of two; this was demanded at Zqn. (3.56). If $\Delta t_{j}$ is longer than $\Delta t, \ldots$ zone $j-t$ will fall due before zone $j$, and there will be no need for an estimate $u_{j}, 1$. So, assuming that $\Delta t ;$, $\Delta t,-$, . 1 t must then be that $t$; falls no later than $t ; j-z$ a $2 \Delta i j-f$. And, In order to warrant $u ;-1$ al a time as late as $1^{n}$. it is suflicient th it the difference equetion be stable for a lime of duration $\Delta i_{j-2}^{n-2}+\Delta t_{j-1}^{n-1} \leq 3 \Delta t_{j}^{n-2}$ (by Eqn. (3. i)), In most situations. however. The timestep need nol be cul. If bol, the tirst and second line derivative of the lemperalure are positive, the temperalure eatimate lor neighboring zone will be low, by using an old value of the firat derivative, and inrrefor il will be safely bounded. If the second derivalive is negallve and the first positive, more caution is indicated. according to the rule just indicaled. If the first derivalive is negative. The timestep need not be cul, since the temperatures will always be sarely bounded.

Having thus prepared the calculations at zone, $y^{-1}$, it is now sale to use $u_{j-1}$ and the calculation at zone $j$ may proceed in complete assurance of stability. and. Therefore, the entire calculation is stable.

\section{Hydrodynamics: Stability}

There are many hyperbolic equalions, but the argument for stability here is intended specifically for thase of hydradynamss. The work in independent $t$ imesteps was all done with hydrodynamics and the situation there should be lypical. 


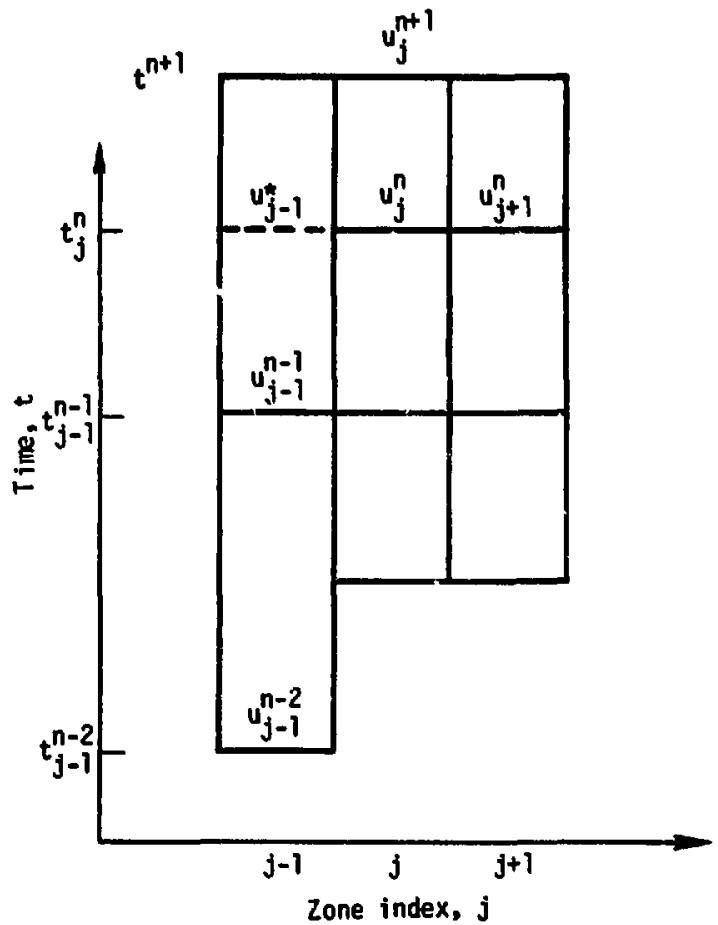

Fig. (6.1) An Estimate of a Neighboring Temperalure 
The reduction to pair of first order equations is slraightforward. along the lines of the argument of the last rhapter. In the requisite definitions the timesteps have been changed in order 10 yield the alsered difference equalions. The norm may be defined as before. Proving that il is bounded is no longer so simple, however. There is a theorem which slates that stable aystem of difference equalions can tolerate small perlurbalions and still remain stable; and Il may be seen that independent limesteps inlroduce just such a amall perturbetion.

The reduction to a pair of (irst order equations (eqn. (5.14)) may proceed as before if one now defines the quantities $y$ and $u$ by

$$
y_{j}^{n}=\frac{P_{j}^{n-P_{j}^{n-1}}}{c \Delta t_{j}^{n}} . \quad w_{j}^{n}=2 \frac{P_{j}^{n}-P_{j-1}^{n}}{m_{j}+m_{j}-1}
$$

and the coefficients $a$ and $b$ by

$$
A_{j}^{n}=\frac{2 m_{j} v_{j}^{2}}{\left.c\left(t^{n+1}-t\right)^{n-1}\right)} \quad B_{j}^{n}=\frac{m_{j}+m_{j+1}}{2 \cos \eta_{j}}
$$

The difference equet ions then become

$$
\begin{aligned}
& A_{j}^{n}\left(y_{j}^{n+1}-y_{j}^{n}\right)=w_{j+1}^{n}-w_{j}^{n} \\
& \theta_{j}^{n}\left(w_{j}^{n+1}-w_{j}^{n}\right)=y_{j}^{n+1}-y_{j}^{n+!}
\end{aligned}
$$

The timestep in the denominator of $A_{j}^{n}$ is chosen 10 rover the $t$ ime spanned by the two quanitities $y_{j}^{n+1}$ and $y_{j}^{n}$. 


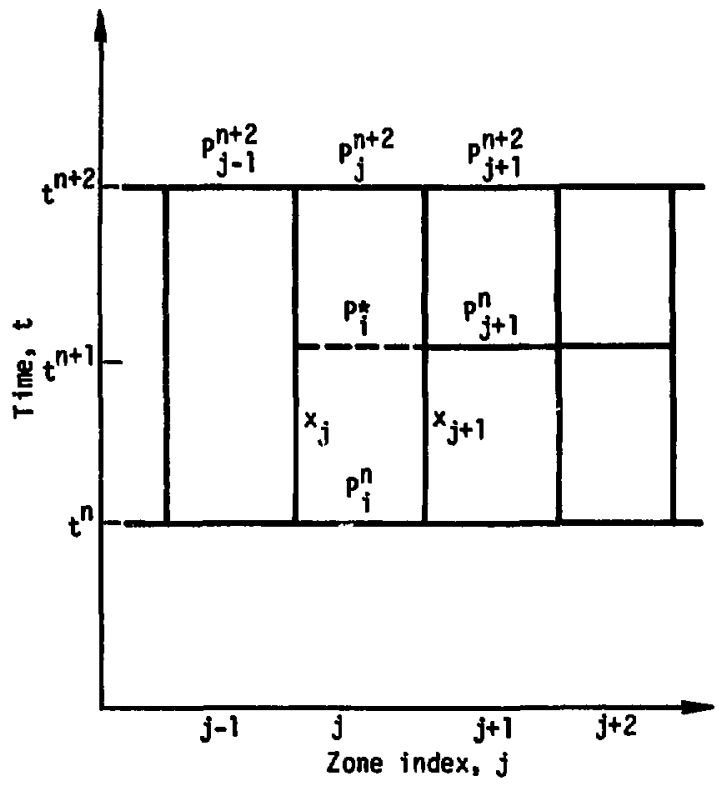

Fig. (6.2) A Mesh with Independent Timesteps 
The squared norm of the tunction $(y, u)$ may be defined exactly as in Eqn. (5.25).

$$
\begin{aligned}
& \|Z\|^{2}=\Sigma Q_{j}^{n}, \text { with } \\
& Q_{j}^{n}=\frac{l}{2}\left(A, y_{j}^{2}+B, u_{j}^{2}-2 y_{j} w_{j}\right)+\frac{l}{2}\left(A_{j} y_{j}^{2}+B_{j}, w_{j+1}^{2}+2 y_{j}, w_{j+1}\right)
\end{aligned}
$$

with the terma a. b. $y$, uh here defined for independent limesteps by Eqns. (6.3-4). In regions of a compulation mesh which have a rommon limestep. advancing the computation will not change $\Sigma Q_{y}$, and this is so in different regious regardless of the fact that they proceed with different $t$ imesteps. But where adjacent zones do not share a common timestep, it is not clear that what is taken trom one $Q_{j}$ is what is given 10 ils neighbor. $Q_{j-}$, . The mesh contemplated is illustrated in Fie. (6.2). At time $t^{n+1}$. The pressure $P_{j+1}^{n+1}$ is unavallable and is approximated by $P_{j}$. So. lollowing Eqns. (2.1-2.6), as $x_{j}+1$ is advanced Irom $t^{n+1}$ to $t^{n+2}$. the elfect shows up in the volumes $v_{j+1}^{n+2}$ and $v_{j}^{n+2}$, and Irom there by the energy equation and the pressure equation of state the change shows up in the pressures $P_{j+1}^{n+2}$ and $P_{j}^{n+2}$. The two pressures $P_{j}^{n+2}$ and $P_{j+1}^{n+2}$ contribute to the terms $Q_{j-1}^{n+2}, Q_{j}^{n+2}, Q_{j+1}^{n+2}, Q_{j+2}^{n+2}$ in the sum $8 Q_{k}^{n+2}$. for each term $Q_{k}^{n}$ in that sum depends on the four pressures $p_{k}^{n-1}$. $P_{k}^{n} . P_{k+1}^{n}, P_{k-1}^{n}$. through its dependence on $y_{k}^{n}, w_{k}^{n}$, and $w_{k+1}^{n}$. In the mesh illustrated in Fig. (6.2). there is no effect on $Q_{t}$ for $k j j-t$ or $k>j+2$. It is now necessary to estimale how serious is the plect on the terms $a_{j-1}, \ldots a_{j+2}$

There is a theorem of Kreiss and strang summarized by Richtmyer' which

1 Richlmyer Morton (1967), pp. 58-59. 
says in effect that a sufficiently small perturbation will not affect the stabilijty of an already slable difference scheme. If the difference system $u^{n+t}=C(\Delta t) u^{n}$ is stable, and if $C(\Delta t)$ is a bounded family al operators. then the systen $u^{n+1}=(C+\Delta t C) u^{n}$ is also stable. The aperator $C+\Delta l C$ depends through $C$ and $C$ on $\Delta t$, What is in effect said is that the perturbalion operator $\Delta l C$ must vanish as $\Delta f$ is refined. Then the operator

$$
(c(\Delta t / m)+(\Delta t / m) C(\Delta t / m))
$$

remains finite as $m$ tends to infinity, and it is llis operator which carries the runction $u^{n}$ forward to some $t$ ixed $t$ ime $t=m(\Delta t / m)$. (It is by the same principle that interest at a constant rate compounded ever more finely still only yields a finite return on investment.)

So, if the perturbation on the lerms $q_{j}^{n+2} \ldots \ldots, q_{j+2}^{n+2}$ can be shown to be of first or higher order in $\Delta t$, then the sum $\Sigma Q\left(t^{n+2}\right)$ will remain linite as the mesh is refined and $t$ ime $t^{n+2}$ is reached in ever more and ever briefer timesteps.

The argument is pretty much the same for each of the four $Q$ 's mentioned, and so only $Q_{j}^{n+2}$ will be examined in any detail. The perturbation on $Q_{j}^{n+2}$ will be found by repeated use of the chain rule for derivalives. Suppose, in Fig. (6.2), the pressure $P_{j}^{n+}$ uere available. The perturbation first appears as $d P=P_{j}^{*}-P_{j}^{n+1}$. Let this be denoted as $U_{j}^{n+1}$. or simply $d P$ if no indices are specified. It is required to 1 ind $d P_{j}^{\eta+2}$ and $d P_{j}^{\eta+2}$, and from these, the $d Q^{n+2}$. Following Eqns. $(2,1-3)$. one has 
126

$$
u_{j+1}^{n+2}-u_{j ! 1}^{n+!}=-2\left(r^{n+2}-(, n+1)\left(P_{j+1}^{n+1} \cdot P_{j}\right)\left(\left(m_{j}+m_{j+!}\right)\right.\right.
$$

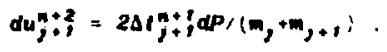

$$
d x_{z+1}^{n+2}=2\left(\Delta(j+1)^{2} d P /(m,+m,+1)\right.
$$

$$
\begin{aligned}
& d n_{j+1}=2 \frac{-\left(\Delta t_{j+1}^{n+1}\right)^{2} d p}{m_{j+1}\left(m_{j}+m_{j+1}\right)} \\
& d \eta_{j}+2=2 \frac{\left(\Delta(j+1)^{2} d p\right.}{m_{j}\left(m_{j}+m_{j, 1}\right)}
\end{aligned}
$$

(6. 10)

From the definition $-V^{2} d P=c^{2} d V$ of the sound speed $c$. wa may obtain the pressure perturbations at $t$ time $i^{n+2}$ :

$$
\begin{aligned}
d_{j+1}^{n+2} & =\frac{c^{2}\left(\Delta t_{j+j}^{n+j}\right)^{2} d p}{v_{j+1}^{2} m_{j+1}\left(m_{j}+m_{j+1}\right)} \\
d_{j+2}^{n+2} & =-\frac{c^{2}\left(\Delta t_{j+1}^{n+1}\right)^{2} d P}{v_{j}^{2} m_{j}\left(m_{j}+m_{j+1}\right)}
\end{aligned}
$$

These, together with Eau, (6.3) yield

$$
d y_{j}^{n+2}=\frac{-2 c\left(\Delta t j_{j+!}^{n}\right)^{2} d p}{v_{j}^{2} m_{j}\left(m_{j}+m_{j+l}\right)\left(t^{n+2}-t \eta_{j}^{n}\right)}
$$




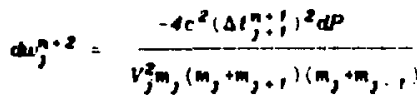

$$
\begin{aligned}
& d v_{z+1}^{n+2}=\frac{c^{2}(\Delta, j, 1)^{2} d p}{v_{j, 1}^{2}\left(m,(m,+m, \ldots)^{2}\right.}
\end{aligned}
$$

The expension of $d Q$; +2 may be written:

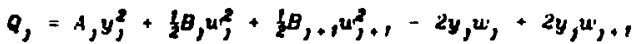

$$
\begin{aligned}
& d q_{2}^{n+2}=\left(2 A, y, d y, \cdot \theta_{1}, d w,+\theta, \ldots, w_{1}, d_{t}, \ldots\right. \\
& \left.2 y_{1} d w_{,}-2 w_{j} d y_{j}+2 y_{,} d u_{1}, \ldots \cdot 2 u_{j}, d y_{1}\right)
\end{aligned}
$$

The expansions of $d Q_{j}, \ldots d Q_{j+1}$. and $d Q_{j+2}$ are similar. To deal with the first of the seven terms of Eqn. (6.15):

$$
2 A_{j} y_{j} d y_{j}=\frac{-B\left(P_{j}^{n+2}-P_{j}^{n}\right)\left(\Delta t_{j+1}^{n+1}\right)^{2} d P}{\left(m_{j}+m_{j+1}\right)\left(\Delta t_{j}^{n}\right)^{2}\left(t^{n+2}-\left(\eta_{j}^{n-1}\right)\right.}
$$

This is of the same order as $d P$, for. $\left(\Delta l_{j+1}^{n+f}\right)^{2} /\left(\Delta l_{j}^{n}\right)^{2}=1 / 4$ : and $\left(P_{j}^{n+2}-P_{j}^{n}\right) /\left(t^{n+2}-t_{j}^{n-1}\right)$ is roughly constant as $\Delta t$ is reduced. This leaves dP. which may be shown of order $\Delta t$.

The timestep is set by a condition on the permissible change in pressure:

$$
P_{j}^{n+2}-P_{j}^{n} \leq P_{j}^{n}
$$

where $\varepsilon$ is some small number. Iypically 0.05 or less. Now $P_{j}^{*}$ and $P_{j}^{n+1}$ 
both will fall in the range of $\left(P_{j}^{n}, P_{j}^{n+2}\right)$, so their difference. $d^{P}$, will be limited by

$$
|P| \leq\left|P_{i}^{n+2}-P_{j}^{n}\right|=(\partial P / \partial t) \Delta t^{n} .
$$

proving that as $\Delta t$ is reduced, dP must vanish Hso. Thus, the first lerm of Eqn. (6.15) is of first order in $\Delta t$, and by similar arguments it may be verifled that the other lerms are all second or third arder in the timesteps. This completes the proof that the equations of hydrodynamics are stable in tie presence of indepelident timesteps.

\section{Parabolic Equalions: Truncation Error}

Having shown stability of asynchronous calculations. it is necessary that the finite equations do in fact approximate the differential equation over a period of one timestep. This is the property of consistency. Given these two properties, it is assured that the system of interest will yield answers converging to the true solution ${ }^{2}$. Analysis of consistency will indicale how the error at each timestep depends on the mesh size. This analysis is obtained by comparing the exact solution with the finite difference solution by means of the Taylor expansion of the exact solution.

In the case of the diffusion equation, one needs Taylor series for $u_{j}^{n+1} \cdot u_{j+1}^{n} \cdot u_{j-1}^{n}:$

2 Richtmyer Morton (1967), see for example p. 45. 


$$
\begin{aligned}
& u_{j}^{n+1}=u_{j}^{n}+\Delta t u_{l}+\frac{1}{2} \Delta t^{2} u_{11}+\frac{1}{6} \Delta t^{3} u_{111}+ \\
& u_{j+1}^{n}=u_{j}^{n}+\Delta x u_{2}+\frac{1}{2} \Delta x^{2} u_{2 x}+\frac{1}{6} \Delta x^{3} u_{x z 2}+(1 / 24) \Delta x^{4} u_{x x 2 x}+\underbrace{}_{(6.20)} \\
& u_{j-1}^{n}=u_{j}^{n}-\Delta x u_{2}+\frac{f}{2} \Delta x^{2} u_{22}-\frac{1}{6} \Delta x^{3} u_{2 x 2}+(1 ; 24) \Delta x^{4} u_{282 x}+\ldots(6.21)
\end{aligned}
$$

The error may be constructed:

$$
E-\frac{u_{j}^{n+t}-u_{j}^{n}}{\Delta t}=\frac{\sigma}{\Delta x^{2}}\left(u_{j+1}^{n},-2 u_{j}^{n}+u_{j-1}^{n}\right)-\left(u_{t}-\sigma u_{x x}\right)_{j}^{n}
$$

And substiluting Eqns (6.19-6.21) into Eqn. (6.22) gives

$$
E=\frac{t}{2} \Delta t u_{t}-(1,12) \Delta x^{2} o u_{x \leq x}+
$$

This will be modified somewhat in the presence of individual limesteps.

For $u_{j-1}^{n}$ in Eqn. (6.22) substitute

$$
u_{j-1}=u_{j-1}^{n-1}+\left(t_{j}^{n-t} t_{j-1}^{n-1}\right) \frac{u_{j-i}^{n-1}-u_{j-1}^{n-2}}{t_{j-i}^{n-1} t_{j-1}^{n-2}}
$$

\section{Def ining}

$$
R=\frac{t_{j}^{n}-t_{j-i}^{n-i}}{t_{j-i}^{n-i}-t_{j-i}^{n-2}}
$$

one has 


$$
\begin{aligned}
u_{j-1}^{*}= & (t+R)\left(u_{j}^{n}-\Delta x u_{x}-\Delta t u_{t}+\frac{1}{2} \Delta x^{2} u_{x z}\right. \\
& \left.+\frac{1}{2} \Delta t^{2} u_{1}-\frac{1}{3} \Delta t^{3} u_{31}-\frac{1}{6} \Delta x^{3} u_{3 x}+(t / 24) \Delta x^{2} u_{4 s}\right) \\
& -R\left(u_{j}^{n}-\Delta x u_{1}-2 \Delta t u_{t}+\frac{1}{2} \Delta x^{2} u_{2 x}+2 \Delta t^{2} u_{2}\right. \\
& -\left(\Delta t u_{3}^{3} u_{3}-\frac{1}{6} \Delta x^{3} u_{3 x}+(1 / 24) \Delta x^{4} u_{48}\right)
\end{aligned}
$$

By comparison with Eqn. (0.21) this may be reduced to

$$
\left.u_{j-1}=u_{j-1}^{n}+(R-1) \Delta t u_{1}+(\}-\frac{1}{2} R\right) \Delta t^{2} u_{1}+
$$

Substituting Eqn. (6.26) into Eqn. (6.22) in place of $4, \ldots, 1$, the new error $E^{\prime}$ is given by

$$
E^{*}=E+\frac{\sigma \Delta t}{\Delta x^{2}}(R-t) u_{1}+\Delta l\left(\frac{1}{2}-\frac{3}{2} R\right) \frac{\sigma \Delta l}{\Delta x^{2}} u_{l} t
$$

This equation indicales the additional error introduced where the timestep changes from one zone to the next. Where adjacent timesteps are the same. The error is given by Eqn. (6.23) as before. The quantity $u_{t} \Delta t$ is cenerally used to set the timestep (in the absence of stronger atability constraints) in order 10 control the error. With independent timesteps the contributions to the error are commensurate throughout the mesh. In Eqn. (6.27) the quantity $0 \Delta t / \Delta x^{2}$ is zero order in time, and so the most serious contribution to the er or is the term $\left(\Delta \Delta t / \Delta x^{2}\right)(R-1) u_{1}$.

Il should be noted that the error of Eqn. (6.23) or Eqn. (6.27) is the error not in $u_{j}^{n+1}$ itself but the difference between the differential equation and ils finite approximation: the error quoted is the error in the lirst derivative of $u$. And where adjacent limesteps differ, this 
error appears as an inconsistency with the differential equation. Although only conditionally consistent. salculation with independent limesleps yields answers within 1 to 3 percent of the same calculations with common timestep. So, the error of Eqn. (6.27) (and it is an occasional error. not a chronic one) evidently does not adversely aflert the results. The error in approximating the differential equation is (occasionally) of zero order in $\Delta t$. amounting to altering the value of o. The resultant error in $u_{j}^{n \cdot t}$ is roughly given by factors of order unity times $u, \Delta t$.

\section{Hydrodynamics: Truncalion Error}

The equations of hydrodynamics present consistency behavior essentially like that of parabolic equations. It is sufficient to examine the acceleration equation. As written, the pressures were referred to zones $j$ and $j-1$, since in FORTRAN, one has only integral indices of variables. But to be more precise. the pressure $P_{j}$ at the zone center should be called $P_{j}, 1_{2}$, and $P_{j}$, should be called $P_{j-1,2}$. and their Taylor series construcled accordingly. The error in the equation is

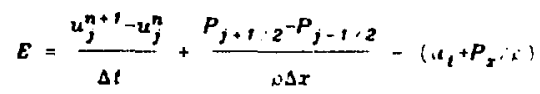

The Taylor expansions required are

$$
u_{j}^{n+t}=u_{j}^{n}+\Delta t u_{t}+\frac{t}{2} \Delta t^{3} u_{t \ell}+\frac{t}{6} \Delta t^{3} u_{l t l}+
$$




$$
P_{j+1: 2}=P_{j}^{n}+\frac{1}{2} \Delta x P_{2}+f \Delta x^{2} P_{s z}+(1 ; \Delta 8) \Delta x^{3} p_{3 x}+
$$

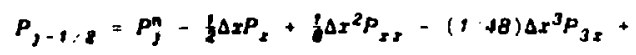

The error may be exhibiled:

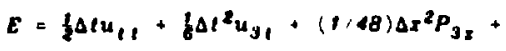

$A=$ betore, the quantily $P_{j-1,2}$ used in the absence of $P_{j-1,2}$ is given by

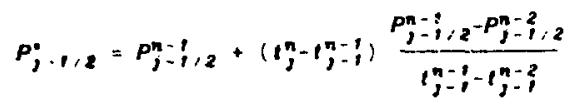

Its Taylor series is

$$
P_{j-1 / 2}^{*}=F_{j-1,2}^{n}+\left(\frac{t}{2}-\frac{R}{2} R\right) \Delta t^{2} P_{t 1}+\cdots
$$

The resulting altered error is

$$
E^{*}=E-\frac{(R-t) \Delta t}{\Delta x} P_{t}-\left(\frac{t}{2}-\frac{3}{2} R\right) \frac{\Delta t^{2}}{\mu \Delta x} P_{t}
$$

The same observations might be made here as applied to the casp of paraholic equations. The error is of zero order, occasionally, and usually of Iirst order in $\Delta t$. The remarks of Chapter $I I$ on the accuracy of hydrodynamics with independent limesteps should provide an index of their effect on the answers obtained. 


\section{CHAPTER VII}

COMPARATIVE ECONOMICS: TIMING TRIALS

\section{Time Trials in One Dimension: Hydrodynamics}

As this work has progressed there has been a continuing interest in t iming comparisons between asynchronous and synchronous methods. whatever the synchronous difference techniques appropriate to that problem were. The early results were encouraging, albeit barely so. Ail of the time trials used very simple test problems; this is the conservalive way to test the method, inasmuch as more complex problems may be expected to show the melhod of independent limesteps in a much betler light. Such problems are common in real applications, and there it should not be out of the ordinary for a very few rones to want timesteps much briefer than the rest of the mesh. The present liming trials are unrealistically conservative in two other respects as well. Nowhere have real world properties of matler been approximated, and as physical equations of state are computalionally expensive to handle. independent timesteps should yield proportionalely larger savings. Instead, a perfect gas equation of state and simple analytir. heat 
conductivities have been assumed. Also nowhele have advantages been laker of hand coding the management of independent timestep logic: in particular. there ore last search routines which could searcil a mesil for zones due for updaiing (Equ. (3,7)). Equ. (3.7) was everywhere coded in rORTRAN, and in the hydrotymamic work, very inefficiently.

In tact the hydrodynamis timo trials in one dimension yielded results consistently but barely iaster than conventional explicit yon Neumann difference p untions. A factor of two or be ier was occasionalt:' seen, but $50 \%$ speed increuses were often only to be hoped for. And looking at the FORTRAN in question, one may be amazed that unoipendent timesteps ever did as ivell as conventiona" methods. For seeminely ot every opportunity. The entire mesh was searched (afler a subroutine jump!), and operalions which could have been combined in one loop were apportioned among severa!. Ior ease in debugging.

Still, it is fair to describe the exper.ance with one dimensional hydrodynamics. A shock problem of $8 !$ zones and three regions was computed. The shock is reated by a constant over-pressire at one boundary. while the other boundary is held lixed in position. The dimensionless shock strength varied from to to $10^{5}$. and the shock impinges itrst on a region of density 2 g/ce. then a thin region of den-tay $20 \mathrm{~g} / \mathrm{cc}$, and then into a region of density $0.001 \mathrm{~g} / \mathrm{cc}$. aftording a siluation with severa! shock reflections. The t iming results were prelty much the same regirdless of shock strength. In one such problem. independent timestups crmpleted the lask in 0.307 mimules. and the corventional method in: $31: 3$; in another the comparison Has 0.386 minutes (independent timesteps) and 0.428 (comventional), de difference 
of about 10\%. Times of 8.53 and 10.36 mimules were observed in a simpler problem (1wo regions, comparab!e densities). A time difference of $15 \%$. The chief reason why independent limesteps took so loug is that the FORTRAN coding of the control logic was so fearsomely inefficient. These compartsons were made on a CDC 0600 . That the method of independent limesleps did so well under such burdensore rifrumslances motivaled more aludy and development of the technique.

\section{Time Trials in One Dimension: Dilfusion}

In preparalion for two dimensional diffusion trials. The one dimensional diffusion equations were differenced and tested with independent limesteps. The liming results were quite tavorable. yielding comparisons of a tactor of 3 tu 5 quile routinely on very conservative test problems. The equation to be integrated was discussed at Eqns. (4,2-4,3). The boundary conditions represented a bar heated at one end, and the problems were lerminaled only when nearly in temperalure equilibrium. Forty zones were used and the diffusion coefficient was laken as having the form $a=A u^{m}$. This represents the minimum of realism necessary to use independent IImesteps at all. If a constant diffusion coefficient is used, the timesteps will be comensurate in all zones, and an implicit codp will always run faster. but if the exponent in the diffusion coefficient is taken as low as 1 . the situatuion is altogether reversed. In all calculations, the timestep was governed by the requirement that $\Delta u$ u be less than $s$, with $z=0.01$ to $\varepsilon=0.05$. In the independent timestep rode. Which is explicit. the timestep is limited also be the courint condition. With it 
conductivily proportitional to the temperalure. the temperature profile resembles that of a shock, as in Fig. $(7,1)$. Ahead of the thermal wave the conductivity is small and behind it very large, resulting in near equilibrium behind the Iront, In these calrulations, equ. (3.6), the restriction on disparity of neighboring limesteps, whs enforced at every cycle over the whole mesh. The briefest timestep is in the growing edge of the warmed region, al about zone 22 in Fig. (7.1), and the limesteps on either side of this zone may be seen to imrease by a factor of two par zone. The lemperatures and limesteps plotted in Fig. (7.1) are laken Irom data at cycle 373 I of a computation with diffusion coefficient given by $\alpha=10^{-12} u^{3}$, and $\Delta u / u \leq 0.05$.

The calculations were lerminated when a fixed amount of heat has diffused into the problem across the hot boundary. The stop lime is therelore somewhat variable. depending on the accuracy demanded, and its convergence may taken as measure of that accuracy. The results of the time trials are summarised in Table $(7,1)$. The first column identifies the code: MITS. The Method of Indenendent Timesteps, IMFD, IMplicit Forward Differences, or EXBD. EXplicil Backward Differences. The second column is the time in seconds required for the calculation as monitored b; the system liming routine TICHEK. The third and fourth columns are the cycle number and physical time at the end of compulation. When the heal source has warmed almost all of the problem. The column labelled Au'u identifies the maximum permissible change per cycle in any lemperature. It will be seen that $\Delta u ; u$ and the ending cycle number vary more or less inversely as one another. The last column indicates ror the Mits code the ratio of the number of zone-cycles it would have computed if it never skipped calculations, to the number of zone-cycles 
actually calculaled. Il may be seen that a more siringent au/u control requires that MITs calculate some zones more often, but not all. It may also be seen that the implicit code required a tighter $\Delta u / u$ control and briefer timesteps to approach its limiting value of the stop time. The trials are presented in three groups, for the diffusion coefficients of $10^{-12} u^{3}, u$, and $10^{12}$ reapectively. In the lirst group, with $\sigma=10^{-12} u^{3}$. It may be seen that all three codes eventually converged to a Elop time of 8.084 to $8.101 \times 10^{-4}$ ser, a range of $0.2 \%$. At $7.82 \times 10^{-4}$ sec. The Initial guess by IMFD (with $\Delta u / u=.05$ ) is bad by about 37 . This raises the question of whlch run time. $65 . ? \sec (w i t / 1 \Delta u / u=.05)$ or $155.6 \mathrm{sec}$ (with $\Delta u / u=.01)$ should be used for IMFD. The ratio of run times. IMFD/MITS, is 7.13 or 3.01 depending on which value one preferra. In the second group of Irials, os in the first, the timestep must be briefer for the implicit code to yield accuracy comparable to the explicit results. The run lime ratio may be estimated at 4.0 to 8.5. In the last group. with the diffusion coefficient a constant independent of $u$, IMFD runs about Iwice as fast as the MITS or EXBD codes, as expecled. Two conclusions may be drawn from this experience. First. as hoped, even on very conservative test problems, independent timesteps run signilicantly laster than implicit methods. Secondly, it is possible to demand fine accuracy of MITS in a few crucial zones withoul bogeing down the whole problem in needlessly precise calculations. 
Table (7.1) Time Trials in One Dimension: Diffusion Diffusion Coefficient $=10^{-12} u^{3}$

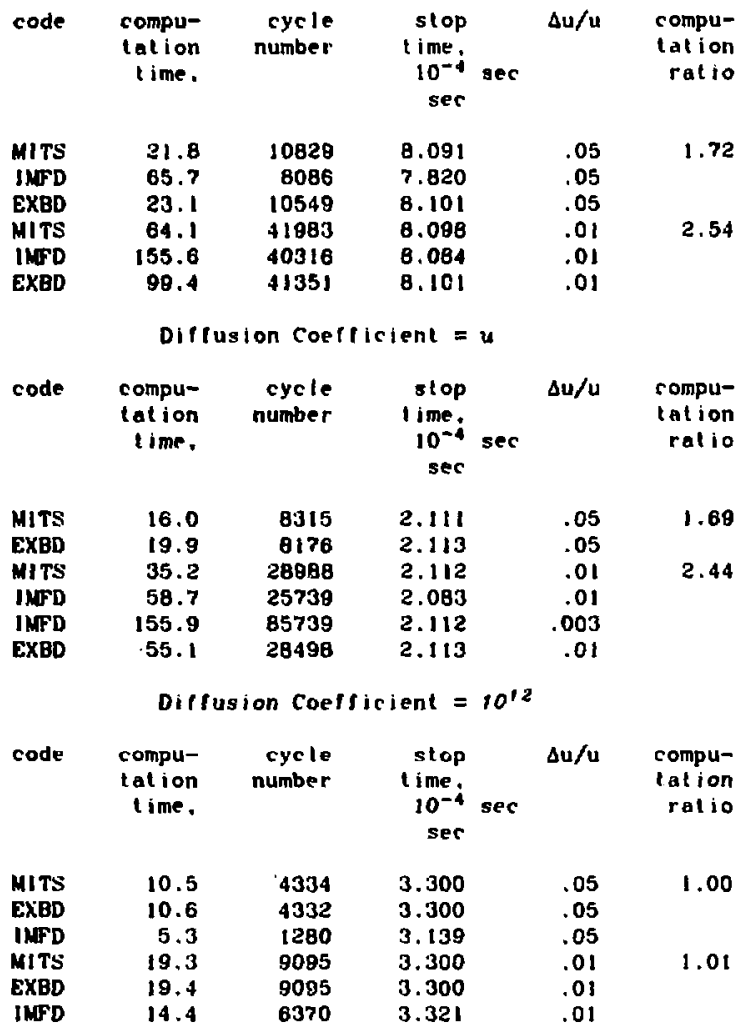




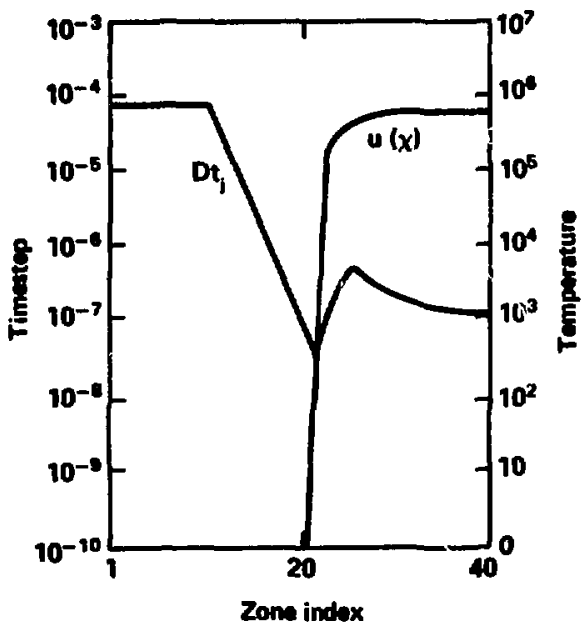

Fig. (7.1) A One Dimensional Heat Diffusion Problem 


\section{Time Triuls in Two Dimensions}

The experience in two dimensional calculations of heat diffusion problems confirms and extends the conclusious drawn from one dimensional nork. There were very lew peculiarities of two dimensions which required different handling than in one dimphsion, and these werp treated in chapler 111 . It was remarked there that carsfut coding of Eqn. (3.6). the restriction on neighboring timesteps, affords a savings of up to $50 \%$ in running lime, clearly well worth while.

As in the one dimensional calculations. The two dimpnsional itme trials were made with conservative lest problems, somp of which do not have much two dimensional structure. The results are a factor of threp to ten observed in running speed between the 20 MITs and the ADI codes. The equalions integrated were discussed at Eqns. (3.24-3.25), and independent limesteps we implemented as discussed in the beginning of chapter 111. Eqns. (3,1-3.7), and at Eqns. (4.2-4.3). The diflusion coefficient is laken as variable, again of the form $a$ : tum.

The problem of chapter Ill may be summarized. The diffusion coefficient wos $\sigma=6 \times 10^{-16} u^{4}$. the mesh was $30 \times 30$ zones square, and auiu 5.05 . The problems were all stopped at $t=5.263 \times 10^{-5} \mathrm{sec}$. and the running $t$ imes are as follows: 
Table (7.2) Timing in the Problem of Chapter III

$\begin{array}{rrr} & \text { cycle } & \text { lime } \\ \text { MITS } & 3357 & 34.85 \\ \text { ADI } & 3596 & 268.62 \\ \text { EXBD } & 3454 & 107.45\end{array}$

The computalion ratio for Muts was 27: and the :atio o: running times is 7.7. This problem was not run very far towards equilibrium, as Figs. (3.6-3.6) show.

Two problems were run which are very similar to the one dimengional tests. one with $\sigma=10^{-12} u^{3}$ and one with $\sigma=u$. The heat is supplied at the corner of the mesh. which is $16 \times 16$ zones. The inilial lemperatures are $1^{\circ}$ and the source is at $10^{60}$. The tirst problem, with $a=u$, may be summarized at two times, roughly $1.5 \times 10^{-4} \mathrm{sec}$ and $6.6 \times 10^{-4} \mathrm{sec}$ :

Table (7.3) Two Dimensional Timing Comparisons

$\begin{array}{rlrr}\text { code } & \begin{array}{l}\text { lime } \\ 10^{-4}\end{array} \text { sec } & & \begin{array}{c}\text { run lime } \\ \text { sec }\end{array} \\ \text { MITS } & 1.68 & 3003 & 10.96 \\ \text { ADI } & 1.51 & 2905 & 62.88 \\ & & & \\ \text { MITS } & 6.68 & 5681 & 26.60 \\ \text { ADI } & 6.52 & 3723 & 80.51\end{array}$

The ratios of run times are about 6 and 3 . These latter numbers are taken as the problem reaches equilibrium. The temperature distributions plotled by Mits at cycle 3003 is shown in Fig. (7.2). 


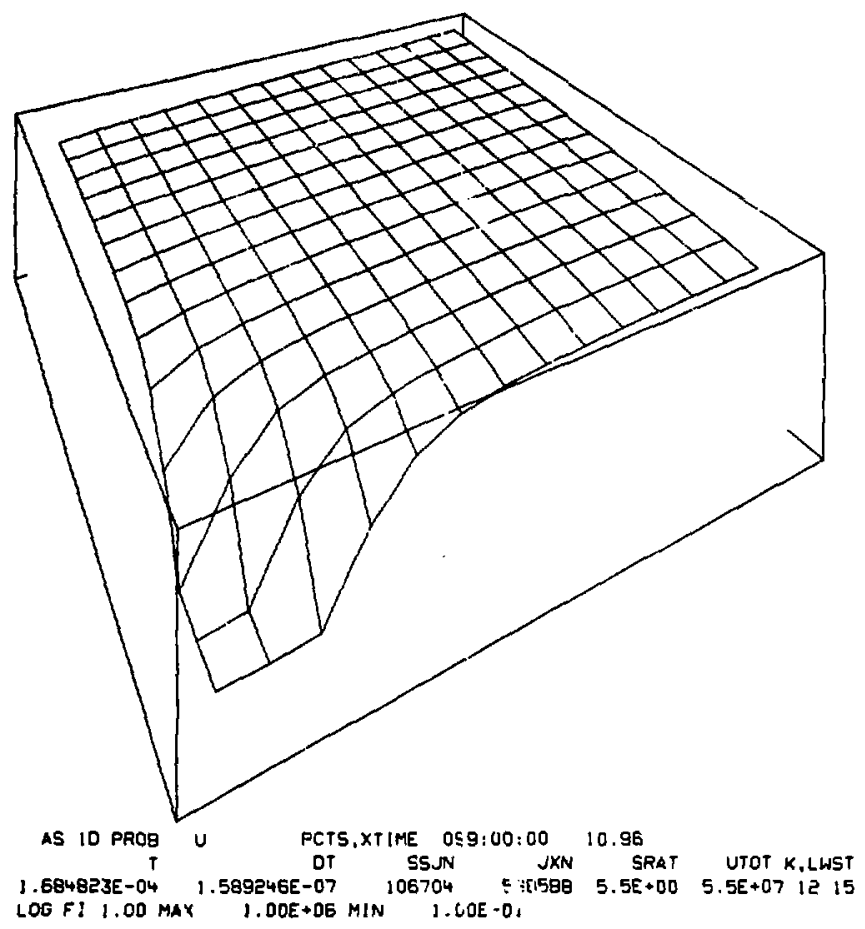

Fig. (7.2) A Two Dimensional Heal Diffusion Problem. 

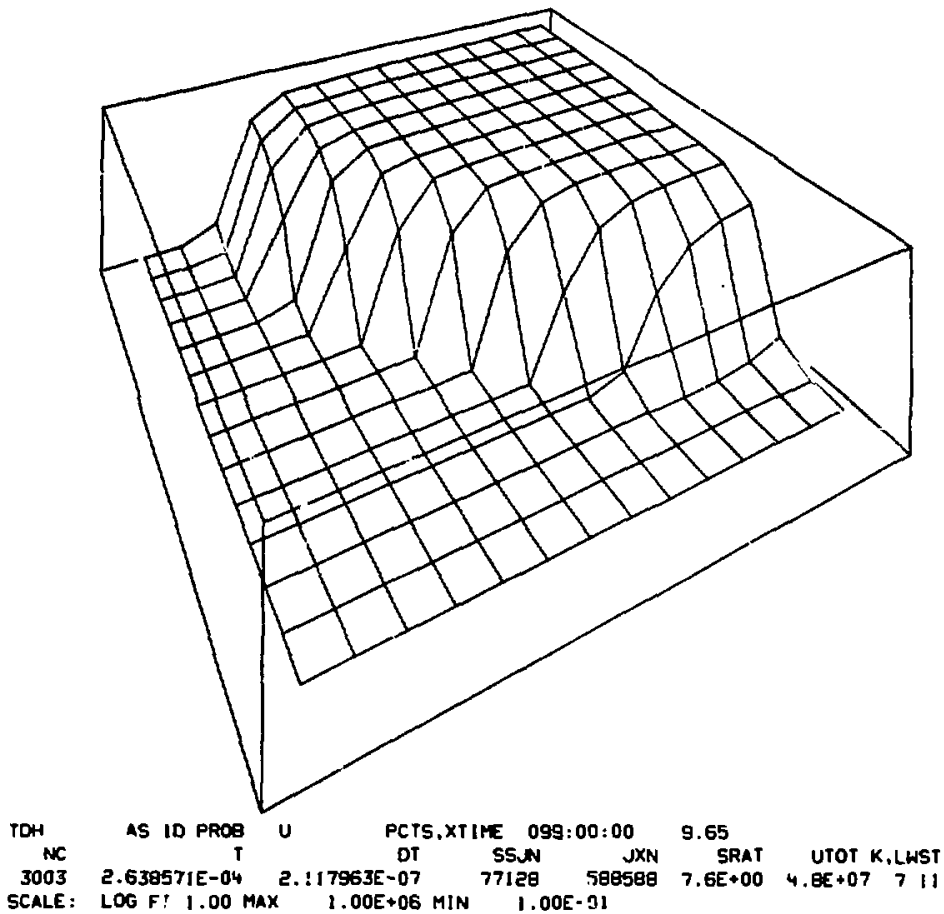

Fig. (7.3) A Two Dimensional Heat Diffusion Problem. 
The problem with $k=10^{-12} u^{3}$ and $s u ' u=.05$ produced resules which may be quoled at three successive limes close to equilibrium:

Table (7.4) Two Dimensional Tining Comparisons

\begin{tabular}{|c|c|c|c|c|}
\hline cods. & $\begin{array}{r}\text { time } \\
10^{-4} \\
\text { sec }\end{array}$ & $\begin{array}{c}\text { rompu- } \\
\text { lation } \\
\text { time } \\
\text { ser }\end{array}$ & cycle & $\begin{array}{l}\text { compu- } \\
\text { lation } \\
\text { ratio }\end{array}$ \\
\hline $\begin{array}{r}\text { MITS } \\
\text { ADI }\end{array}$ & $\begin{array}{l}2.6 \\
2.5\end{array}$ & $\begin{array}{r}9.61 \\
64.87\end{array}$ & $\begin{array}{l}3003 \\
3003\end{array}$ & 7.6 \\
\hline $\begin{array}{r}\text { MITS } \\
\text { ADI }\end{array}$ & $\begin{array}{l}7.6 \\
6.4\end{array}$ & $\begin{array}{l}21.06 \\
101.8\end{array}$ & $\begin{array}{l}5171 \\
4716\end{array}$ & 4.5 \\
\hline $\begin{array}{r}\text { MITs } \\
\text { ADI }\end{array}$ & $\begin{array}{l}12.6 \\
11.0\end{array}$ & $\begin{array}{l}32.38 \\
124.2\end{array}$ & $\begin{array}{l}7168 \\
5749\end{array}$ & 37 \\
\hline
\end{tabular}

The ratio of run limes starts at about 8 and degrades 10 about 4 as equilibrium is approached more closely. This latter situation corresponds to a substantially isothermal problem, in which the effective thermal conductivily is everywhere aboul the same. We have seen previously that implicit equalions are strongly preferred over explicil methods in such circumstances. but that such circumstances are cenerally of very little interest. The first comparison. at about $2.5 \times 10^{-4}$ sec, Is about halt way to equilibrium; the last two temperature distributions are essentially similar to Fig. (7.3). The agreement between MITs and ADI at cycle 300:3, corrected for being at slightly different limes, is about $1 \%$. These trials seem to be typical of the experience to date in two dimensions. 


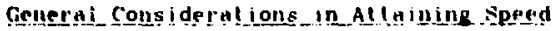

For each difference technique there are particular aspects of the programing which reguige special care. As in lorward diflerenced work. the solution of the implicil equalions requires ils own handing. So also in explicil equations with independent i imestops, the machinery of independent limesteps requires special allention. It is of course not lor this that a code enrns ils pay: that concs fron doung phystes. And the explicit physics is prelty much the same with or without independent limesteps. The lime spent by the code may roughty be apportioned between logis and physics: the logic manages the difference equations which do the physics. In conventional explicit codes that logic is talrly simple and 11 is diredly proportional to the amount of physics done. With independent timesteps, the logic required is a little more intricate. comprising the coding of Eqns. (3.3-3.7). Here the logic is somewhat more than proportional to the physics. The sucress of independent limesteps depends wholly on discharging its logical duties with a minimum of effort. Comparisons of concentiont explicit and explicil-wilh-independent 1 Imesteps rodes always indicale that a significanl portion of the lume gained by not dolng physics is lost 10 the extra logic required. Grevious as that loss may be, the results of the timing trials incicate that independent limesteps slll] ruu three to eight times as fast as the best consentional codes on conservalive test problens. Much greater gains are to be expected from codes embody'the the method of independent timesteps which are tiahtly coded for production. rather than research ptirposes, and which treat correspondingly more coinplex physics. 
A compllation may be described for ecomomis purposes by lour ntimbers. How many sycles $(N)$ did il run? How inany $t$ imes ( $L$ ) did it do major prinloul? How many zones $(J)$ does it have? And how many zone-cycles (SEJN) of physies did it do? Nornally in a synchronous explicit rode, $S S J N=J X N$. Here SWJN, JMN, by a factor commonly of 5 10 20. The limr spent in romputations is proportiont in parl lo al! of these parameters:

$$
l=a+2 S S J N+4 J N N+r E+n N
$$

For different codes, the coefficients a, z, k, r, n may vary. For a coiventional synchronous code, $t$ may be taken as zero and the $\$ S J N$ and JN terms combined. ludependent timesteps seek 10 minimize SSJN with respect to JXN. And so to lake full advantage of this, one mist minimize 4 with respect to 2 . \$till, there is a minimum of work that mist be done at every zone for every cycle. Equalion (3.7) is in this calegory. and its coding significantly affects the size of the coefficient $t$. Equations (3.4-3.5), the normal timestep control, need be done only with the physics. and so contribute to the coefficient $z$ Equation (3.6). as remarked in chapler ll1. tiay be roded in a varlety of ways. In all the one dimensional york. It was enforced over lte whole mesh at every cycle, and so contributes to the coefficient $x$. In the two dimensional codes. It was done morc carefully and 1 contributes roughly 10 z: 11 was enforced only as oflen as a timestep was retually used. which is 10 say only as often as the zone was updated. Equat ion (3.3). the interpolations necessary to supply wanlini adjacent quantities, are done somewhat less often than every zone-cycle. but may be taken as nevertheless contributinu to $z$. The coufticient a 
represents that ovelhead whica one must pay to run a problean at all: initialization, and so forth. It was generally considered to be negligible. The time spent in $1 / 0$ also was neglecled, as suppressing All output allects the run times imperceptibly.

There are many coding elfects which contribule to $k$, namely, all those things which must be done for every zone every cycle. The simple mechanics of cycling a FORTRAN DO loop through the mesh contributes noticeably $10 k$. Il paid $20 \%$ or so to combine loops in the two dimensional wolk in order 10 minimize this effecl. It may be noled that in the method of Grandey. the entire mest must be scarched every zone cycle in order 10 find the next zon: to bs updated, and one suspects that this requirement may contribute oeriously to $k$. In the present work. as long as several zones fall due at onct this problem should not be too severe. It is for this reason in addition to those of chapter I that the present work sought a method different trom that of Grandey.

The liming experienre of the previous sections may be analysed in the I Ight oi Eqn. (7.1). The limiting value of speed advanlage over conventional explicil codes is JXN SSJN. the compulation ratio. The advantage is somewhat less over implicit calculations, since these are permitted longer timesteps, in the work reported the speed advantage is generally a factor of two or so down from the maximum, JAN/SSJN. There are several reasons for this. First, as noted. the logic peculiar to MITS was never hand coded in machine language; and secondly. there were olten unnecessary loops over the whole mesh. 
The FORTRAN in the two dimensional work whs douse fairly carefully. and it may be seen from Table (7.4) lhat at cycle 3003 the ratio of run limes is about 7.1. almost equal to SRFT, 7.6. But the real difference between these lest problems and practical problems is in the complexity of the physics. For the z coefficient in Eqn. (7.1) Null always be greater for a MITs than for a syuchronous code, and preater by the amount of logie dame. But if the contribution of the physirs to $z$ is Itse!f very great, this will be negligible alfect. One hears' that steck hydrodynamic calculations call spend $30 \%$ to $40 \%$ of their time in equation of state routines alone, in spite of great calp Iavished on efficient coding of those rostines. to name only one aspect of calculations with real properties of matter. Applied lo real world problems instend of research tests. the method of independent timesteps should be expected to yield substantially greater computation savings than have been seen above.

I Zimmerman, private communscation. 
CHAPTER VIII

CONCLUSIONS

\section{In sunnary}

The method of independent timesteps has been presented in ils conceplion and motivalion. in the context of related work. and in the details of implementation in several Iinite difference schemes. In order to maintain a well posed problem as the computatiol. proceeds, a differenl approach was taken from the work of Grandey. The present work maintains a Couchy surface everywhere prochronic 10 the crisis zones of the problem. General specifications lor independent timesteps were presented logether with details of specific instonces in particular finite difierence schemes.

In order to prove stability, asynchronous techniques require resources somewhat different from those adequate for conventional synchronous difterence methods, and those arguments were exhibited as applied to both synchronous and wsynchronous computations. The expected speed advantage was indeed observed, and oven on very conservat jue test 
problems. The accuracy was not degraded materially by indepentent limesteps. The consideralions pertinent to the liming cconomien were indicaled. The method of independent limesteps was tested on a sample of equations of a vast class, but it is believed that with the examples lested. (rom boll. parabolic and liyperbolic problems. this sampling is representative. And the sample of equations tested with independent limesteps may be small compared to the whole field of initial value problems, but il is nevertheless targe enough so that il may be said with confidence that the successes observed were not accidental or peculiar but typical of all shock hydrodynanics problems with stiffly nonlinear equations.

\section{Implicalions}

In chapter 1, an inlerest was announced in a very limiled portion of the even broader class of all inilial value problem.. This limiled subsel is shock hydrodynamics, broadly construed. It is fair to note that even this is a broad area. and in the years since the first modern digital conputers, a tremendous oral and written tradition has grown up in this work. There ore many computational lochniques, and many physical affects must be trealed meticulousiy if one is 10 model high temperature shocks. Ior example.

Indeed. the development of larke and fast digital computers may be credited to the need for practical solutions to problems in shock hydrodynamics. As much can also be said for the theoretical toundation work in numerical solution of partlal differential equalions with lime 
as one independent variable. The effort expended on thickind of problem is still great. and large new machines are still buill with the prime design consideration being fast simulation of shock hydrodynamica problems. So anmerical technique which affords proven speed advantagey of a lactor of three to eight and substantially greater promised advanlages $i$; of no meall significance. It is also philosophically significant. In that it conslitules the comencement of doing for the logle of computation what digilal romputer have done for compulation ltself: creatly speeding up what humans do, but without loss of quality in how humans do it.

The history of numerical computation in differential equations since 1945 has been a steady progression of ever more complex problems treated in ever more detail. It a problem of one hundred zones colld be trealed before. ten thousand can be handled now. If some property of malter had to be idealised before. and evoluated with no more than a handful of arithmelic operations, now one can afford painslaking care in estimating properties of matter. And as it was pointed out in chapter VIl. the more complex the physics of interest, the more suitable the problem is te independent limesteps. The logic required for this method should not in principle become more onerous as the physics is treated more accurately.

As in all endeavors, to get something. One must pay something. Here the price of speed is paid in memary requirements, as illustrated in chapter 11. But at the present state of the art of digital hardware design. memory is beconing more plentiful much faster than is compuling speed. There is a price paid in accuracy alsc. but as remarked in chapters II. VI, and VII, accuracy is not greatly affected by 
independent 1 imesteps. The cost in menory requirenienls is nol 100 greal: in hydrodynumics it was of the order of $50 \%$ addizional, and will be relatively less in more complex problems.

The present work is only a beginning in a new ared of computational hydrodynamics, and some idea may be sketched of the imnediate work yet to be done. It is with some regret that the case of spherical waves could not be included in the stability arguments of chapter $v$. for the sake of the current research in supernova dynamics. No wave norm is known to me and the problem has resisted efforts to devise ond. The method of independent timesteps has so far been tested only on small problems for research purposes. not yet on real problems for practical molives. Two dimensional Lagrangian hydrodynamics is yet to be tested, as is Eulerian hydrodynamics. The method seems suilable lor generalization in parabolic problems to any number of dependent or independent variables. with no qualifatively new behavior anlicipated.

The initial motivation for this work was simply to instruct the modern digital compuler how to operale more like a human. who does nol add or multiply very quickly but does his arithmelic selectively and to great advantage. Now, It may be said that the machine's strenglh is arithmelic, and il should be used as a dumb adding machine. laking maximum advanfage of its strengths. The logical capacities of modern digital computers are also greal, however, and very little used by compulational physicists. If has been noled above that at presenl. computer speed is not increasing nearly as quickly as people would like il to, and so al 50 multiplies per microsecond. even compulers can be frustratingly slow in theis arjthmetic. The philosophy of independent limesteps will someday prove crudely simple. but now it is quile 
umusuhl. That philasophy may fairly be slated as "skip calculations where you can". and the work here outlined merely indicates how to do so. which is to sny, how to tell "when and where you can". It is still a very loral upproach to problems, enploying none of the global perspective that affords the human calculator (one might more nppropriately call him an estimator!) his advantages of apeed for the amount of arithmetic be does. The human will first crudely solve the whole problem and then refine his estimate: there has ns yet been no way In model independent limesteps on Ihis virtue of himan caleulation. When confronted with a new problem and a computer to solve it with, there is always the templation to treat it with as little thought and as much compulation as possible. If a problem is to be solved only once. this may be cheaper in human efforl, yielding an arceptable answer quickly. But if one is faced with n whole class of problems, then it behoves one to spend a little more time thinking. since even compulers still only run al finile speeds. One is always faced with the choice between thinking or computing, and there are usually ample rewards for choosing the rormer. The method of independent timesteps is a first effort in leaching the computer also to take this attitude. 
REFERENCES

Aarselli, s. J. (1967) On a Coltisiontess Hethod in Sifllar Dymamirs. 1 Bulletin Astronomique, $3^{r}$ serie. Tome 11, p, 47.

Aarselh, s. J. (1908) Dynmirat Evolution of Simulaled N-Body Syslems. Bulletin Astronomique, 3e serie. Tome lll, p. 105.

Aarseth. S. J. (1970) Psrlurbation Tratment of Close Binaries in the N-Body Problem.

Astronomy Astrophysics $\underline{9}$. P. 64.

larseth, S. J. (1971) Momertcal Experiments on the N-Body Problem. Astrophysirs and Space Science, 14, p. 20.

Aarseth. S. J. Dircct Integration Methods of the N-Body Problem. Astrophysies and Space Srience 14, p. 118

Acton. F. S. (1970) Nemerical Melhods that Work Harper \& Row, New York. 1970.

Allen. C. W. (1973) Astrophysical Quentities Athlone Press. London (1973)

Boole. G. (1872) A Treatise on the Calculus of Finilc Differences Reprinled. Dover Publications. New York (1960).

Chevalier, R. A. (1976). The Elolution of Supremava Remants. III. Thermal Waves Astrophysical Journal, 198, p. 355.

Coleate. S., White, R. H. (1966) The Hydrodynamir Behavior of Supernova Explosions. Astrophysical Journal 14! (1966) 626.

Courant. R.. Friedrichs. K. O.. l.ewy, H. (1928) on The Parlint Differential Equations of Hathrmatical Physics

Malh. Ann. 100 (1928) 32; reprinted in English in IBM Journal of Research and Development. March 1967, P. 215.

Crowley, W. P. Second Order Nhemeriral Advection

J. Computational Physies, 1. P. 471.

Davis, C. W.. (1965) The AFWL ROC-l'TS Computer Cods Technical Report No. AFWL TR-65-74. July 1965. Air Force 
Weapons laboralory, Kirtland AFB, NM.

Douglas ir.. J. (1955) On the Numprical integralion of $u_{z x}+u_{v y}=u_{e}$ by implicit methods

J. Sor. Ind. Appl. Math. $\underline{3}(1955) 42$.

Douglas jr...J. \& Rachford jr.. H. H. (1956) On the numerical solution of heat condiction problems in two and threr spare variables

Trans. Am. Math. Sor. Be (1856) 421 .

duForl. E. C.. Frankel. S. P. (1953) stability Conditions in the Numerical Treatment of Parabolit Differential Equalions.

Malhemntical Tables and Other Alds to Computation. 2. p. 135.

Garabedian, P. R. (1964) Parlial Differential Equalions

J. Wiley, New York. (1964).

Gear. C. W. (1971) Numericat Initial Value Problems in Ordinary Differential Equations.

Prentice-Hall. Englewood clitis, (1971).

Grandey. R. A. (1961) Application of Finite Difference Methods to Problems in Ruo-Dimensianal Hydrodynamics Aeronutronic Publication No. Ii-l130. Contract No. DA-04-495-ORD-3095. Project No. TS1-200, Sumary Report.. for the Feltman Research and Engineering Laboratories, Picalinny Arsenal. Dover. New Jersey.

Grandey, R, A., (1962)

(SECRET Report) AFSWC-TDR-62-151. Air Forre Special Weapons Center. Kirtland AFB. New Hexico.

Grandey. R. A.. (1063) The PUFF-VTS Computer Codr.

(CONFIDENTI al Reporl, scheduled for declassification 1975) AFSWC-TDR-62-76. Research Directorate. Air Force Special Weapons Center. Kirlland AFB. New Mexico.

Grandey. R. A. (1963) The ROC-VTS Compuler Program

Air Force Special Weapons Center. Publication No. AFSWC-TDR-62-114, Kirlland AFB, July 1963.

Grandey, R. A. (1966) Final Trchnical Rrport on Tuo-Dimensional Hydrodynamir Calculations. Aeronutronic Publication No. 1-3039, Contract No. DA-04-495-ORD-3513. Aeronutronic Division. Philco Corp. Newport Beach, CA. March, 1966. Lor Ammumilion Engireering Directorate. Warheads and Special Projects Laboratory. Picatinny Arsenal. Dover. New Jersey.

Grasberger. W. H., (1965) Thr Populalion of Bound Stales of Hydrogenic lons in a steady State Hith Nonthermodynamic Equilibrium University of California. Lawrence livermore Laboratory. Report UCRL-12408. February, 1965. 
Herstein. 1. N., (1964) Topirs in Algrbra Blaisdell. New York (1064).

Hindmarsh, A. C., (1972) Lincar Mhllistep Melhods for Ordinary Differential Equalions: Mrthod Formulations. Stability. and thr Methods of Nordsicck and Crar Universily of Califolnia. Lawrence Livermore Liboratory, report UCRL-51180 Rev. I

Joubert. G. R, (1971) Explictt Diffrence Approximalions of the One-Dimensional Diffusion Equation. lising a smoothing Technique Numer. Math, 17, p. 409.

Joubert, G. R, (1972) Explicit Differcince Approximations of on Fort-Frankel Type of the One-Dimcnsional Diffusion Equation Numer. Math. 18, p. 18

Lathrop. K., Carlson, B. (1907) Numerical Solution of thr Boltzmann Transport Equation

J. Computalional Physics?, p. 173

Landau. L. D., Lilshilz, E. M. (1959) Fluid mrchantirs Trans. Sykes Reid: Addison-Wesley, Reading. Mass. (1959).

Leith, C. E. (1964) Lagrangian Advection in an Atmospheric Model Universily of California. Lawrence Livermore Laboralory. Report UCRL-7822. November. 1964.

Leith. C. E.. (1965) Numerical Simelation of the Earth's Atmospherp in Melhods in Computational Physics. (1964) ed. Alder. Fernbach, Rolenberg. Vol. A. Apptications in Hydrodymamics. Academic Press, New York. 1964.

Lelevier. R. (1954) Lectures on Mydrodynanics and Shork Waves. University of California, Lawrence Livermore Laboratory, Report UCRL-4333, April, 1954.

LeBlanc, J. M. W Wilson. J. R. (1970) A Numerical Examplp of the Collapse of a Rolaling Magnelized Star Astrophysical Journal 161. p. 541.

May, M. H.. White, R. H. (1966) Hydrodymamic Calculations of Ceneral-Relativistir Collapse

Phys. Rev. 141, p. 1232.

Mekee, S, (1972) A Generalization of the Du Fort-Frankel Sirhomf J. Inst. Maths, Applics 9. p. 42 .

MacLane. S.. E Birkhoff, G. (1967) Algebra Macmillan. New York (1967).

Mpthods in Computational Physirs, (1964) ed. Alder, Fernbach, \& Rotenberg. Vol. 3. Fundamental Methods in Hydrodynamics, Vol. 4. Applications in Hydrodynamics Academic Press. New York, 1964. 
Nuckolls, J. H. (1972) lascr Induced Implosion and Thermonue Laar Burn University of Californin. Lawrence Livernore laboratory. Report IICRL-74345.

Nurkolls, J., Wood, L. Thiessell. A., Zimmernitn, (i. (1872) Lasar Compression of Natter to Super-High Densitirs Thermomurlear (CTR) Applicalions Nature. 2339, p. 139.

Peaceman. D. W. Rachlold Jr.. H. H. (1955) The numerical solution of parabolic and rlliptir differential equalions.

J. Soc. Ind. Appl. Malh. 3 (1955) 28.

Richtmyer, R. D., Morlon, K. W. (1967) Difference Methods for Initial-Value Probloms. Second Ed. Interscience Publishers. New York (1967).

Schulz, W. D., (1864), Tro-Dimensional Lagrangzan Hydrodynamir Difference Equalions. In Melhods in Computalional Physics. (1964) ed. Alder. Fernbach, Rolenbera. Vol. 3. Fundamental Helhods in Hydrodynamirs.

Academic Press. New York. 1964.

Sneddon, 1. N. (1957) Elcments of Partial Differenlial Equations MeGraw-Hill. New York. (1957).

Spitzer, L. (1967) The Physics if Fully lonized Gases Second Ed. Interscience. New York. 1967.

Weaver. T. A. (1976) The Structure of Supernora Shock Waves Astrophysical Journal Supplement. in press.

Yanenko. N. N. (1967) The Mcthod of tractional Timesteps Trans. M. Holl. Springer Verlag. New York, 1971.

Zel'dovich, Ya. B.. Raizer, Yu. P. (1966) Physies of Shock Waves and High Temperafure Hydrodymamic Phenomena, trans. Scripta Technica, Ine.

Academic Press, New York. (1966).

Zimmermann. G. B. (1973) Nimeriral simulation of the High Density Approach to Lascr-fusion

Universily of Californta, Lawrence Livermore Laboratory, Reporl UCRL-74811, Oclober. 1973.

Zimmermann. G. B. (1974) Numerical Simulation of Laser-lnitiofed Fusion University of California, Lawrence Livermore Laboralory. Report UCRL-75548. March 1974.

Zimme rmann, G. B. (1975) Throry of High Densuly laser Fusion University of lalifornia, Lawrence Livermore Laboratory. Report UTRL-76888. May 1975. 


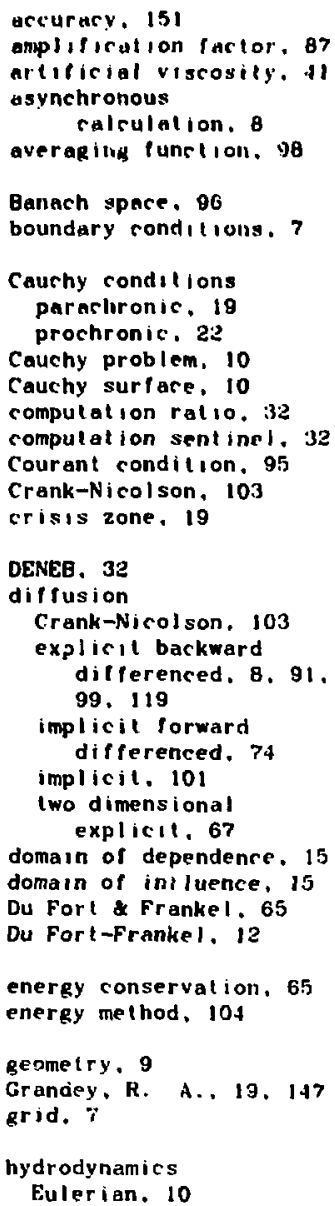

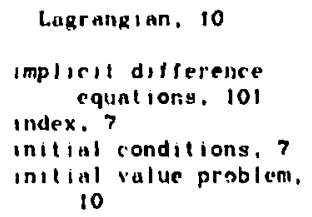

